\title{
TESTING AND ANALYSIS OF SOLDER JOINT RELIABILITY FOR BGA ASSEMBLY UNDER FLEXURAL LOADING
}

\author{
by \\ MING ZHOU \\ B.S., Northeast Forestry University, P.R. China, 1982
}

\author{
A project \\ Presented to Ryerson University \\ In partial fulfillment of the \\ Requirements for the degree of \\ Master of Engineering \\ In the Program of \\ Mechanical Engineering
}

Toronto, Ontario, Canada, 2009

(C) Ming Zhou, 2009 


\section{Author's Declaration}

I hereby declare that I am the sole author of this project.

I authorize Ryerson University to lend this project to other institutions or other individuals for the purpose of scholarly research.

Ming Zhou

I further authorize Ryerson University to reproduce this project by photocopying or by other means, in total or in part, at the request of other institutions or individuals for the purpose of scholarly research.

Ming Zhou 


\title{
Abstract \\ TESTING AND ANALYSIS OF SOLDER JOINT RELIABILITY FOR BGA ASSEMBLY UNDER FLEXURAL LOADING
}

\author{
Ming Zhou \\ Master of Engineering \\ Mechanical Engineering \\ Ryerson University, 2009
}

The solder joint reliability for BGA (Ball Grid Array) assembly is becoming a more concerned issue as these packages are featuring higher density interconnections, multiple functionality and higher speed combined with smaller size. The traditional test methods for second level PCBA (Printed Circuit Board Assembly) mechanical reliability monitor the electric resistance changes of Daisy chains in the test samples under 4-point bending. The method has been documented by Interconnecting and Packaging Electronic Circuits and Joint Electronic Devices Engineering Council in PC/JEDEC 9702 standard. The effectiveness of the test has been questioned when applied to the new lead-free soldered packages. Due to the failure mode shift from solder jointcopper pad interface cracking in Tin-lead PCBAs to pad-cratering cracking in leadfree packages, the electrical continuity monitoring becomes ineffective in detecting the interconnect failure. On the other hand, the strain gauges recorded PCB strains during bend tests show little increase that would be indicative of an onset failure. This project applies Fiber Bragg Grating (FBG) strain sensors to detect the pad-cratering failure. FBG have been employed widely in different areas of engineering due to its advantages of small size, light weight and high sensitivity. In this project the FBG sensors are laid to the vicinity of the BGA substrate corners. By detecting and recording the solder joint fracture induced strain release, the onset of pad-cratering is explicitly revealed. The study has demonstrated that the FBG sensors are much more sensitive than electric resistance strain gauges in detecting the substrate strain release in BGA assembly 4-point bend testing due primarily to the sensor's much smaller geometric size. By placing the sensors very close to the corner solder joints, the new test obtains accurate strain information related to the first solder joint cracking. Furthermore, the recorded strain release enables the detecting, understanding and analysis of the critical load of the solder joint fracture, the brittle and ductile fractures and related strain relaxation phenomenon during the PBGA flexural loading, etc. 


\section{Acknowledgements}

I would like to thank my advisor, Dr. Hua Lu at Ryerson University for his knowledgeable guidance and constant encouragement and support. I would like to thank the other committee members, Dr. J. (Greg) Kawall, Dr. Ahmad Varvani, and Dr. Xijia Gu for sparing their time generously to help me improve the quality of my project. I would like to thank the financial support by Ontario Centers of Excellence (OCE) and facilities to enable me to pursuer my work.

I would like to give a special thanks to my family and especially my husband and my daughter for their love and support. 


\section{Table of Contents}

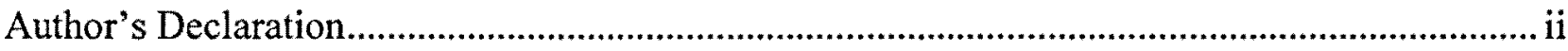

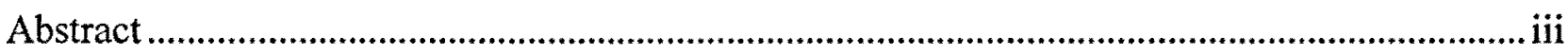

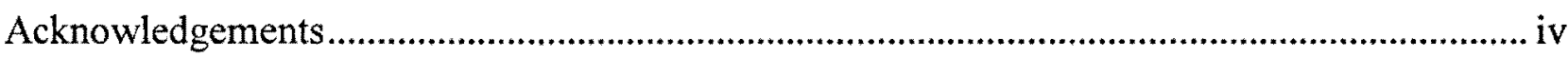

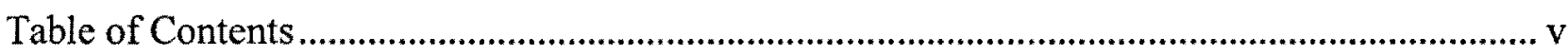

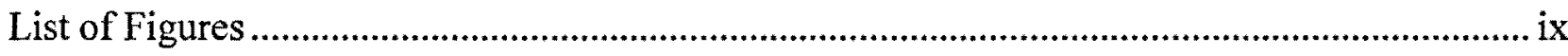

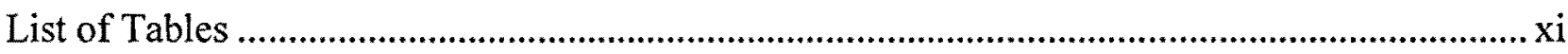

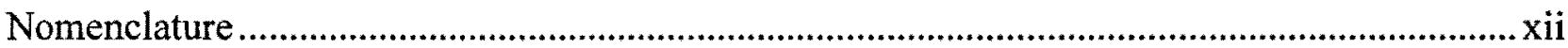

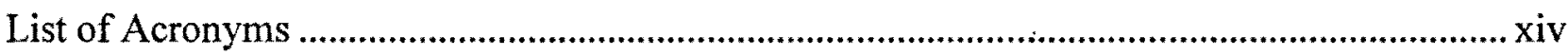

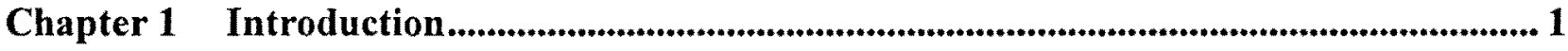

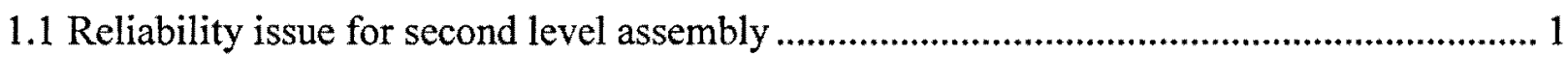

1.1.1 Stress and strain induce during reflow assembly ....................................................... 2

1.1.2 Cycling thermal stresses and strains during working environment .............................. 2

1.1.3 Mechanical bending induced damages ........................................................................... 3

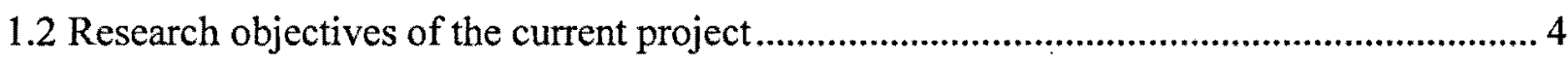

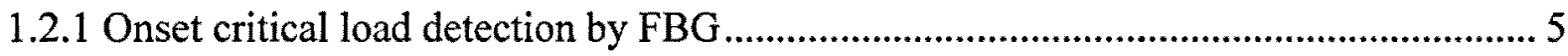

Chapter 2 Basics of electronic packaging and mechanics .......................................................... 7

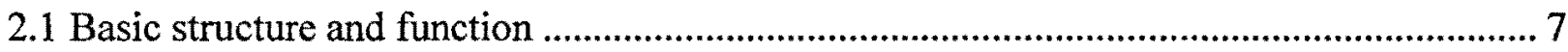

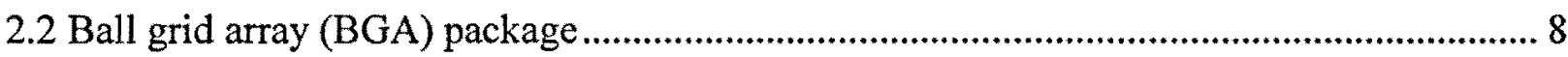

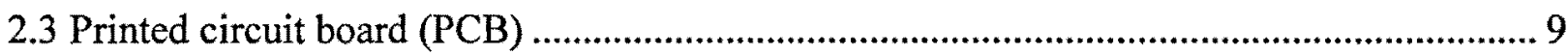

2.3.1 Structure of a PCB

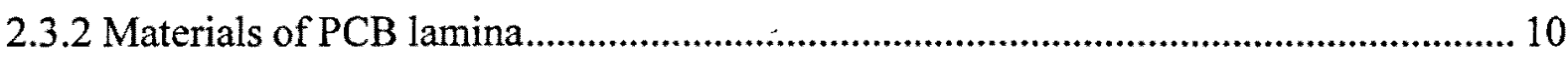

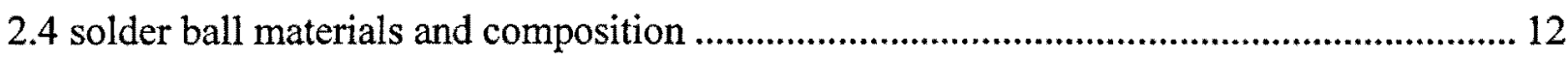

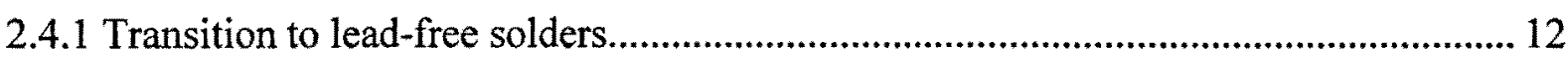

2.4.2 Peak reflow temperature increase ............................................................................. 12

2.4.3 Difference material properties comparing to $\mathrm{PbSn}$ solders .......................................... 13

2.4.4 Mechanical and thermal properties for SAC solders ..................................................... 13

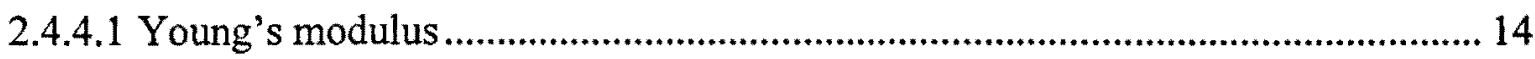

2.4.4.2 The coefficient of thermal expansion ............................................................. 15

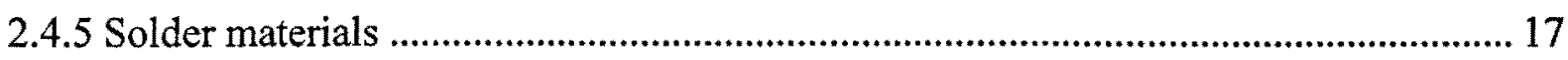

2.4.5.1 Chemical compositions of SAC solders ......................................................... 17 
2.4.5.2 The ternary eutectic composition of SAC solders

2.5 Solder joints

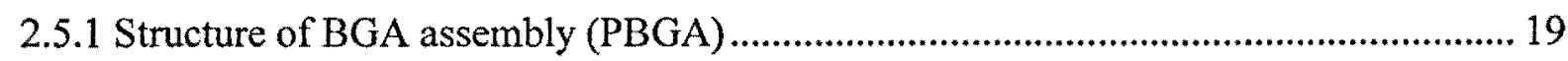

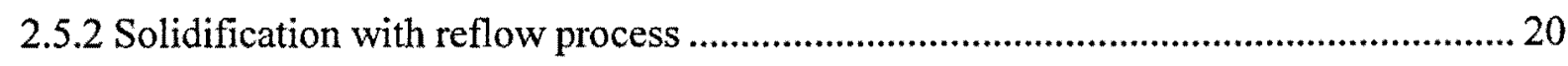

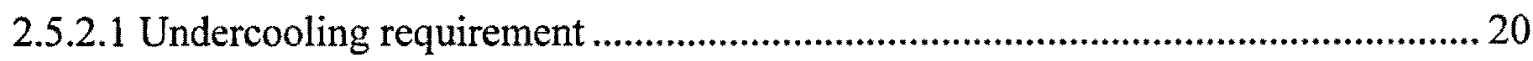

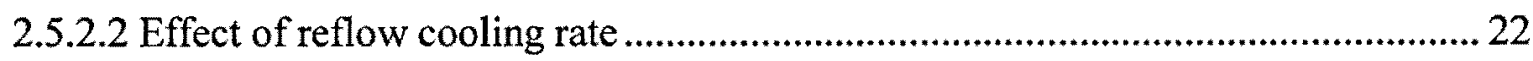

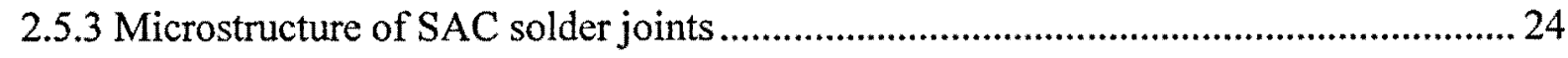

2.5.3.1 Microstructure of solders and its impact on solder joint behaviors...................... 24

2.5.4 Deformation of solder joints under a thermal load ...................................................... 25

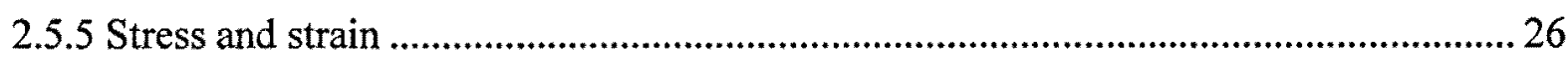

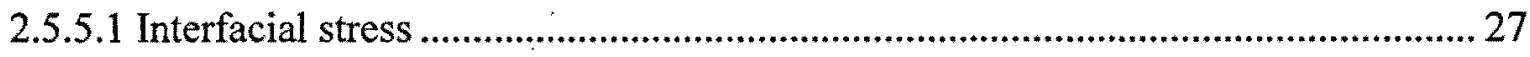

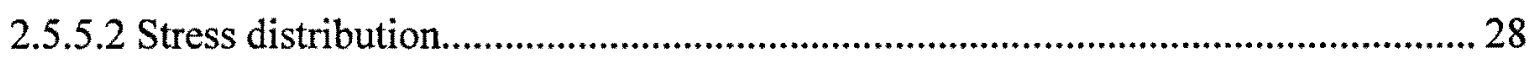

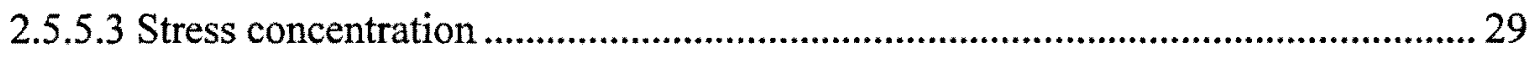

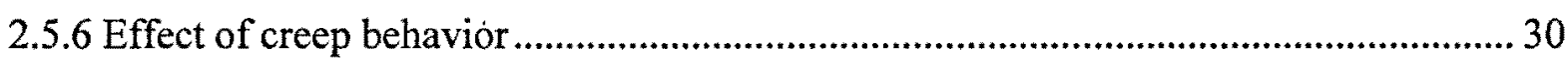

2.5.6.1 Creep - time dependent mechanical behaviours ................................................... 30

2.5.6.2 Hall's Stress/ Strain Hysteresis Loop ..................................................................... 31

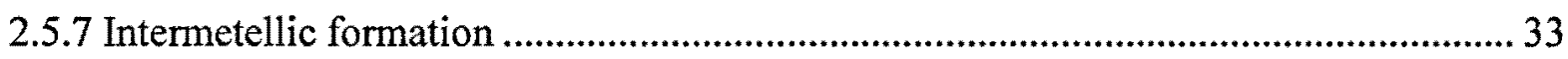

2.5.7.1 IMC (Intermetallic Compound) layer grown.......................................................... 33

2.5.7.2 Metallization diffusion and solder flux burning ................................................... 34

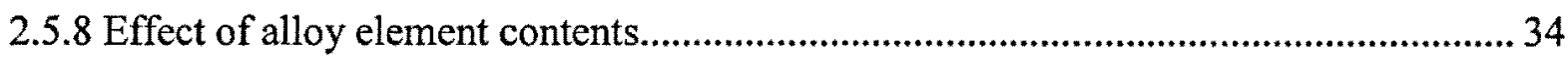

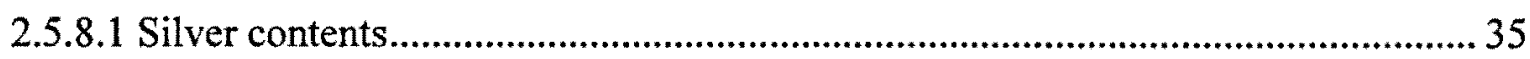

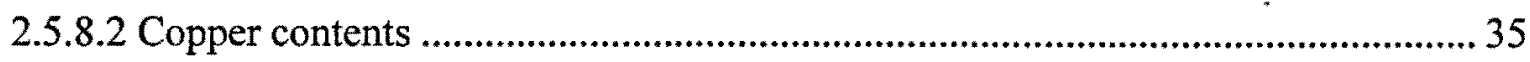

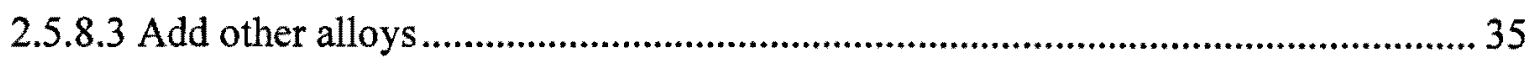

Chapter 3 Theoretical background of flexural test methods ...............................................37

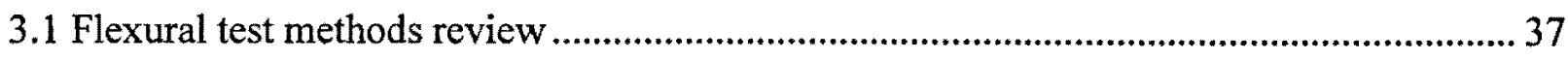

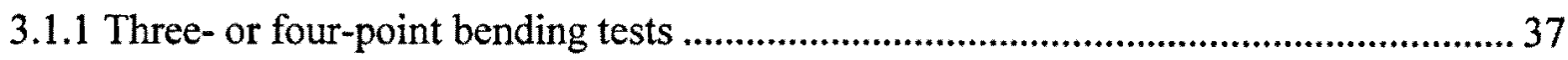

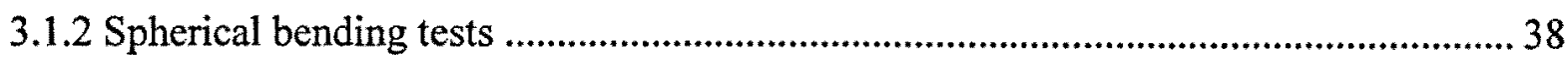

3.2 Literature review for BGA solder joint flexural reliability............................................... 38

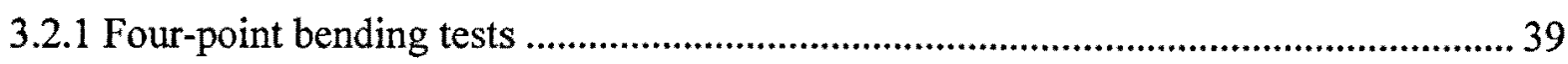

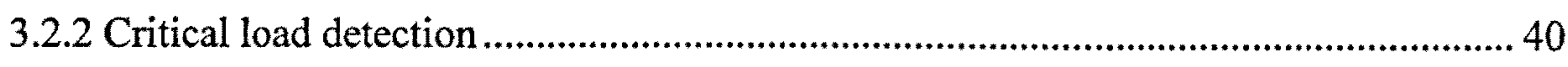

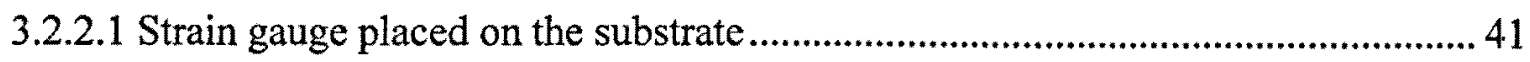


3.2.2.2 Strain relaxation

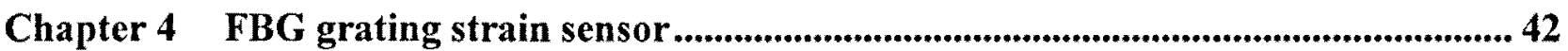

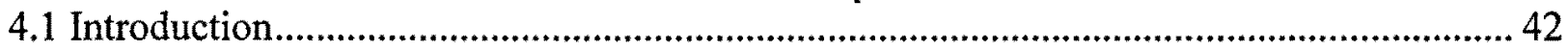

4.2 Literature review of FBG sensor application for strain measurement ................................. 42

4.3 Theoretical background and operating principles................................................................ 45

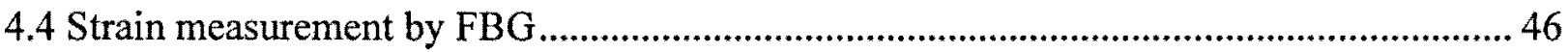

Chapter 5 Four-point bend test with BGA strain measured by FBG ..................................... 48

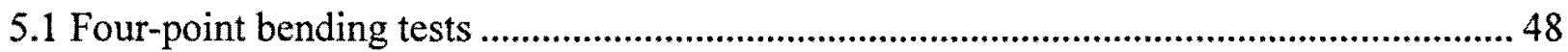

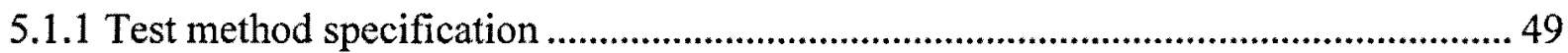

5.1.2 Strain rate

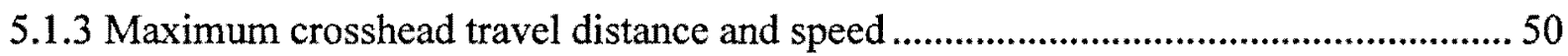

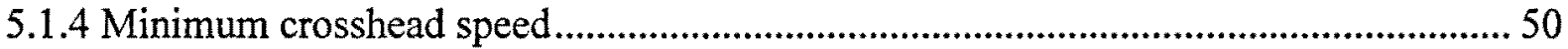

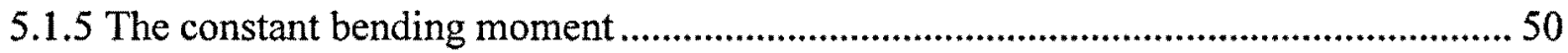

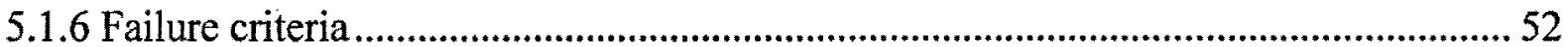

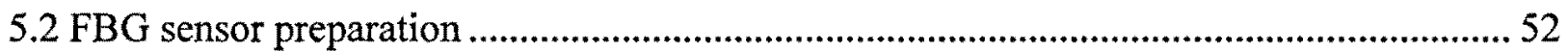

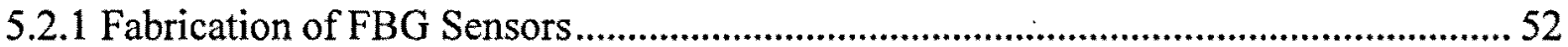

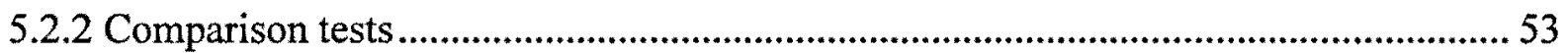

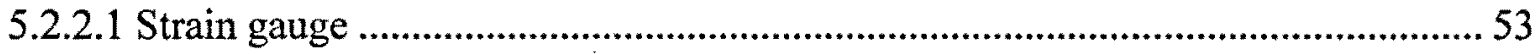

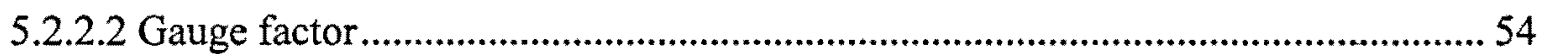

5.2.2.3 Comparison of strain gauge and FBG................................................................... 54

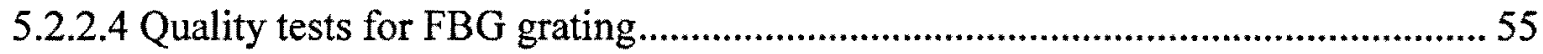

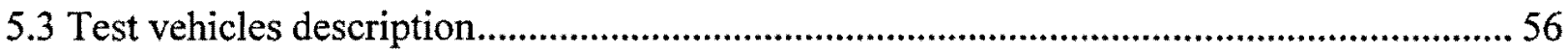

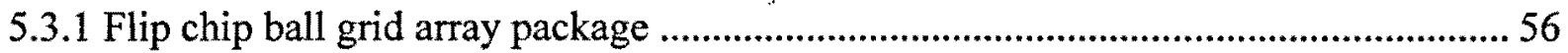

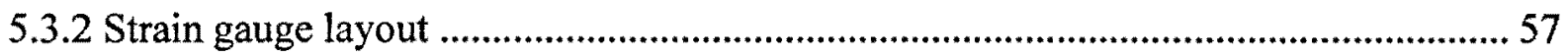

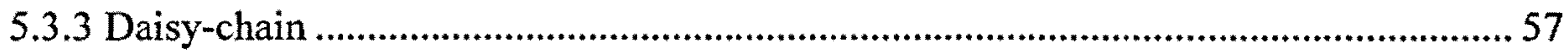

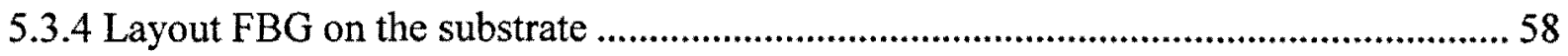

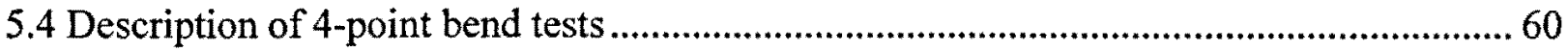

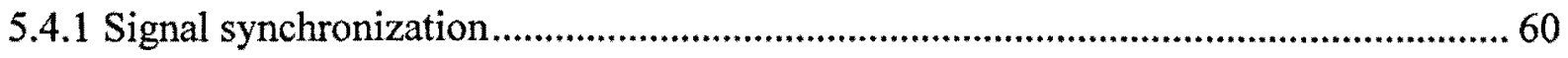

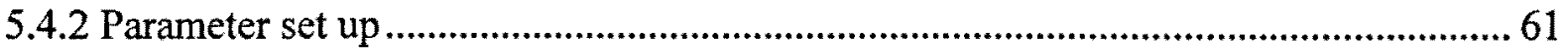

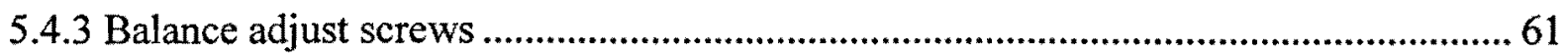

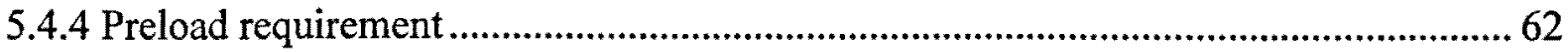




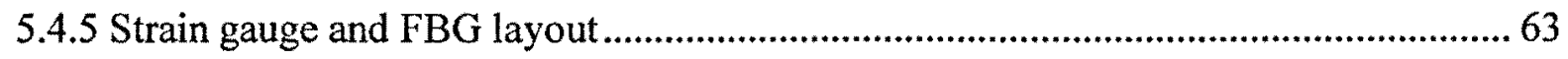

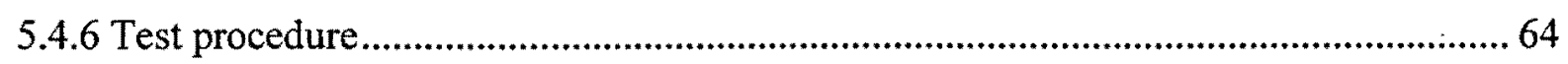

Chapter 6 Failure inspection and analysis..................................................................................6 68

6.1 Fracture modes under mechanical bend loading............................................................6 68

6.1.1 The second level interconnect failure mechanisms......................................................69

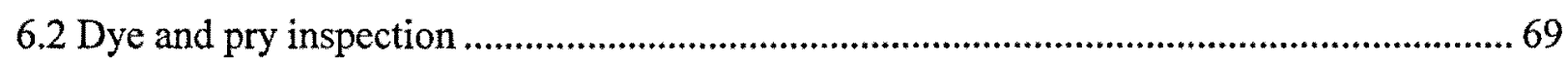

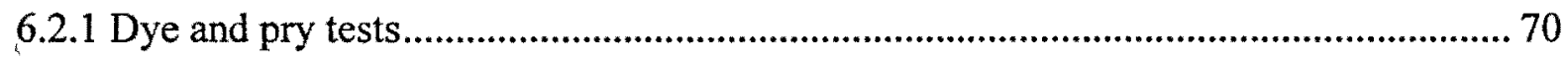

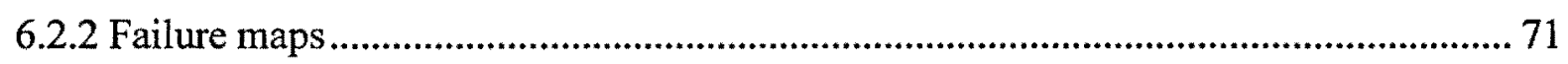

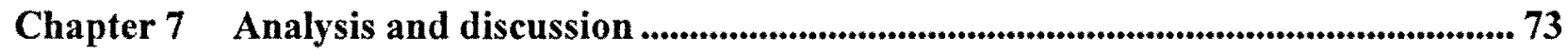

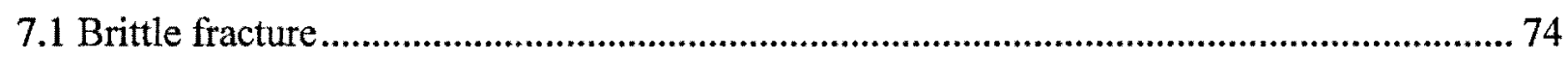

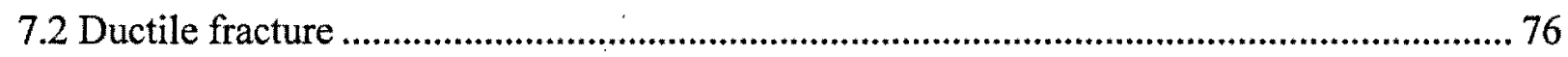

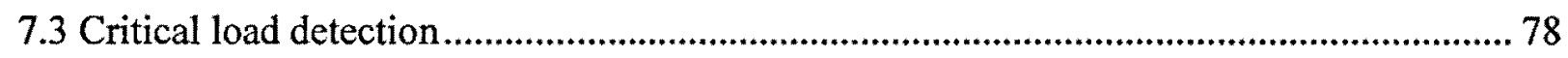

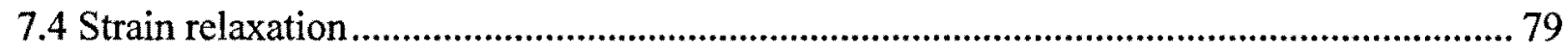

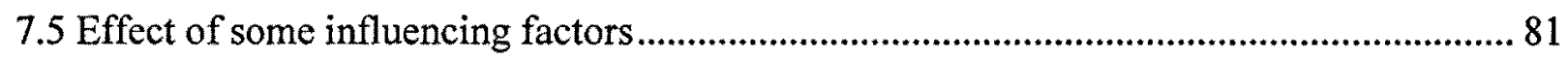

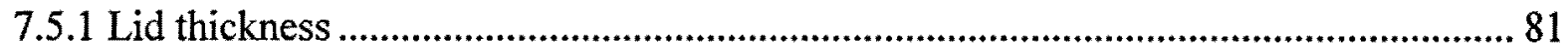

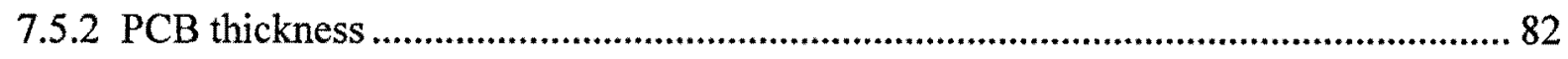

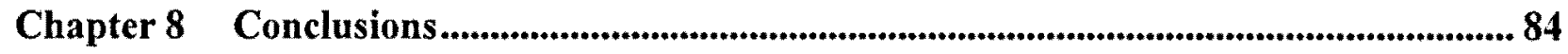

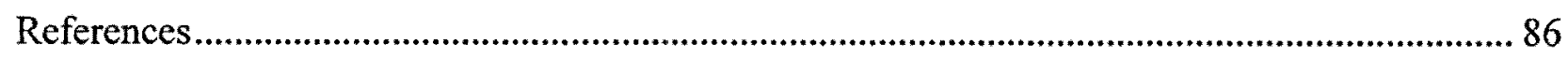




\section{List of Figures}

2.1 Outline of a substrate with a die and solder balls..................................... 8

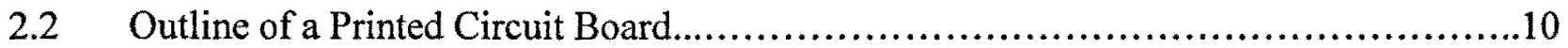

2.3 Cross section view of a PCB made by glass fiber woven laminate......................10

$2.4 \quad$ Reflow temperature profiles.......................................................

2.5 Typical stress-strain curve for pure metal or alloy..................................14

2.6 Young's modulus versus temperature for SAC materials................................ 15

2.7 Coefficient of Thermal Expansion of SAC solders versus temperature $. . \ldots \ldots \ldots \ldots \ldots \ldots \ldots . . .16$

2.8 Calculated liquid phase diagram of SAC alloy...................................... 18

2.9 The phase diagram of SAC alloy .................................................. 19

2.10 The cross section view of a BGA package.........................................20

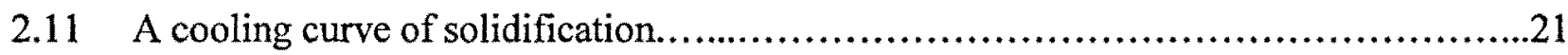

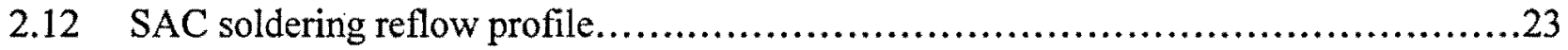

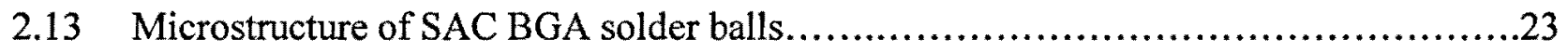

2.14 Peel and shear stresses in a continuous joint of two dissimilar materials.................28

2.15 Pattern of stress distribution along a row of solder joints..............................29

2.16 Two type BGA Solder lands (SMD and NSMD) ...................................

2.17 SEM for solder joints crack along the corner after 4440 thermal cycles...................30

2.18 Creep curve: strain versus time under constant stress.................................. 31

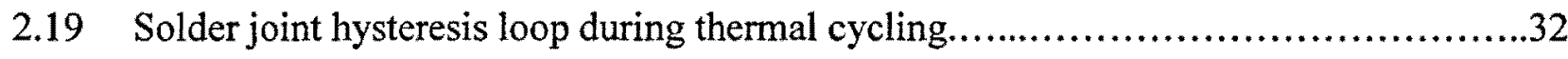

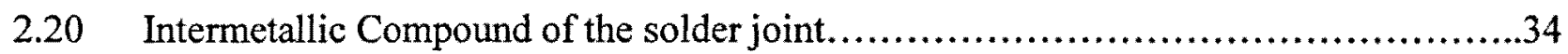

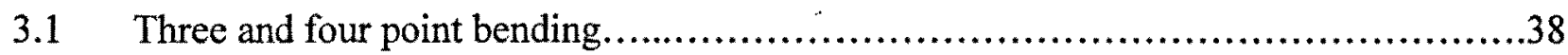

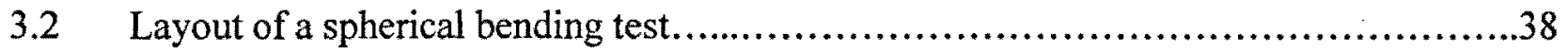

4.1 Transmission and reflection spectra of a fiber Bragg grating...........................46

$5.1 \quad$ A sketch of the universal tester of 4 point bending test................................. 48

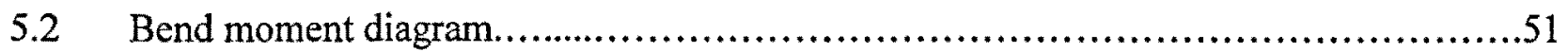

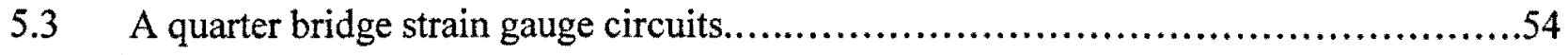

5.4 Correlation of FBG and strain gauge in a beam bending test.........................55

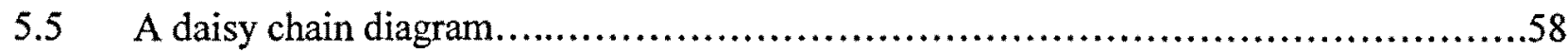

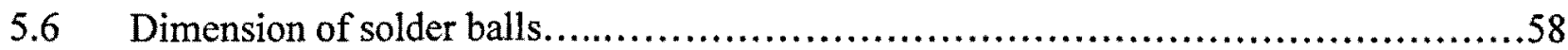


5.7 Critical strain distributions under flexible loading .................................59

5.8 Installation of FBG on corners of BGA substrate ...................................59

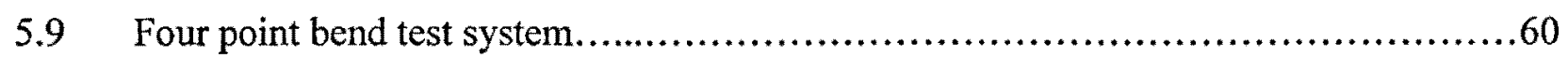

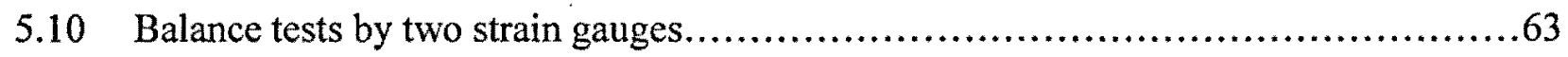

5.11 Jake screws for adjusting load balance.............................................63

5.12 Strain gauge and FBG layout.................................................... 64

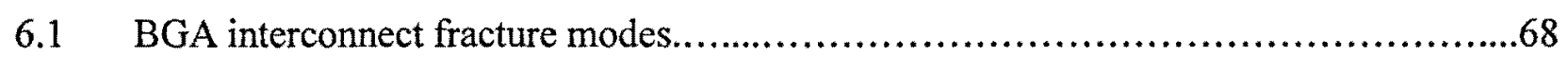

6.2 (a) IMC fracture on PCB side (b) pad crater on PCB side..............................

6.3 Sample A4 fracture failure map and strain curves....................................... 71

6.4 Sample B1 fracture failure map and strain curves................................... 72

6.5 Sample C8 fracture failure map and strain curves.....................................72

6.6 Sample D2 fracture failure map and strain curves................................... 72

7.1 Dye and pry maps and a spike of strain curve with strain rate increase....................75

7.2 Dye and pry maps and a spike of strain curve with strain rate decrease .....................76

7.3 Dye and pry maps and a ductile crack with slop change of strain curves..................77

7.4 Critical load detection by FBG................................................ 79

7.5 Strain curves versus time for sample B1 ........................................ 80

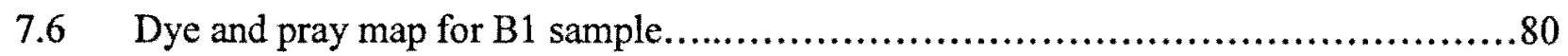

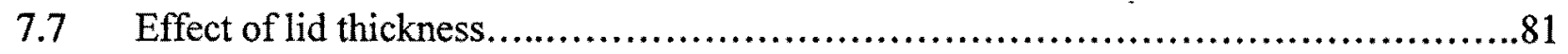

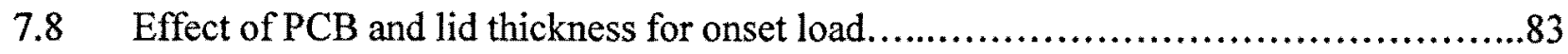




\section{List of Tables}

1.1 Thermal environment for solder joints in different electronic packages...................

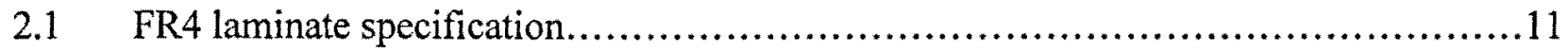

2.2 BT/ Epoxy specification.................................................... 11

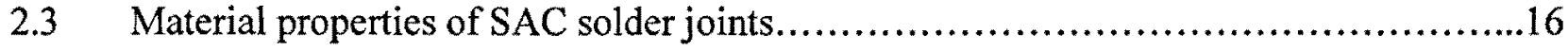

2.4 Calculated eutectic equilibrium of the SAC system...................................19

2.5 Undercooling requirement for the solidification of $\mathrm{SAC}$ and $\mathrm{Pb} \mathrm{Sn}$ solders..............22

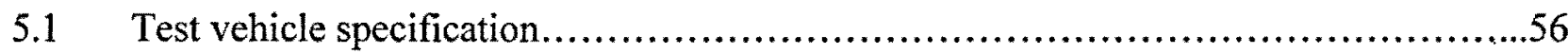

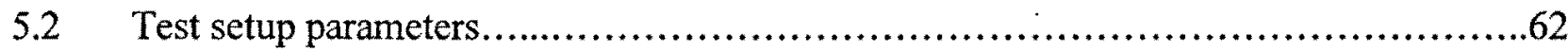

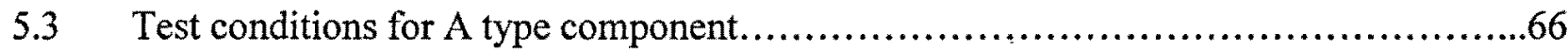

$5.4 \quad$ Test conditions for B type component................................................

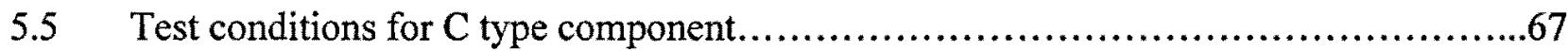

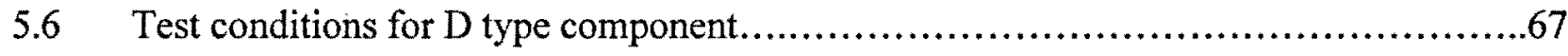

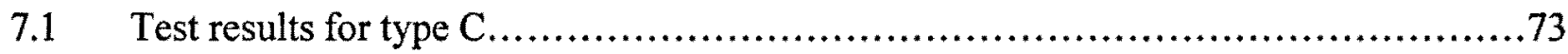




\section{Nomenclature}

\section{Greek}

$\begin{array}{ll}\sigma & \text { Engineering stress } \\ \varepsilon & \text { Engineering strain } \\ \alpha & \text { Particular solid phase } \\ \beta & \text { Particular solid phase } \\ \gamma & \text { Particular solid phase } \\ \alpha_{1} & \text { Linear coefficient of thermal expansion } \\ \alpha_{V} & \text { Volume coefficient of thermal expansion } \\ \varepsilon_{\mathrm{x}} & \text { Normal strain of X direction } \\ \varepsilon_{\mathrm{y}} & \text { Normal strain of Y direction } \\ \gamma_{\mathrm{xy}} & \text { Shear strain in xy plane } \\ \lambda_{\mathrm{b}} & \text { Grating wavelength } \\ \delta & \text { Crosshead travel distance } \\ \& & \text { Crosshead speed } \\ \varepsilon & \text { Global PWB strain } \\ \& & \text { Global PWB strain rate } \\ \Omega & \text { Electrical resistance }\end{array}$

English

$\mathrm{Tg}$

$\Delta \mathrm{T}$

$\Delta l$

$l_{0}$

$\Delta V$

$V_{0}$

$\mathrm{T}_{\mathrm{m}}$

$\pi$
Glass transition temperature

Temperature change

Original in length

Change in length

Original in volume

Change in volume

Temperature of melting point

Fiber Bragg grating period 
$\mathrm{L}_{\mathrm{S}}$

$\mathrm{L}_{\mathrm{L}}$

t

Support span

Load span

PCB thickness 


\section{List of Acronyms}

IPC Packaging Electronic Circuits

JEDEC Joint Electronic Devices Engineering Council

FBG Fiber Bragg Grating

LPG Long-Period Grating

PCB Printed Circuit Board

PWB Printed Wiring Board

OCE Ontario Centers of Excellence

IC Integrated Circuit

C4 Controlled Collapse Chip Connection

BGA Ball Grid Array

I/O Input/ Output

PBGA Plastic Ball Grid Array

CBGA Ceramic Ball Grid Array

FC-CBGA Flip Chip-Ball Grid Array

UHV Ultra High Vacuum

BT Bismaleimide Triazine

SAC Sn-Ag-Copper alloy

E Young's modulus

CTE Coefficient of thermal expansion

SMT Surface mount technology

BCT Body center tetragonal

FCC Face center cubic

CCP Cubic close-packed

K Kelvin

NIST National Institute of Standards and Technology

FR4 Flame retardant fiber glass epoxy

IMC Intermetallic compound

NSMD Non solder mask defined

SMD Solder mask defined pad 
SEM

LCCC

UBM

ASTM

FEA

NDE

OSA

LVDT
Scanning Electron Microscopes

Leadless ceramic chip carrier

Under bump metallization

American Society for Testing and Materials

Finite Element Analysis

Non-destructive evaluation

Optical Spectrum Analyzer

Linear Variable Differential Transformer 


\section{Chapter 1 Introduction}

The electronics industry is one of the most fascinating, dynamic and rapidly developing industries. It has over a 100 year history since the first amplifying vacuum tube emerged in the world. Moore's law governs the packaging development for the past decades that predicted semiconductor technology would double its effectiveness every 18 months. Microelectronic products such as telephones, televisions, and computers are so closely related to our daily lives that it is difficult to imagine what will the world around us become without them.

Electronic packaging includes all structures that are designed to protect the integrated circuits, the attendant interconnections and the related circuitry from physical and chemical damages and any other impediment to achieving design performance. Interconnections include all means of communication (power, timing, data, results) from one integrated circuit to another or from one system of circuits to another.

An electronic package typically consists of basic elements including a silicon integrated circuit (IC) chip, a substrate and solder joints interconnecting the component to a printed circuit board (PCB). The IC chip communicates with other components in a system through solder interconnects to realize the signal input and output (I/O). An electronic package has these basic functions: signal and power distribution is accomplished through solder balls or $\mathrm{C} 4$ bumps to provide paths for the electrical current that powers the circuits on the IC chip; the heat dissipation is accomplished through leads and chip supports to remove the heat generated by the circuit. Support and protection of the chip from hostile environments are accomplished through the PCBs and substrates, or external packages, and resin.

\subsection{Reliability issue for second level assembly}

For many years the electronic industry had been concentrating on increasing the performance of ICs resulting in the trend toward higher circuit densities and higher operating speed on a silicon chip. With the application of new electronic packaging technologies, large silicon devices and components, such as the BGA chip and the rapidly evolving multi-chip module, have resulted in substantial increase in the number of joints per package. The signal transition time between chips 
becomes a limiting factor too. It can be seen in personal and mainframe computer applications in that new power devices able to dissipate more heat are mounted closer to the neighbouring packages. This situation leads to increased possibility of solder joints thermal fatigue failures.

\subsubsection{Stress and strain induce during reflow assembly}

A solder joint is constructed of a solder ball and solder pads that are printed on both PCB and substrate surfaces. Individual components mounted in a system are interconnected through solder joints and PCB routings. These elements in an electronic package typically have different thermal expansion coefficients (CTE). During reflow soldering and cooling down process the soldered assembly undergoes a temperature cycle to induce thermal stress and strain in the solder joints due to the expand rate difference between the joint materials. Such stress and strain are also cyclic in nature which results in thermo-mechanical fatigue failure of the joints. During a soldering process at second level assembly, the lower CTE materials such as silicon die and ceramic substrate would expand upon heating at a slower rate than the higher CTE materials such as solders and FR4 PCBs. This will put the solder and PCBs in a compressive stress state, whereas upon cooling the opposite occurs and the solder will be in tension. Shear stress is also applied to the joints at different rates from either side of the solder layers due to substrate with an IC chip with low CTE (3-6ppm $\left./{ }^{\circ} \mathrm{C}\right)$. The shear stresses will take effect both at the interfaces and across the entire solder layer, inducing interface or solder ball cracking.

\subsubsection{Cycling thermal stresses and strains during working environment}

The reliability of BGA operation in customer environments is another key issue in electronics packaging design. The potential premature fatigues can occur in the solder joints in a working environment. There fatigue failures are induced by the thermal expansion mismatch between the module and the PCB, as well as between the die chip and substrates, which creates cyclic loads on the solder joints as they are thermally cycled during normal operation and working environment. Table 1.1 shows the thermal environments expected for electronic packages.

An electronic package is responsible to carry electronic signals on and off frequently between electronic parts which generate heat and accelerate creep of solder joints, resulting in thermal fatigue failure. Thermal fatigue failure may occur under actual operating conditions. This is 
because the residual stress caused by CTE mismatch between silicon die, substrates, and PCB during reflow assembly processes. These stressed and strained solder joints are subjected to electrical, thermal, and mechanical cycle loading condition and may generate failure of solder joints due to fatigue, creep, stress relaxation, stress concentration, as well as residual stress caused by CTE mismatch between components and a PCB. Thus, one of the key concerns is the mismatch of CTE between components and their interconnections.

Table 1.1 Thermal environment for solder joints in different electronic packages [7]

\begin{tabular}{ll}
\hline Use conditions & Thermal excursion $\left({ }^{\circ} \mathrm{C}\right)$ \\
\hline Consumer electronics & 0 to 60 \\
Computers & 15 to 60 \\
Telecommunications & -40 to 85 \\
Commercial aircraft & -55 to 95 \\
Military aircraft & -55 to 125 \\
Space & -40 to 85 \\
Automotive- Passenger compartment & -55 to 65 \\
Automotive-Under the hood & -55 to 150 \\
\hline
\end{tabular}

\subsubsection{Mechanical bending induced damages}

In electronic systems a number of different types of electronic packages are employed to mount integrated circuits and other electronic devices. These packages are used since they can provide the advantages of physical protection, electrical interconnect, and thermal dissipation for the mounted devices. In order to reduce the risk of a failure in the electronic package, mechanical stops and interposers have been included to provide some support to the substrates. These designs typically use metal or plastic spacers inserted under the package corners or edges. It is relatively effective for ceramic package since ceramic substrates have a high mechanical strength and can withstand the high stress exerted on the package corners and edges. However, for other types, such as plastic laminate packages, the substrates cannot withstand the high stresses typically involved in the assembly process. 
A large mechanical load due to manufacturing, handling, shipping and rework of the packages can easily break the laminate substrate at its comers or edges and result in the fracture of solder ball interconnects. It is important to establish the relationship between the flexure induced strain on the PCB and substrates in order to provide assurance to customers. The standard of IPC/JEDEC-9702 intends to characterize the fracture strength of a board level interconnects using the four point bending method to simulate the condition of flexural loading during manufacturing, packaging, and servicing.

\subsection{Research objectives of the current project}

With the package size and density increase, the reliability of board level solder joints has been of concerted from manufacturers and end customers due to the potential damage during board assembly and in the environment of custom operation.

Four-point bending, a mechanical test method for mounted electronic package, was designed to provide a measurement method of fracture resistance to mechanical loading that may occur during conventional board assembly, shipping, handling and field operation. IPC/JECEC 9702 has particularly established a detailed 4-point bend test standard for documenting the solder joint reliability issues as "Monotonic Bend Characterization of Board Level Interconnects". The IPC/JEDEC 9702 monotonic bend test standard provides a uniform set of guidelines on the test procedure as well a measure method of fracture resistance to flexural loading under relatively high strain rate loads. The methodology mainly consists of monitoring the electrical resistance increase of daisy chain in assembly board that undergoes flexural deformation. The strength of solder joints under flexural loading is affected by pad size and shape, PCB material and construction of solder joints, etc. A significant resistance change indicates that rapid fracture damage happened in the electronic chain and solder joints. The dye and pry failure visual inspection is applied to the post-test samples to verify the solder joint failure distribution and failure modes. The drawback of the standard test method is shown when it is applied to the new leadfree packages. As some studies found the pad lift phenomenon replaced the solder ball cracks in the reliability testing and the field returned failures. Due to such a shift of failure mode from the solder joint-copper pad interface cracking for Tin-lead soldered PCBAs to the padcratering cracking in leadfree ones, the traditional electric continuity based test methods can no 
longer detect the failure. A recently proposed test modification used strain gauges to monitor the BGA substrate strain change in responding to the pad cratering failure. But the alternative tests also encountered difficulty for applications to BGAs with thermal lid since the gauges are too big in size to be laid to corners of a BGA substrate when a metallic lid is installed on top of the substrate. Given that the most pad lift cracking and interconnect fracture start to occur at the BGA corner areas, the failure onset can be detected by monitoring the substrate comer strain release. The use of FBG strain sensor can resolve the problem and, if successful, presents an effective new test method to capture the onset failure of BGA assembly with thermal lid.

The objectives of this project are, first, to study the feasibility of using an Optical Fiber Bragg grating (FBG) Sensor as an alternative means to observe the characteristic behaviour of board level interconnects under flexible mechanical loading and, second, to possibly determine the critical point of the interconnect crack initiation and damage development. The study focuses on the second level solder joints reliability under flexural mechanical loading (four-point bending) in order to characterize the mechanisms of mechanically induced joint fracture and material damage development under flexural loading.

\subsubsection{Onset critical load detection by FBG}

The FBG strain sensor is one of the uppermost sensor inventions in the 90's of the last century. It is a passive optical device with good reliability, high measurement precision, resistance to electromagnetic interference and anti-lightning characteristics. Adopting a 1510 1590 nm wave band grating the FBG sensor greatly increases its capability connected to a single fiber. With up to $35 \mathrm{~km}$ transmission distance allowable, the FBG sensor is capable of a long-distance measurement. Having anti-lightning characteristics, the FBG sensor is particularly suitable for field use. And the FBG sensor can be applied to static as well as high-speed dynamic tests.

The FBG technique offers a wide dynamic range of strain measurement since it has high sensitivity and small dimension. FBG sensor measurement provides more detailed information of the bending induced mechanical onset failure or critical load. In this project, the FBG strain sensors were employed to detect the pad cratering related crack initiation in evaluating the reliability of second level solder joints. The two primary phenomena in the testing for solder 
joint reliability were observed in this research. The first is the critical load which provides information for designers to determine limiting applied forces during assembly and shipping of electronic package so as to reduce the possible damage; the second is the assembly substrate strain release detected for the analysis of the impact on the package interconnect fracture behaviour and resistance of different factors, such as the solder joint microstructure, and reflow solidification process, etc.

In the tests, the FBG, with an external diameter of $0.15 \mathrm{~mm}$ including the layers of cladding and coating, was attached to each corner of module under the lid. At the same time, the conventional strain gauges were still used to monitor the PCB strains. The test data presented further show that the sensors are effective in capturing the pad-lifting induced strain spike and release. This characteristic behaviour made possible the determination of the critical point of the interconnect crack initiation and damage development. 


\section{Chapter 2 Basics of electronic packaging and mechanics}

Based on the science of establishing interconnection, electronic packaging is classified into three levels: zero-level, first-level, and second-level. The zero-level packaging is for integrated circuit (IC) chip fabrication. The electronic circuit built on a semiconductor substrate is called gate to gate interconnections on the chip by photolithographic masking, developing and level definition, etching, implanting, deposition, etc. A typical IC chip includes a stack of several sequentially formed layers of shapes, also known as mask levels. Each layer may be created or printed optically through well known photolithography and chemical fabrication. The circuit, often called a chip, is packaged in a hermetically sealed case or a non-hermetic plastic capsule, with leads extending from it for input, output, and power-supply connections. The first level packaging is chip to module connections. It is called either single chip or multi-chip modules including modules that attached IC chips on the substrates by flip over $\mathrm{C} 4$ (Controlled Collapse Chip Connection) pumps or face up and down by directly binding configuration. The second level packaging is board level interconnections that put the substrate with IC chip and solder balls pumped on the top of the printed circuit board heating and bound the substrate on PCBs by solder balls in a reflow oven.

\subsection{Basic structure and function}

An electronic package consists of silicon IC chips, substrates, and solder joints interconnecting the component to a PCB. The silicon IC chip is bond to a plastic or ceramic substrate by flip down $\mathrm{C} 4$ bumps or conducting adhesive that is call the first level package. The substrate made of polymer with an IC chip is attached to a PCB by solder balls to construct an electronic current circuit system that is called the second level assembly. Packaging and interconnection provide structural support, mechanical and chemical protection, thermal management, power, ground, and signal transmission.

In the level two packaging, a module substrate with bumped solder balls on its surface is layout on a PCB through a solder reflow process to form a strong bound between the module and PCB. The PCB carries copper pads in a pattern matching the pattern of the solder balls. The assembly unit is heated either in a reflow oven or by an infrared heater to melt the solder balls. The surface tension causes the molten solder to hold the package in alignment with the circuit board 
while at a correct separation distance as the solder cools and solidifies. The composition of the solder alloy and the soldering temperature are carefully chosen so that the solder does not completely melt but stays semi-liquid, allowing each ball to stay separate from its neighbors. Figure 2.1 illustrates an outline of a substrate with a die and solder balls structural details of a BGA package.
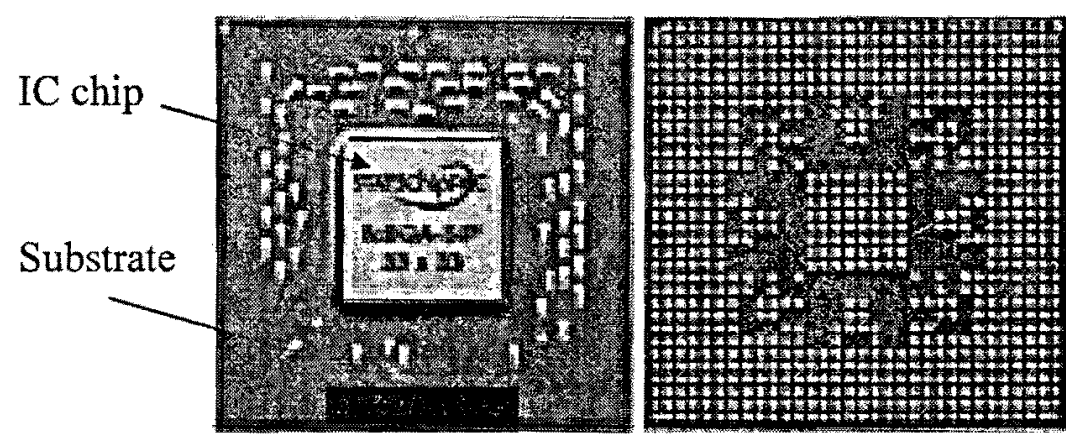

Solder ball on the bottom of a substrate

Figure 2.1: Outline of a substrate with a die and solder balls

\subsection{Ball grid array (BGA) package}

Ball Grid Array (BGA) packages are a category of surface mount chip packages that uses a square grid of solder balls as its connectors. BGA packages have had wide applications in the electronic industry since 1990s. BGA packages have been developed rapidly for the following reasons: the compact size that allows more components to be mounted on a module with high $\mathrm{I} / \mathrm{O}$ (Input/output) density to meet the demands of increased IC complexity; the high power; the larger die or package size; the higher lead counts and low inductance; and the better heat dissipation that will improve the package performance.

The BGA is a semiconductor component assembled on either a plastic laminate or ceramic substrate instead of a lead frame. Comparing with the old, lead-frame packages (i.e. the packages with legs) a further advantage of BGA packages is the low thermal resistance between the package and the PCB. This allows the heat generated by the integrated circuit inside the package to flow more easily to the PCB, thus preventing the chip from overheating. Another obvious advantage of BGA packages is its lower inductance. The shorter an electrical conductor, the lower its inductance that can cause unwanted distortion of signals in high-speed electronic 
circuits. BGAs, with their very short distance between the package and the PCB and low inductances, show far superior electrical performance as compared to the leaded devices.

A disadvantage of BGAs, however, is that the solder balls cannot flex in the way that longer leads can. Due to that, bending and thermal expansion of the PCB is transmitted directly to the package, causing the solder joints to fracture under thermal or mechanical stress. Another disadvantage of BGAs is that, once the package is soldered down, it is difficult to detect soldering faults. There are two basic kinds of BGA current available in the market, namely the PBGA (Plastic Ball Grid Array) with plastic matrix substrate and the CBGA (Ceramic Ball Grid Array) with ceramic matrix substrate. The PBGA and CBGA present much different performance due to their substrate material property difference.

\subsection{Printed circuit board (PCB)}

A PCB is categorized as the second level of the electronic packaging hierarchy. A printed circuit board supports a large number of electronic components such as first level electronic packages in one side or two sides. The basic function of PCB is to provide an electronic interconnects and mechanical support for components and IC chips. Above all, a PCB needs to provide a safe working environment for the components.

\subsubsection{Structure of a PCB}

A typical PCB consists of conducting layers that connects the electronic current to power IC chips and insulating layers that inhibit or prevent the conduction of heat or electricity. Conducting layers of a PCB are made of thin copper foils while insulating layers of a PCB are typically laminated together with epoxy resin. The copper layers usually are separated by organic dielectric interlayer, usually polyimide. Figure 2.2 shows a typical structure of a PCB and Figure 2.3 gives a cross section view of a PCB made by glass fiber woven laminate. 


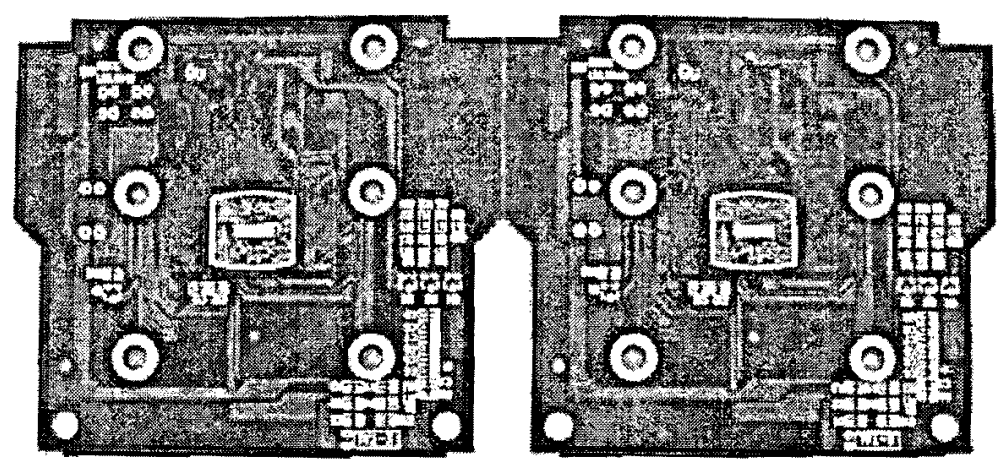

Figure 2.2: Outline of a Printed Circuit Board

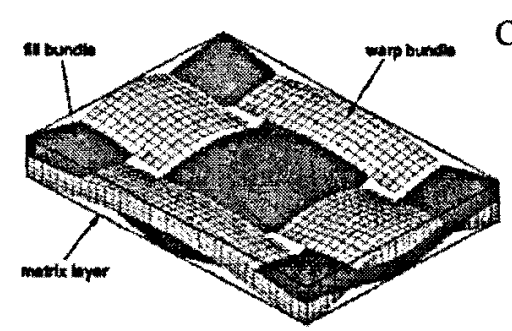

Copper foil E-glass $/$ epoxy $\left(0^{\circ}\right.$ orientation $)$

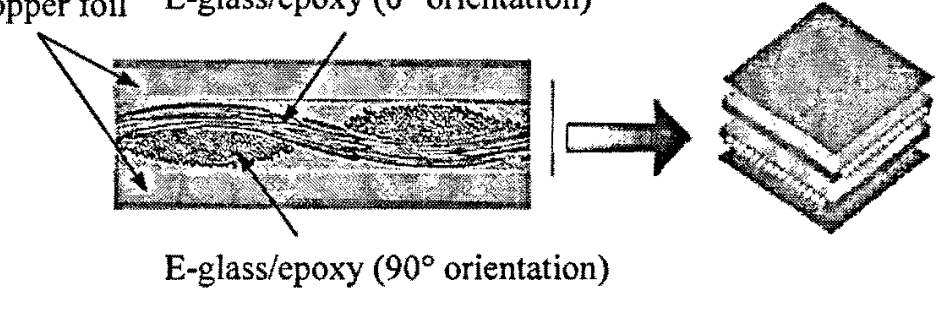

Figure 2.3: Cross section view of a PCB made by glass fiber woven laminate [26]

\subsubsection{Materials of PCB lamina}

The current PCBs made of FR4-materials with high or low glass transition temperature (Tg) are traditionally composed of an epoxy resin, dicyandiamide curing agent, and woven glass reinforcement. These materials have been used for decades due to their low price and good mechanical and thermal properties. FR4 materials have good mechanical and electrical properties such as less loss at high frequencies, less moisture absorption, greater strength and stiffness, high flame resistance, ultra high vacuum (UHV) compatible and low cost. E-glass fibers are applied as the predominant reinforcement for FR4 materials due to their properties, such as high electrical insulating ability, low susceptibility to moisture, high mechanical properties, and good impact resistance. Thermosetting resins are used as matrix for FR4 materials because they have good thermal stability and chemical resistance, and excellent mechanical properties, and they can retain the strength and shape even under elevated temperature during the usage. Generally, thermosetting resin will solidify during being heated and cured, but cannot be remolded or 
softened after their initial heat-formation. The mechanical properties of FR4 are shown in table 2 and the mechanical properties of BT/ Epoxy are shown in table 2.1 .

Table 2.1 FR4 laminate specification [27]

\begin{tabular}{ll}
\hline \multicolumn{1}{c}{ Test/Specification } & \multicolumn{1}{c}{ FR4 Laminate Typical Values } \\
\hline Thermal Stress, Solder bath 288 deg. C & $>60$ \\
Dimensional Stability, E-2/150 & $<0.04 \%$ Warp/fill \\
& $<1.00 \%$ Bow/Twist \\
Flammability, Classification UL94 & V0 \\
Water Absorption E-1/105 & $0.10 \%$ \\
Peel Strength After Thermal Stress & $11 \mathrm{lb}$./in After 10s/288 Deg. C \\
Flexural Strength & $100,000 \mathrm{lbf} / \mathrm{in}^{2}$ Lengthwise \\
& $75,000 \mathrm{lbf} / \mathrm{in}^{2}$ Crosswise \\
Resistivity After Damp Heat Volume & $10^{\wedge} 8 \mathrm{M} \mathrm{ohms} \mathrm{cm}$ \\
Resistivity After Damp Heat Surface & $10^{\wedge} 8 \mathrm{M} \mathrm{ohms}$ \\
Dielectric Breakdown. Parallel to & $>60 \mathrm{KV}$ \\
laminate & \\
Dielectric Constant @ 1MHz & 4.7 \\
Dissipation Factor @ 1MHz & 0.014. \\
Q-Resonance @ 1 MHz & $>75$ \\
Q-Resonance @ $50 \mathrm{MHz}$ & $>95$ \\
Arc Resistance & $125 \mathrm{~s}$ \\
Glass Transition Temperature & $135 \mathrm{Deg} . \mathrm{C}$ \\
\hline
\end{tabular}

Table 2.2 BT/ Epoxy specification [27]

\begin{tabular}{ll}
\hline \multicolumn{1}{c}{ Test/Specification } & \multicolumn{1}{c}{ BT/Epoxy Typical Values } \\
\hline X-axis Dimensional Stability & $15 \mathrm{ppm} /{ }^{\circ} \mathrm{C}$ \\
Y axis & $18 \mathrm{ppm} /{ }^{\circ} \mathrm{C}$ \\
Z-axis & $140 \mathrm{ppm} /{ }^{\circ} \mathrm{C}$ \\
Flammability, Classification UL94 & V0 \\
Water Absorption E-1/105 & $0.14 \%$ \\
Peel Strength After Thermal Stress & $7 \mathrm{lb} . / \mathrm{in} \mathrm{After} 10 \mathrm{~s} / 288^{\circ} \mathrm{C}$ \\
& $100,000 \mathrm{lbf} / \mathrm{in}^{2}$ Lengthwise \\
Flexural Strength * & $75,000 \mathrm{lbf} / \mathrm{in}^{2} \mathrm{Crosswise}$ \\
Resistivity After Damp Heat Volume & $10^{\wedge} 7 \mathrm{M} \mathrm{ohms} \mathrm{cm}$ \\
Resistivity After Damp Heat Surface & $10^{\wedge} 6 \mathrm{M} \mathrm{ohms}$ \\
Dielectric Constant @ 1MHz & 4.1 \\
Dissipation Factor @ 1MHz & 0.013 \\
Arc Resistance & $115 \mathrm{~s}$ \\
Glass Transition Temperature & $185^{\circ} \mathrm{C}$ \\
\hline
\end{tabular}




\section{4 solder ball materials and composition}

\subsubsection{Transition to lead-free solders}

Soft solders (melting temperature lower than $450^{\circ} \mathrm{C}$ ) are usually tin based because tin has good wetting properties and market availability, as well as low price. The $\mathrm{Pb}$ (lead) alloy electroplated component terminal finishes have been successfully used for over 60 years by the electronic industry. Manufacturing standards are well established and databases are accumulated. $\mathrm{Pb}-\mathrm{Sn}$ solder joints reliability has been studied for several decades. However, in order to keep the "green" environment, the use of $\mathrm{Pb}$ is restricted and has been generally eliminated from various microelectronic applications including the solders since the European legislation ban of the use of $\mathrm{Pb}$ effective in July 2006. The industry has adopted alternative, lead-free solders. Many different soft solders were found to be used as substitutes for the standard $\mathrm{Sn}-\mathrm{Pb}$ solders. The most favored lead-free solders fall into two general alloy families, the Sn-Ag group and the Sn$\mathrm{Ag}-\mathrm{Cu}$ group. These solders have the advantages of good processability and producing high reliability solder joints. $\mathrm{Sn}-\mathrm{Ag}-\mathrm{Cu}$ (SAC), the second group, has become the most in common usage now.

\subsubsection{Peak reflow temperature increase}

Reflow soldering is the most common method to attach components to a PCB for second level package process. The process of reflow is to melt the solder alloy particles within the solder paste and without overheating and damaging the electrical components. The purpose of soldering is to form a strong, long-lasting metallurgical bond between the surfaces being joined, both for structural integrity of the assembly and electrical conductivity of the electronic circuits. A key difference between $\mathrm{Pb}-\mathrm{Sn}$ and lead-free $\mathrm{Sn}$-Ag-Cu SMT assembly processes is the solder reflow temperature because $\mathrm{SAC}$ solder materials have higher melting point at $217^{\circ} \mathrm{C}$, compared with $183^{\circ} \mathrm{C}$ for $\mathrm{PbSn}$. Higher reflow temperatures may damage components and increase residual stresses and strains as well decrease service life. Recently, extensive research efforts have focused on redesigning the reflow machine for $\mathrm{Sn}-\mathrm{Ag}-\mathrm{Cu}$ solder pastes in order to keep the peak component temperature to a minimum. This enables manufacturers to automate soldering of lowheat-tolerance components using $\mathrm{Sn}-\mathrm{Ag}$-Cu lead-free solder alloys, thus to take the pressure off 
the component suppliers and to reduce the costs. Figure 2.4 plots leaded and lead free solder assembly reflow temperature profiles.

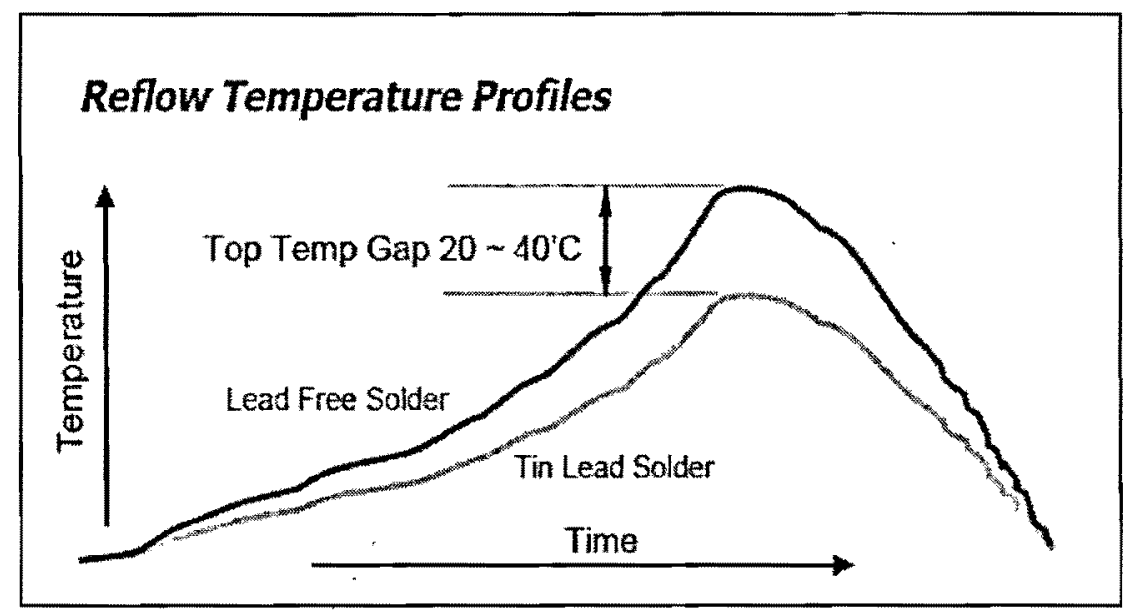

Figure 2.4: Reflow temperature profiles

\subsubsection{Difference material properties comparing to PbSn solders}

Extensive research and development activities have been focused on the $\mathrm{Sn}-\mathrm{Ag}-\mathrm{Cu}$ composite in order to understand the fundamentals of the material properties and to evaluate the reliability issues associated with solder joints formed from their alloy family as compared with the wellestablished PbSn solder joints. The SAC solders material has higher Young's modulus, higher strength and higher coefficient of thermal expansion but lower creep strain rate than that of $\mathrm{Pb}$ Sn solders, especially at higher temperatures. In general, lower creep strain is expected in the lead-free solder joints [4]. SAC solder materials are more difficult to mechanically deform than $\mathrm{Pb}-\mathrm{Sn}$ solder materials due to restricted symmetry in crystal structure.

\subsubsection{Mechanical and thermal properties for SAC solders}

Mechanical properties are much more difficult to determine for SAC solder joints as compared with the bulk solders. The initial properties of the solder joints depend on their solidification condition that varies with solder joint geometry, solder volume, pad shape, thermal treatment, soldering process and interface metallurgy of solder joints. 


\subsubsection{Young's modulus}

Young's modulus is an important design parameter that determines the amount of elastic deformation that a structure will exhibit under loading. It is one of the most structure-insensitive mechanical properties and is affected only slightly by alloying additions, heat treatment or cold work. Figure 2.5 plots a typical stress-strain curve for pure metal or alloy. The first of part of the curve $(0-A)$ is elastic deformation. The point $\mathrm{A}$ is the yield point that represents the start of plastic deformation. The engineering stress and strain can be defined as:

$$
\begin{aligned}
& \text { Engineering stress: } \sigma=\frac{F}{A_{0}} \\
& \text { Engineering strain: } \varepsilon=\frac{l-l_{0}}{l_{0}}
\end{aligned}
$$

Where $A_{0}$ is the original cross sectional area of the specimen before testing; $l_{0}$ is the original gage length and $l$ is the gage length after the force has been applied. The point A is normally defined in terms of the stress that produces a 0.002 strain for engineering application. Curve (A-B) is stress hardening range that increases stress for additional plastic deformation. The slope of the elastic section is defined as Young's modulus

$$
E=\frac{\sigma}{\varepsilon}
$$

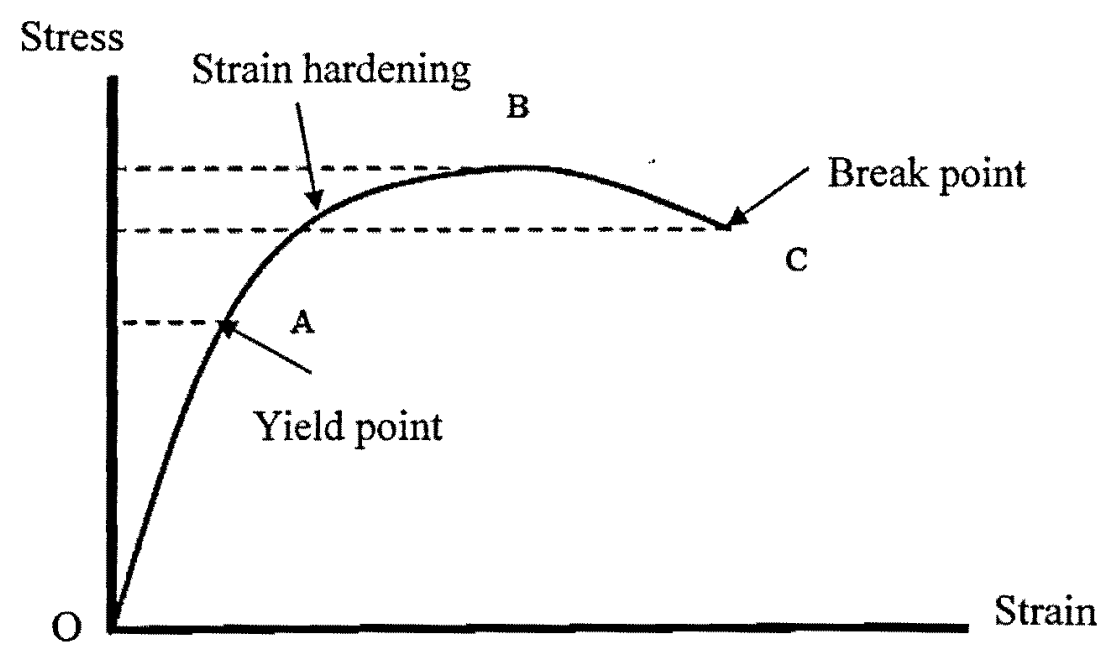

Figure 2.5: Typical stress-strain curve for pure metal or alloy 
The values of Young's modulus for the SAC solder vary widely. This is because the temperature range at which the solder is tested is usually higher than its homologous temperature (half of the melting temperature in Kelvin). In this temperature range, viscoelastic and viscoplastic deformations, which are deformation rate dependent, become important and significant. Caution must be taken if Young's modulus is to be determined from stress-strain curves obtained from tensile tests. To obtain an accurate value, testing must be performed at low stresses so that minimal yielding occurs at a strain rate high enough to eliminate viscoplastic effects [10]. Figure 2.6 shows the curve of Young's modulus versus temperature for $\mathrm{Sn}-\mathrm{Ag}-\mathrm{Cu}$ solders.

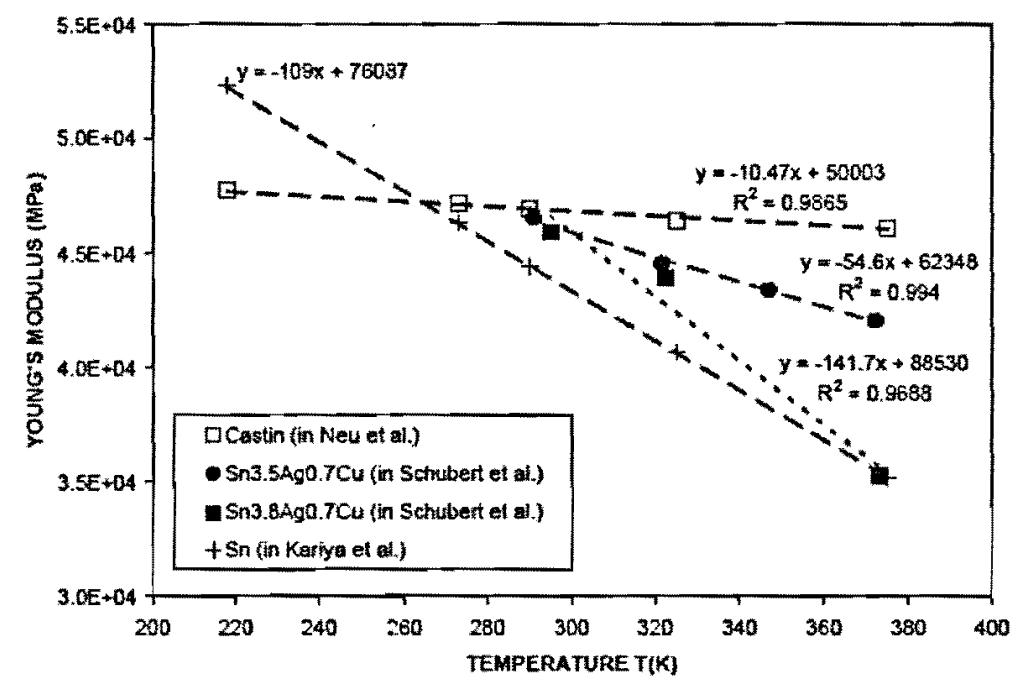

Figure 2.6: Young's modulus versus temperature for SAC materials [NIST]

\subsubsection{The coefficient of thermal expansion}

The coefficient of thermal expansion (CTE) is a materials property that indicates the extent to which a material expands upon heating. CTE is one of the most important thermal properties of solder because electronic packages work under various variable and cyclic temperature environments. The coefficient of thermal expansion is defined as:

$$
\frac{\Delta l}{l_{0}}=\alpha_{l} \Delta T
$$

and $\frac{\Delta V}{V_{0}}=\alpha_{V} \Delta T$

Where $\alpha_{1}=$ linear coefficient of thermal expansion

$\alpha_{V}=$ volume coefficient of thermal expansion 


$$
\begin{aligned}
& \Delta \mathrm{T}=\text { temperature change } \\
& l_{0} \text { and } \Delta l=\text { original and change in length } \\
& V_{0} \text { and } \Delta V=\text { original and change in volume }
\end{aligned}
$$

Figure 2.7 plots the test data for coefficient of thermal expansion of SAC solder versus temperatures. Table 2.3 gives out the thermal and mechanical properties for SAC solder joints.

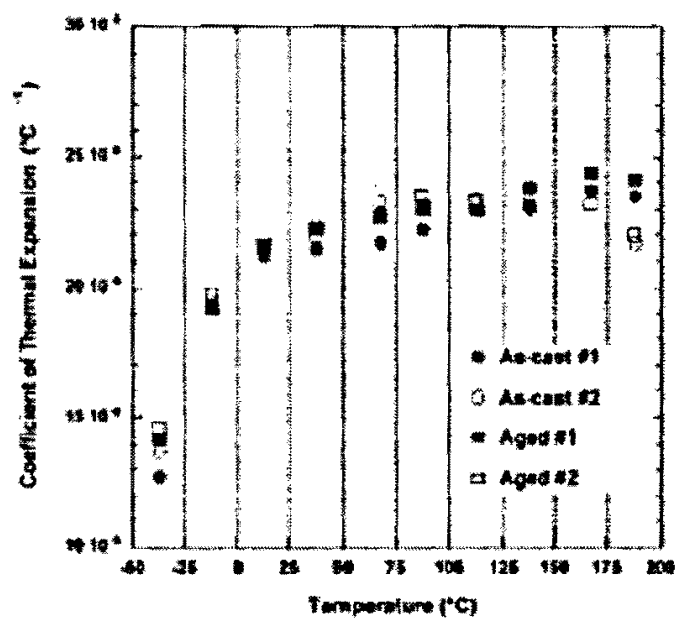

\begin{tabular}{|c|c|c|c|}
\hline Iaterial & $\begin{array}{l}\text { Young's modulus } \\
\left(G P_{a}\right)\end{array}$ & Poisson's ratio & $\mathrm{CIE}\left(p p m^{1} / \mathrm{h}\right)$ \\
\hline PC board & 27 & 0.39 & 18 \\
\hline Copper pad & 76 & 0.35 & 17 \\
\hline $95.5 \mathrm{Sn}-3.9 \mathrm{Ag}-0.6 \mathrm{Cu}$ & $74.84-0.08 \mathrm{~T}$ & 0.3 & $16.66+0.017 \mathrm{~T}$ \\
\hline $\mathrm{Sn}-\mathrm{Pb}$ & $75.94-0.152 \mathrm{I}$ & 0.35 & 24.5 \\
\hline $10 \mathrm{Sn}-90 \mathrm{~Pb}$ & $23.71-0.047 \mathrm{~T}$ & 0.35 & $24.495+0.015 \mathrm{~T}$ \\
\hline Laminate substrate & \multicolumn{3}{|c|}{ Same as PC board } \\
\hline $\mathrm{Al}_{2} \mathrm{O}_{3}$ substrate & 270 & 0.3 & 5.5 \\
\hline $\mathrm{Si}$ & 167 & 0.28 & 2.54 \\
\hline 256 PBG A orermold & 13 & 0.3 & 15 \\
\hline $38 S$ PBG t otermold & 20 & 0.25 & 10 \\
\hline 1657 CCGAlid & 70 & 0.33 & 23 \\
\hline 1657 CCGA lid seal & 0.0024 & 0.35 & 270 \\
\hline
\end{tabular}

Figure 2.7: Coefficient of Thermal Expansion of SAC solders versus temperature [29]

Table 2.3 Material properties of SAC solder joints [29]

Sote: All temperatures are in ${ }^{\circ} \mathrm{K}$ 


\subsubsection{Solder materials}

\subsubsection{Chemical compositions of SAC solders}

Lead-free solders are Sn-rich (typically containing over $90 \%$ of $\mathrm{Sn}$ ). The SAC solders' physical, chemical and mechanical properties are heavily influenced by the properties of pure $\mathrm{Sn}$ [12]. Pure Sn exists in three crystal structures $(\alpha, \beta, \gamma)$, depending on the temperature and pressure [12]; Pure Sn phase ( $\beta-\mathrm{Sn})$ has body centered tetragonal (BCT) crystal structure that is less isotropic than those of $\mathrm{Pb}$ that has FCC crystal structure. Its $\mathrm{c} / \mathrm{a}$ ratio is less than one, which means that the unit cell for tetragonal tin is rectangular in cross section. This configuration is usually an indication of anisotropic properties of a material. The coefficient of thermal expansion (CTE) and self diffusion coefficient are higher in longer side ("a" direction) than short side ("c" direction).

\subsubsection{The ternary eutectic composition of SAC solders}

A eutectic composition provides the benefit of an alloy with the lowest melting temperature of all alloys comprising the system. When two or more pure materials are mixed to form an alloy, several important features of the alloy become functions of composition and temperature. In order to work with alloys and to predict their structure in the solid condition, it is essential to understand how the melting point and the solid phases change with alloy composition and temperature. In solidification processing, the most distinguishing characteristic of an alloy compared to a pure element is that an alloy contains more than one chemical species. Solidification rarely results in a solid in which the alloying elements are distributed uniformly. In general, a redistribution of that solute takes place during freezing, resulting in a solid that is inhomogeneous on the microscale, the macroscale or both.

The eutectic microstructure is often complicated by precipitation within one or more of the eutectic constituents when the alloy is cooled below the eutectic solidification temperature that means the eutectic constituents will depend on time and temperature. The eutectic microstructure has a very high surface area per unit volume and thermodynamically unstable with respect to reconfiguration into a mixture of coarser or more equiaxed grains [13]. The properties of a compound are often very different from those of any of the individual elements that make up the 
compound such as pure metals tend to be soft and ductile while intermetallic compounds are usually hard and brittle. Single element systems have a single melting point where the material changes from a single phase solid material to a single phase liquid material. In SAC solder alloy, pure $\mathrm{Ag}$ melts at $961^{\circ} \mathrm{C}$ while pure $\mathrm{Sn}$ melts at $232^{\circ} \mathrm{C}$ and copper at $1084^{\circ} \mathrm{C}$. However when other elements are added to a pure metal, the melting point of the alloy may be depressed and additional eutectic and peritectic reactions can occur due to thermodynamic considerations.

For $\mathrm{Sn}-\mathrm{Ag}-\mathrm{Cu}$ compositions such as $\mathrm{Sn}-3.8 \mathrm{Ag}-0.7 \mathrm{Cu}$, there are three phase transformations during melting and solidification. The alloy experiences during the solidification sequence should be $\mathrm{L} \rightarrow \mathrm{L}+\alpha ; \mathrm{L}+\alpha \rightarrow \mathrm{L}+\alpha+\beta$; and $\mathrm{L}+\alpha+\beta \rightarrow \alpha+\beta+\mathrm{E}(\alpha+\beta+\gamma)$. There, $\alpha, \beta$, and $\gamma$ denote solid phases that they can be any combination of $\beta-\mathrm{Sn}, \mathrm{Ag}_{3} \mathrm{Sn}$, and $\mathrm{Cu}_{6} \mathrm{Sn}_{5}$. The temperature point $217^{\circ} \mathrm{C}$ is called the eutectic temperature of $\mathrm{Sn}-\mathrm{Ag}-\mathrm{Cu}$ alloy. Figure 2.8 shows a calculated phase diagram for $\mathrm{Sn}-\mathrm{Ag}$-Cu alloy. SAC alloy solidification consists of three stages, primary, secondary, and tertiary. The constitutional phases in the SAC eutectic alloy are the $\beta S n$, $\mathrm{Ag}_{3} \mathrm{Sn}$, and $\mathrm{Cu}_{6} \mathrm{Sn}_{5}$. For the $\mathrm{SAC}$ alloys of primary $(\mathrm{Sn})$ phase region, their solidification paths will consist of three stages: primary ( $\mathrm{Sn}$ ) phase, secondary $\mathrm{Ag}_{3} \mathrm{Sn}$ or $\mathrm{Cu}_{6} \mathrm{Sn}_{5}$, and tertiary $\mathrm{Cu}_{6} \mathrm{Sn}_{5}$ or $\mathrm{Ag}_{3} \mathrm{Sn}$. Figure 2.9 plots a calculated liquid phase diagram for $\mathrm{Sn}-\mathrm{Ag}-\mathrm{Cu}$ alloy. The table 2.4 gives out the eutectic equilibrium of the SAC system.

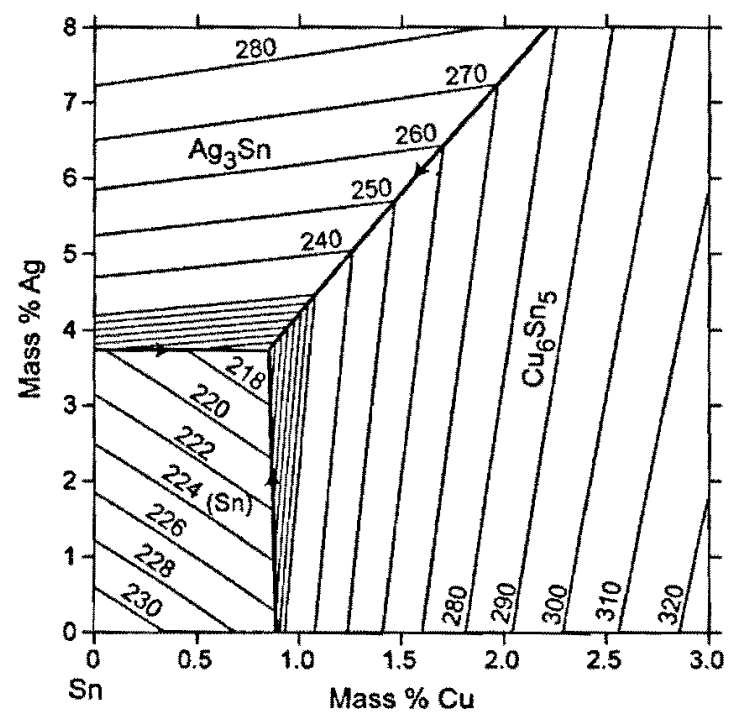

Figure 2.8: Calculated liquid phase diagram of SAC alloy [NIST] 
Table 2.4 Calculated eutectic equilibrium of the SAC system [U.R. Kattner, NIST, 2000]

\begin{tabular}{ccccc}
\hline Reaction & phase & Mass \% $\mathrm{Ag}$ & Mass \% Cu & Mass \% Sn \\
\hline $\mathrm{L} \rightarrow \mathrm{Ag}_{3} \mathrm{Sn}+$ & $\mathrm{L}$ & 3.73 & 0.83 & 95.42 \\
$\mathrm{Cu}_{6} \mathrm{Sn}_{5}+(\mathrm{Sn})$ & $\mathrm{Ag}_{3} \mathrm{Sn}$ & 73.17 & 0 & 26.83 \\
$\left(216.9^{\circ} \mathrm{C}\right)$ & $\mathrm{Cu}_{6} \mathrm{Sn}_{5}$ & 0 & 39.07 & 60.93 \\
& $(\mathrm{Sn})$ & 0.07 & 0 & 99.93 \\
\hline
\end{tabular}

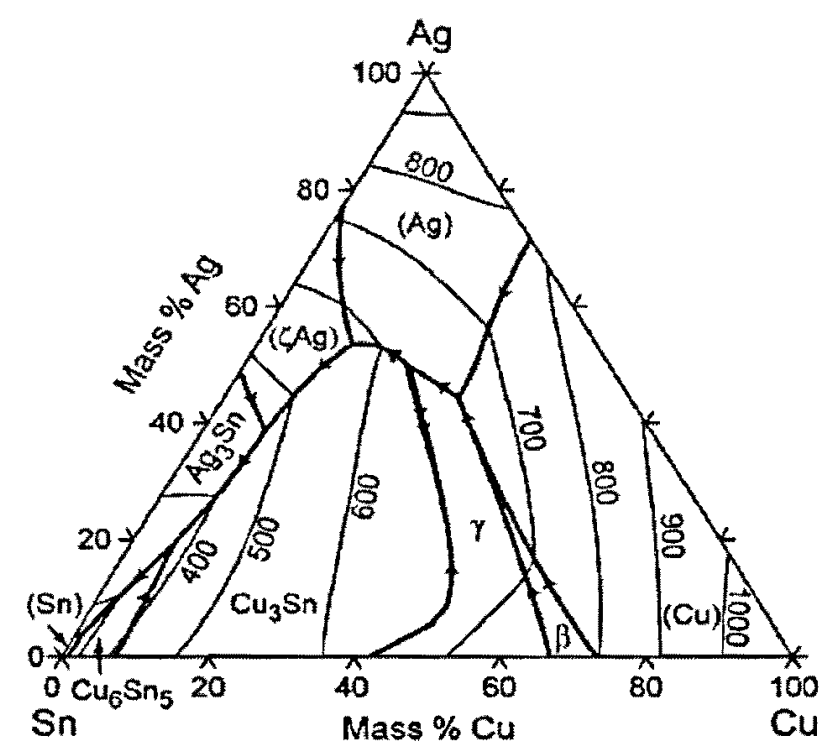

Figure 2.9: The phase diagram of SAC alloy [17]

\subsection{Solder joints}

\subsubsection{Structure of BGA assembly (PBGA)}

BGA assembly (PBGA) is an area array surface mount technology in which ceramic or plastic modules are connected to printed circuit cards by means of solder balls as calling the second level connection. The packaging structures usually consist of several materials and interfaces such as copper pads, alloy solders, silicon die as well as BT substrate and FR4 (Flame Retardant fiber glass epoxy) PCB. All of these materials with different mechanical properties and strain concentration with high magnitudes are frequently localized in very tiny zones of the solder joints. The interconnection between the die and carrier in BGA packaging is made through a conductive "bump" that is placed directly on the die surface. The bumped die is then "flipped over" and placed face down, with the bumps connecting to the carrier directly. A bump called the controlled collapse chip connection (C4) is typically $70-100 \mu \mathrm{m}$ high, and 100-125 $\mu \mathrm{m}$ in 
diameter and the second level solder joints diameter range around $600 \mu \mathrm{m}$. Such a situation makes the accurate determinations no uniform and nonlinear strain distributions extremely difficult. The cross section view of an assembly BGA package is showed at Figure 2.10.

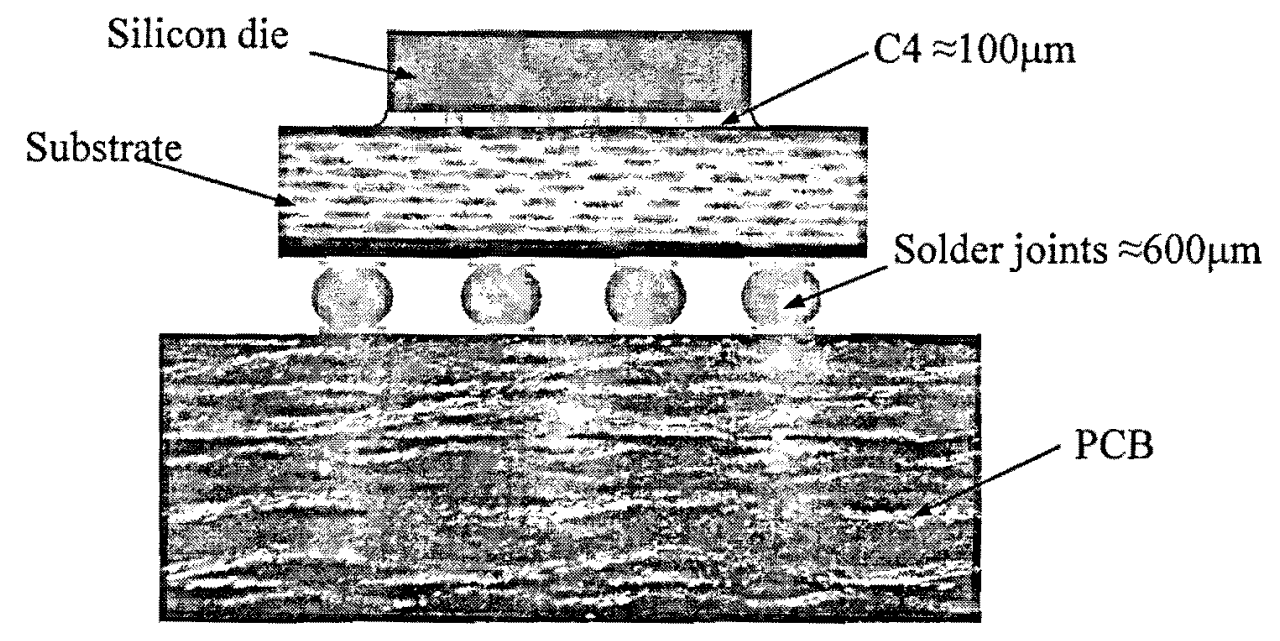

Figure 2.10: The cross section view of a BGA package

\subsubsection{Solidification with reflow process}

\subsubsection{Undercooling requirement}

Undercooling phenomena of liquid is the lowering of the temperature of a liquid beyond the freezing temperature and still maintaining a liquid form. As the nucleation begins, latent heat of fusion is released causing an increase in the temperature of the liquid that is called recalescence. Normal freezing occurs when the atoms of the container walls impose an ordering on the liquid atoms causing them to arrange themselves into a crystalline structure and begin to grow. Figure 2.11 is a typical solidification plot of temperature versus time with an undercooled and nonundercooled liquid. 


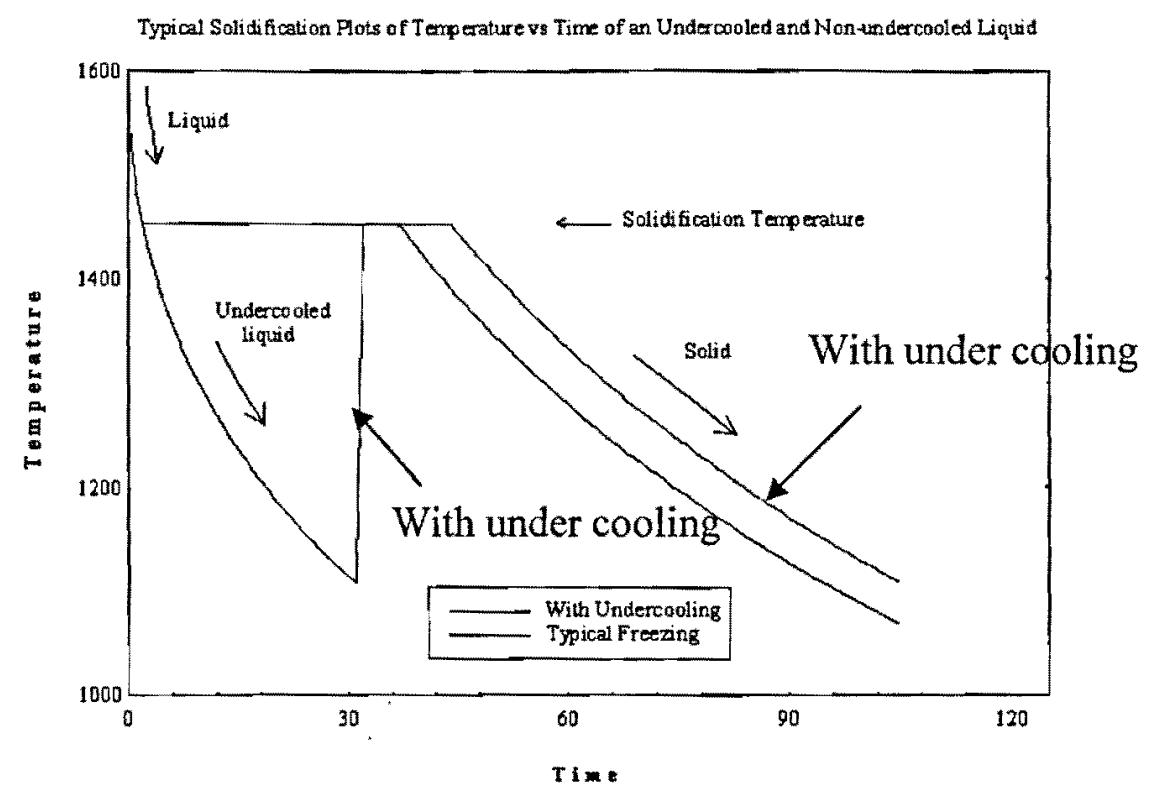

Figure 2.11: A cooling curve of solidification

The microstructure of SAC solder joints are determined by factors such as volume fraction of each phase that is proportional to the alloy composition, and distribution and size of spacing of each phase. It is expected that SAC solder joints will form an equilibrium microstructure at a mixture of three phases, $\beta-\mathrm{Sn}, \mathrm{Ag}_{3} \mathrm{Sn}$, and $\mathrm{Cu}_{6} \mathrm{Sn}_{5}$. But the research found that a microstructure observed in a Sn-3.8-Ag-0.7Cu BGA solder joints is not an equilibrium microstructure but rather with a group of complex Sn's dendritic arm structure surrounded by a network in which all three phases are interspersed [12]. The dendritc arm formation due to the composition of SAC alloy and cooling rate during soldering reflow process. The formation of this dendritic microstructure indicates that pro-eutectic phase to be there and require a large amount of undercooling before the $\mathrm{Sn}$ phase nucleation and solidification. And also the large pro-eutectic $\mathrm{Ag}_{3} \mathrm{Sn}$ plates and $\mathrm{Cu}_{6} \mathrm{Sn}_{5}$ rods may be found in the $\mathrm{SAC}$ solder joints microstructure. Once the pro-eutectic phases form, they deplete $\mathrm{Ag}$ and $\mathrm{Cu}$ atoms from the surrounding $\mathrm{Su}$ rich liquid phase and the composition of the remaining liquid locally deviates from its initial composition. The ternary phase microstructure in the inter-dendritic regions consists of fine particles of $\mathrm{Ag}_{3} \mathrm{Sn}$ and $\mathrm{Cu}_{6} \mathrm{Sn}_{3}$ in a matrix of $\beta-\mathrm{Sn}$. The pure $\beta-\mathrm{Sn}$ regions represent single dendrite arm structures while the three phase regions represent the impingement zones for the growth of the neighboring $\beta$-Sn dendritic arm structures and are formed in the final stages of solidification[12]. The research found that the growth of large pro-eutectic phases can be reduced by a rapid cooling rate or by 
reducing $\mathrm{Ag}$ or $\mathrm{Cu}$ atoms from the surrounding $\mathrm{Sn}$-rich liquid phase. The table 2.5 shows the undercooling requirement comparison with different composition solder alloys.

Table 2.5 Undercooling requirement for the solidification of $\mathrm{SAC}$ and $\mathrm{Pb} \mathrm{Sn}$ solders [12]

\begin{tabular}{|c|c|c|c|}
\hline $\begin{array}{l}\text { Solder composition } \\
\text { (wt. \%) }\end{array}$ & $\begin{array}{l}\text { Melting T during } \\
\text { heating } \mathrm{T} 1\left({ }^{\circ} \mathrm{C}\right)\end{array}$ & $\begin{array}{l}\text { Peak T during } \\
\text { cooling T } 2\left({ }^{\circ} \mathrm{C}\right)\end{array}$ & $\begin{array}{c}\text { Required } \\
\text { undercooling } \\
\Delta \mathrm{T}=(\mathrm{T} 1-\mathrm{T} 2)\left({ }^{\circ} \mathrm{C}\right)\end{array}$ \\
\hline $\begin{array}{l}\text { Sn-3.8-Ag-0.7Cu } \\
(\mathrm{SAC})\end{array}$ & 217.0 & 187.2 & 29.8 \\
\hline $\mathrm{SAC}+0.1 \mathrm{Zn}$ & 217.7 & 213.3 & 4.4 \\
\hline $\mathrm{SAC}+0.1 \mathrm{Zn}$ & 217.2 & 213.6 & 3.6 \\
\hline $\mathrm{Sn}-8-\mathrm{Zn}-3 \mathrm{Bi}(\mathrm{SAC})$ & 193.7 & 191.8 & 1.9 \\
\hline $100 \mathrm{Sn}$ & 232.6 & 217.5 & 15.1 \\
\hline $95 \mathrm{~Pb}-5 \mathrm{Sn}$ & 305.6 & 302.4 & 3.2 \\
\hline $100 \mathrm{~Pb}$ & 328.5 & 324.1 & 4.4 \\
\hline
\end{tabular}

\subsubsection{Effect of reflow cooling rate}

Solder joints in electronic packages are normally undergo a reflow process during manufacturing and a server thermal cycle condition in service. The solder joint stress and strain responding to the thermal expansion mismatch between the materials interconnected by the solder balls are inherent and difficult to predict. The solder microstructure, such as the grain size and shape, spacing of particles and the dislocation density, is sensitive to cooling rate of a reflow process, and may change also due to thermal treatment and storage aging. The solder joint of SAC is soft and more compliant comparing with other alloy solder joints. During thermal cycle condition the specified strain is made up of both elastic and plastic strain. The stresses reached in such a cycle depend on the elastic and plastic compliances of the solder [10].

Temperature has a striking effect for SAC solder joints since the solder volume is small and the joints are thermally well connected to dissipate the latent heat released during the solidification process. The microstructure of solder joints is significantly influenced by reflow condition such as peak temperature and cooling rate after solderding. A very rapid cooling rate (about $100^{\circ} \mathrm{C} / \mathrm{s}$ ) will results a fine primary $\beta$-Sn dendrite structure. The dendrite structre is developed well under 
a rapid cooling rate condition, resulting in a finer dendritic growth that increases the strength of solder joints. On the other hand the slow cooled rate will result in a coarser and largere dendrite structure that reduces the resistence to creep deformation. The major hardening agent of the ternary alooys are $\mathrm{Ag}_{3} \mathrm{Sn}$ and $\mathrm{Cu}_{6} \mathrm{Sn}_{5}$ that have high strength and high resistance to creep deformation. It is not expected that these element will have a big and coarse structure. However, rapid cooling rates will create larger temperature gradients in large mass substrates or packages, which will bring about side effects such as thermal stress or strain to the solder joints. Figure 2.12 plots a typical reflow tmperatur profile for the lead free soldering process. Figure2.13 shows the different microstructure of SAC BGA solder balls solidified at different cooling rate.

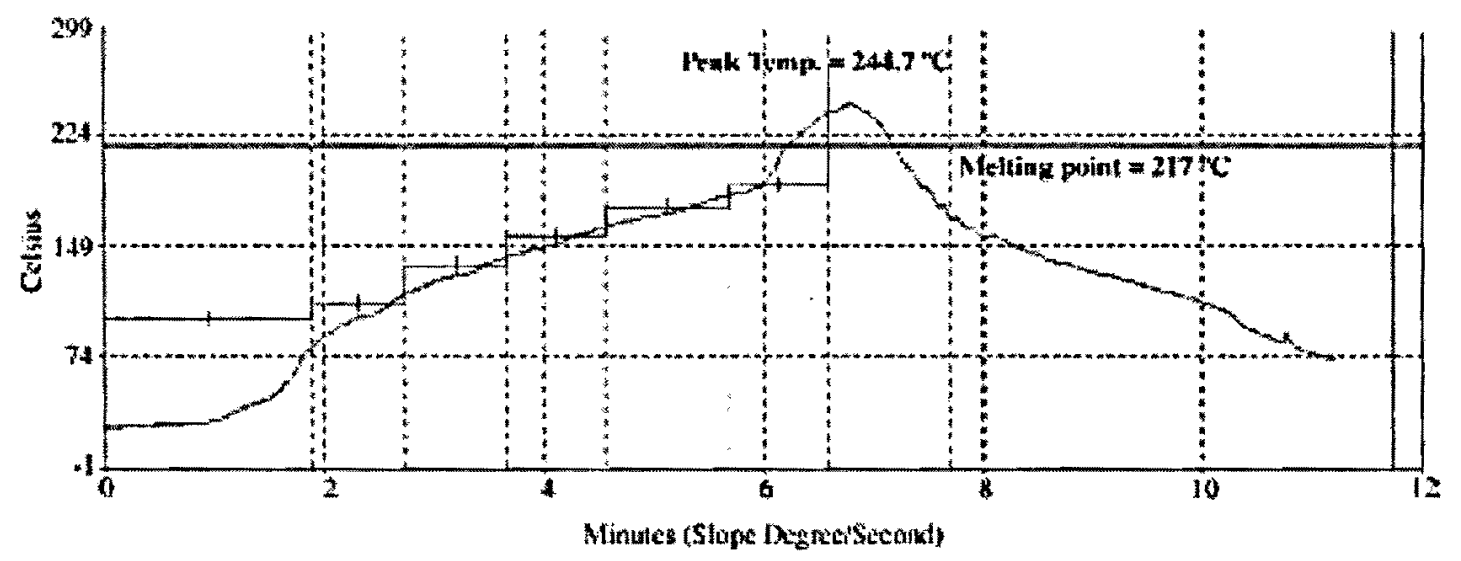

Figure 2.12: SAC soldering reflow profile

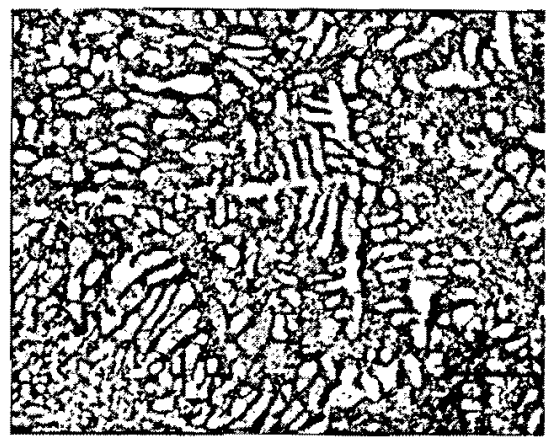

(a)

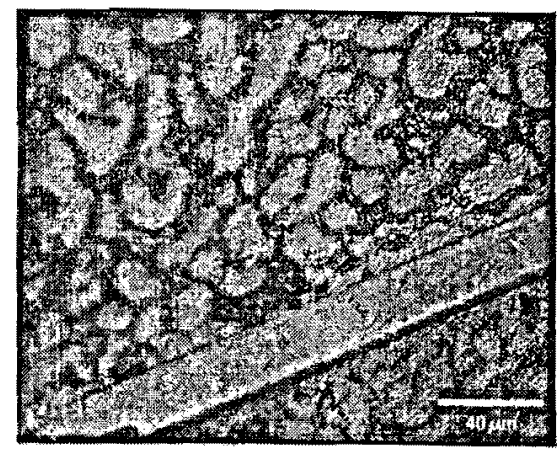

(b)

Figure 2.13: Microstructure of SAC BGA solder balls

(a) Cooling rate $100^{\circ} \mathrm{C} / \mathrm{s}$, (b) Cooling rate $0.02^{\circ} \mathrm{C} / \mathrm{s}$ [18] 


\subsubsection{Microstructure of SAC solder joints}

Solder joints of electronic assemblies are complex elements and the study of solder interconnects usually uses no traditional techniques of structural analysis and fatigue testing of engineering metals. The correlation between the microstructure and the mechanical properties of SAC solder is very important because the mechanical properties of SAC are dependent on the microstructure of the solder and is affected by many parameters such as IMC (intermetallic compounds), joint or specimen size, cooling rate of the assembly after soldering and aging under service environment, etc. The microstructure of solder joints depends on the solder chemical composition, the rate of cooling after soldering as well as the interconnected materials. Most lead free solders have either a binary or ternary eutectic composition and their microstructures are more complex and more affected by the single metals. The ternary phase microstructure in the inter-dendritic regions consists of fine particles of $\mathrm{Ag}_{3} \mathrm{Sn}$ and $\mathrm{Cu}_{6} \mathrm{Sn}_{5}$ in a matrix of $\beta-\mathrm{Sn}$. The regions where all the three phases are present surround the region of essentially pure $\mathrm{Sn}$. The pure $\beta-\mathrm{Sn}$ regions represent dingle-dendrite arm structures. The three phase regions represent the impingement zones for the growth of the neighboring $\beta$-Sn dendritic arm structures and are formed in the final stages of solidification [12].

\subsubsection{Microstructure of solders and its impact on solder joint behaviors}

The microstructure of solder balls depends on the solder chemical composition, the rate of cooling after soldering as well as the interconnected materials. The microstructure of a solder joint influences its mechanical properties in three generically different ways:

\section{- Solder microstructure governs solder joint deformation and failure}

The mechanical properties of a solder joint depend on the motion of dislocations and the growth and reconfiguration of grains. The mechanical properties are more sensitive to the microstructure of the solder than to its chemical composition [12]. Usually, a solder joint microstructure is given at least implicitly without considering the details of, such as, how the joint is solidified, aged and deformed. Since the mechanical behaviours of a solder joint depends more on the solder material's microstructure, how the solder joint is formed and processed is much important.

- Common solders deform in-homogeneously 
Solder joints have complex microstructure, are used at high homologous temperatures and deform under relatively low loads. These factors determine that the solder joint is rarely uniform. From the microscopic perspective, it is insufficient to know the local mechanical properties of the solder joints. It is also necessary to have a sense of how the inhomogeneous deformation develops in an individual solder joint.

\section{- Common solders are microstructurally unstable}

Solders are low melting point alloys. Solders are bounded to the substrate by chemical reaction to form intermetallic compounds at specific eutectic point. Solder joints are used in the solidified or slightly aged condition. There factors ordinarily lead to a microstructure that is thermodynamically unstable. While the joint is aged, thermally cycled or deformed, its microstructure will change with time, so does its mechanical behaviours.

\subsubsection{Deformation of solder joints under a thermal load}

The packaging structures usually consist of several materials and interfaces such as copper pads, Sn-Ag-Cu alloy solders, silicon die as well as BT substrate and FR4 PCB. All of these materials with different mechanical properties and strain concentration with high magnitudes are frequently localized in very tiny zones of the solder joints. From stress and strain deformation theory of plane strain, the mechanical strain equations are listed as below:

$$
\begin{aligned}
& \varepsilon_{x x}=\sqrt{1+2 \frac{\partial u}{\partial x}+\left(\frac{\partial u}{\partial x}\right)^{2}+\left(\frac{\partial v}{\partial x}\right)^{2}}-1 \\
& \varepsilon_{y y}=\sqrt{1+2 \frac{\partial v}{\partial y}+\left(\frac{\partial v}{\partial y}\right)^{2}+\left(\frac{\partial u}{\partial y}\right)^{2}}-1 \\
& \gamma_{x y}=\arcsin \frac{\frac{\partial u}{\partial y}+\frac{\partial v}{\partial x}+\frac{\partial u}{\partial x} \frac{\partial u}{\partial y}+\frac{\partial v}{\partial x} \frac{\partial v}{\partial y}}{\left(1+\varepsilon_{x}\right)\left(1+\varepsilon_{y}\right)}
\end{aligned}
$$

For small deformation, it can be assumed that products and squares of displacement gradients will be small with respect to the displacement gradients and therefore can be neglected. Equation (2.6) can be reduced to equation (2.7) 


$$
\begin{aligned}
& \varepsilon_{x x}=\frac{\partial u}{\partial x} \\
& \varepsilon_{y y}=\frac{\partial v}{\partial y} \\
& \gamma_{x y}=\frac{\partial u}{\partial y}+\frac{\partial v}{\partial x}
\end{aligned}
$$

For the applications with the temperature changes, the total strain also contains the thermal expansions.The equations are shown below:

$$
\begin{aligned}
& \varepsilon_{x x}=\sqrt{1+2 \frac{\partial u}{\partial x}+\left(\frac{\partial u}{\partial x}\right)^{2}+\left(\frac{\partial v}{\partial x}\right)^{2}}-1+\alpha \cdot \Delta T \\
& \varepsilon_{y y}=\sqrt{1+2 \frac{\partial v}{\partial y}+\left(\frac{\partial v}{\partial y}\right)^{2}+\left(\frac{\partial u}{\partial y}\right)^{2}}-1+\alpha \cdot \Delta T \\
& \gamma_{x y}=\arcsin \frac{\frac{\partial u}{\partial y}+\frac{\partial v}{\partial x}+\frac{\partial u}{\partial x} \frac{\partial u}{\partial y}+\frac{\partial v}{\partial x} \frac{\partial v}{\partial y}}{\left(1+\varepsilon_{x}\right)\left(1+\varepsilon_{y}\right)}
\end{aligned}
$$

From small deformation theory that the quadratic terms are discarded, the displacement and strains produced by the applied loaded are reduced to

$$
\begin{aligned}
& \varepsilon_{x x}=\frac{\partial u}{\partial x}+\alpha \cdot \Delta T \\
& \varepsilon_{y y}=\frac{\partial v}{\partial y}+\alpha \cdot \Delta T \\
& \gamma_{x y}=\frac{\partial u}{\partial y}+\frac{\partial v}{\partial x}
\end{aligned}
$$

Therefore in practice the measurement and calculation of stress of solder joints are more difficult compared to other engineering structures. Many simulation and experimental methods are employed to complete strain and stress analysis and also it is noted that the CTE mismatch and the temperature variation subject the solder joint to a displacement/strain controlled boundary condition in experimental methods [28].

\subsubsection{Stress and strain}

A solder joint consists of a solder ball and solder pads that are printed on both PCB and substrate surfaces. Individual components mounted in a system are interconnected through solder joints 
and $\mathrm{PCB}$ routings. These elements in an electronic package typically have different thermal expansion coefficients. During reflow soldering and cooling down process the soldered assembly undergoes a temperature cycle to induce thermal stress and strain in the solder joints. Such stress and strain are also cyclic in nature, which result in thermo-mechanical fatigue failure of the joints. During a soldering process, the lower CTE materials such as substrate and PCB board would expand upon heating at a slower rate than the higher CTE materials such as solder and solder paste. This will put the solder in a compressive stress state, whereas upon cooling the opposite occurs and the solder will be in tension. Shear stress is also applied to the joints at different rates from either side of the solder layers due to CTE mismatch between substrate and IC chip (with low CTE of 3-6 ppm/C). The shear stresses will take effect both at the interfaces and across the entire solder layer, inducing interface or solder ball cracking.

\subsubsection{Interfacial stress}

Solder joints in electronic packages normally undergo a reflow process during manufacturing and a server thermal cycle condition in service. The solder joint stress and strain responding to the thermal expansion mismatch between the materials interconnected by the solder balls are inherent and difficult to predict. The solder microstructure, such as the grain size and shape, spacing of particles and the dislocation density, is sensitive to cooling rate of a reflow process, and may change also due to thermal treatment and storage aging. The solder joint of SAC is soft and more compliant comparing with other alloy solder joints. During thermal cycle condition the specified strain is made up of both elastic and plastic strain. The stresses reached in such a cycle depend on the elastic and plastic compliances of the solder.

The most common cause of solder joint cracking is temperature change. This will cause strains in the solder joints due to thermal expansion mismatch between various materials resulting in fatigue of the solder joints. There is a great difference in the CTE between silicon die (3-6 $\mathrm{ppm} / \mathrm{C})$ and printed circuit boards $(18 \mathrm{ppm} / \mathrm{C})$, which induces stresses and cycling damage for solder joints. The larger the temperature change, thermal mismatches and size of the package, the fewer thermal cycles to failure. 


\subsubsection{Stress distribution}

If two materials with different CTE, stiffness or with different temperatures are bonded together assuming a no slip condition between the layers, the shear force/stress must exist along the interface to keep the length consistency [28]. This is concluded based on the idea of action and reaction of forces along the interface of dissimilar materials. Since the two pieces of different stiffness are subjected to the same force system in order to keep curvature compatible a peel stress must exist and present large magnitude on the edges. Figure 2.14 shows the shape of two warped materials with different CTE. When heated, a bi-material beam always bends with vertex on the higher CTE side, and when cooled, the vertex is always on the lower CTE side.

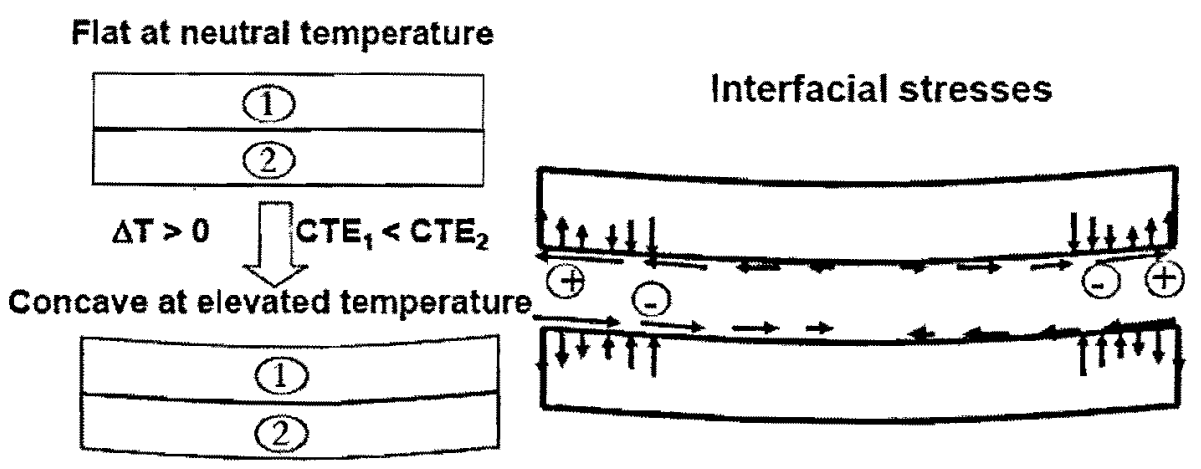

Figure 2.14: Peel and shear stresses in a continuous joint of two dissimilar materials [28]

For solder joint warpage follows the peel stress distribution with various warpage surfaces that presents the similar mechanism with peel stress at board level soldering process. Figure 2.15 shows a pattern of stress distribution along a row of solder joints. When a real BGA assembly is under consideration, the continuous layer of adhesive is replaced by a row of discrete solder joints. Though a similar pattern of stress distribution may generally be assumed, actual stress is far much complicated by structure details and material nonlinearity. In fact, solder joints warpage shape appears convex with a declined temperature after the eutectic temperature while reflow process. 


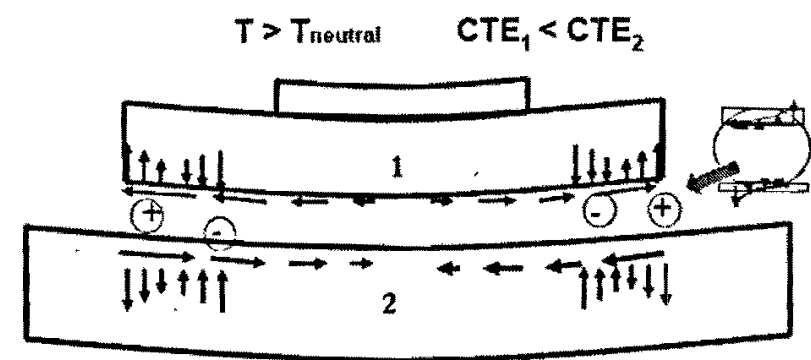

CTE mismatch works with similar
mechanism at board level soldering

Figure 2.15: Pattern of stress distribution along a row of solder joints [28]

\subsubsection{Stress concentration}

Since the solder is usually the weakest material in an electronics assembly, the cyclic strain due to thermal stress is concentrated in the solder joints to cause the solder joints failure. According to IPC 7905A "Design and Assembly Process Implementation for BG0As", there are two ways BGA lands including Non Solder Mask Defined (NSMD) and Solder Mask Defined Pad (SMD) applied by many component manufactures.

For non Solder Mask Defined BGA landing the mask opening is larger than the copper land and hence the ball does not touch the solder mask after reflow. NSMD offers greater area for the solder to bound creating a stronger electrical and mechanical contact. For solder masked defined where the land size is larger than solder mask and the molten BGA ball touches the solder mask after reflow. With SMD, the solder mask opening overlaps the metal pads. The shape of exposed metal is defined by the mask. There is greater chance of solder shorts that is due to the solder ball becoming larger than the intended joint (usually about $0.1 \mathrm{~mm}$ [IPC]). The main disadvantage of SMD land is that the stress concentrations created by SMD solder joint can be the origin of solder joint failures and reduced reliability. The uses of NSDM will improve the solder joint condition and increase in fatigue life by factors of about 1.25 to 3 while with equal solder joint height comparing to SMD solder joint. Figure 2.16 shows two typical NSDM and SMD solder joints. Figure 2.17 plots SEM pictures of the cracked solder joint initial and propagation along stress concentration corner done in SEM at Ryerson lab. 


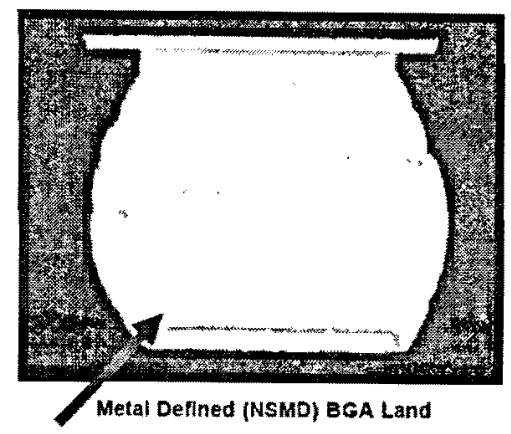

Reduced strain /stress concentration on the root

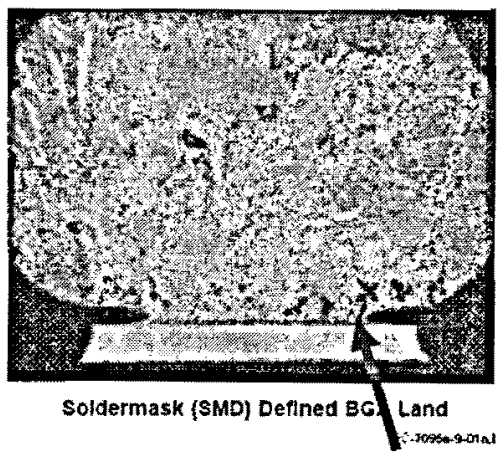

Strain/stress concentration on the root

Figure 2.16: Two type BGA Solder lands (SMD and NSMD)

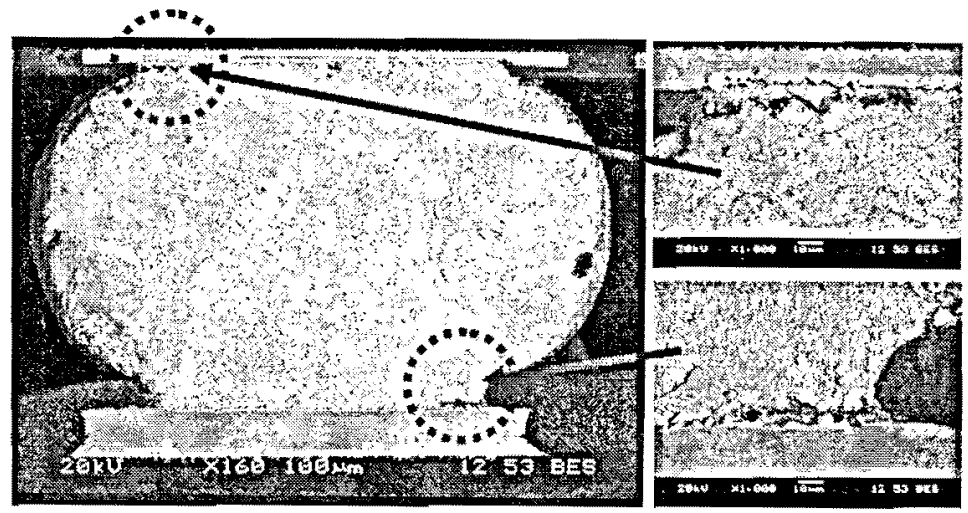

Figure 2.17 SEM for solder joints crack along the corner after 4440 thermal cycles

\subsubsection{Effect of creep behavior}

\subsubsection{Creep - time dependent mechanical behaviours}

Creep is the time dependent and irreversible deformation of a solid metal under a constant load or stresses that below their yield strength. The creep strain develops over time and generally can occur at any temperature above half of melting point absolute zero $(0 \mathrm{~K})$. In the low temperature region below the homologous temperature (or $T<0.5 T_{m}$, where $T_{m}$ is the absolute melting temperature), the creep strain is very limited and deformation normally does not lead to eventual fracture.

The creep response is conveniently divided into three regimes, primary, steady-state and tertiary creep. During primary creep, metals strain-harden. The strain rate decreases over time, as 
hardening of the metal becomes more difficult. Steady state creep happens when specimen deformation is kept increasing and the secondary creep proceeds at a steady strain rate. The last stage of deformation is tertiary creep that represents a region of rapidly increasing strain rate. Tertiary creep ends finally in creep fracture. The fracture develops early in this stage as the growth of voids at the grain boundaries. The voids extend and open up as grain boundary sliding, leading finally to inter-granular creep fracture.

For most metals, secondary or steady state creep is the dominant deformation mode at temperatures above half the melting point, $T_{m}$, in degree Kelvin. Other deformation modes, such as initial deformations, rapid plastic flow and primary creep, are rarely reported because they appear less significant under high stress conditions. However, these deformation modes need to be investigated further since they may become more significant under rapid thermal cycling conditions with high ramp rates and/or short dwell times. Figure 2.18 shows a creep curve during a constant stress load.

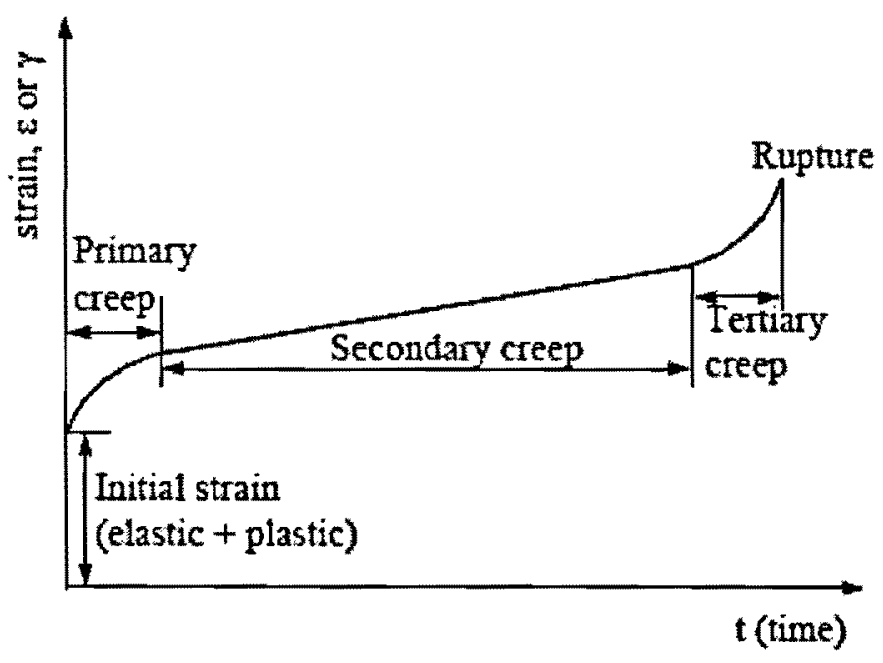

Figure 2.18: Creep curve: strain versus time under constant stress

\subsubsection{Hall's Stress/ Strain Hysteresis Loop}

One of the most significant contributions to the field of solder joint mechanics is the shear strain and hysteresis loop measurements and the theory developed by Peter Hall at AT\&T Bell Laboratories (Hall, 1984 and 1991). Using strain gauge measurements and a simplified analysis of shear forces exerted on the solder joints of LCCC (Leadless Ceramic Chip Carrier) assemblies, 
Hall showed that the stress/strain response of solder joints during temperature cycling is a hysteresis loop. The shape of the loop reflects the temperature-dependent inelastic deformations of solder and elastic deformations of the entire assembly. The thermal expansion mismatch between board and component is accommodated by shear of the solder joints and simultaneous stretching and bending of the board and component. These elastic deformations of the interconnected parts provide compliance to the assembly, suggesting practical ways to reduce solder joint stresses by designing boards and components that are more compliant. Figure 2.19 shows the hysteresis loop.

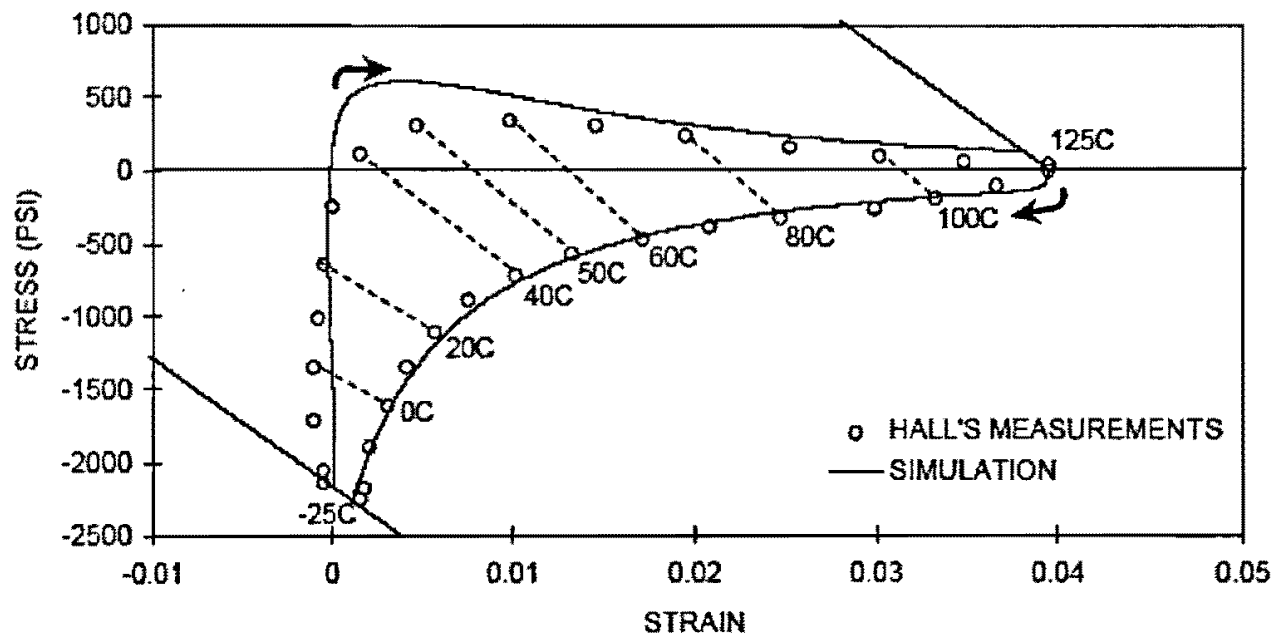

Figure 2.19: Solder joint hysteresis loop during thermal cycling [22]

The shape of the hysteresis loop in Figure 2.19 reflects the non-linear, temperature-dependent constitutive behavior of solder. The loop is described clock-wise. Isothermal stress reduction lines are drawn as dashed lines between the data points corresponding to equal temperatures during the ramp-up and ramp-down phases of the thermal cycle. The stress reduction lines are almost parallel to each other. During the dwell periods at the temperature extremes, stresses are reduced along the stress-reduction lines (shown as solid lines) for those temperatures. At $125^{\circ} \mathrm{C}$, the solder becomes very soft and the shear strain is large but the stress is relatively low at less than 200 psi. Also, the creep rate is very high and stress reduction is rapid. The intersection of the stress reduction line with the strain axis is the maximum available strain due the thermal expansion mismatch between the board and the LCCC component. At $-25^{\circ} \mathrm{C}$, initial stresses are 
much higher, of the order of -2300 psi. In spite of high stresses, there is not much stress reduction during the two-hour dwell because creep rates are rather small at cold temperatures.

\subsubsection{Intermetellic formation}

\subsubsection{IMC (Intermetallic Compound) layer grown}

The composition of a solder forms a strong bond to the metal surfaces that it is intended to join. Bonding is promoted by chemical reactions between the solder and the substrate that form intermetallic compounds. The most common interfacial intermetallics are $\mathrm{Cu}-\mathrm{Sn}$ and $\mathrm{Ni}-\mathrm{Sn}$ that are formed by reaction between tin in the solder and copper or nickel in the substrate.

In order to obtain a good metallurgical bond at the solder joints and to apply enough solder strength it is essential to understand the interfacial reaction between the molten solder and a surface finish on a PCB or on a substrate. When molten SAC solder contacts with the Cu-pad surface, the intermetallic compounds (MIC) are formed between the solder and the pad that servers as a bounding material for the solder joints. The intermetallic compounds such as the large brittle $\mathrm{Ag}_{3} \mathrm{Sn}$ plates in SAC solders might seriously influence the mechanical performance of solder joints due to the actual service stressed condition of solder joints. The thickness of the IMC layer depends on the reflow time and peak temperature. Intermetallic compounds can grow and increase in thickness at the interface of the solder and the substrate during long term storage at ambient temperature and more rapidly at high temperature. Too thick IMC layer will possibly cause a poor solder joint to result in mechanical failure under operating environment such as thermal or power cycling. Since $\mathrm{Sn}$ is the most active metal to react with the surface finish layer during reflow, the amount of base metal dissolution and IMC growth are strong functions of the Sn content of a solder, reflow temperature and time. The researches have found that the formation of primary $\mathrm{Ag}_{3} \mathrm{Sn}$ precipitates could avoided by increasing the cooling rate of soldering process or lowering the Ag concentration in SAC alloy composite. Figure 2.20 shows SEM pictures of the IMC layer of interface between solder ball and copper pad in PCB side after solder joint assembly. 


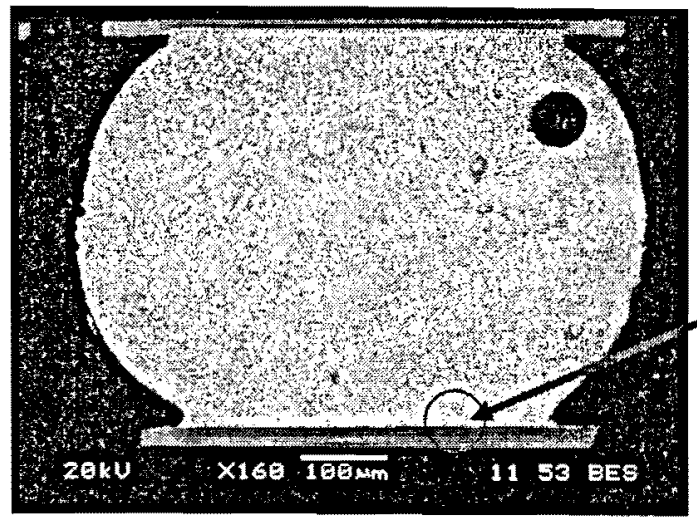

A Solder joint

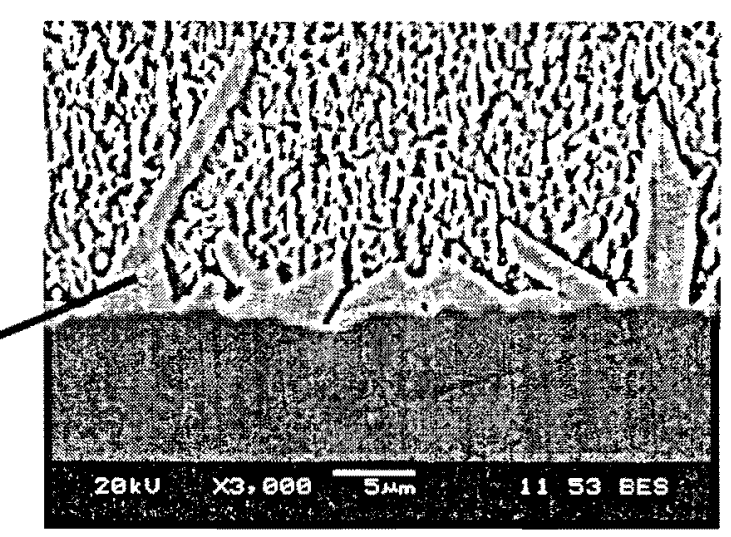

Interface-PCB side

Figure 2.20: Intermetallic Compound of the solder joint

\subsubsection{Metallization diffusion and solder flux burning}

Metallization diffusion occurs when the solder is held too long at or above the reflow temperature. This allows the metallization to completely diffuse into the molten solder, weakening the bound between the solder and the substrate or PCB. Flux burning occurs when the solder does not reach reflow temperature quickly enough. The flux burns off before the solder melts, leaving flux residue with in the solder. So to elaborately determine the reflow peak temperature, ramping up and cooling down rates is extremely important for the reliability of solder joints in the sense of solder creep resistance.

\subsubsection{Effect of alloy element contents}

During solder joints reflow process the interfacial reaction between molten solder and a surface of PCB or UBM (Under Bump Metallization) is essential to provide proper wetting of the solder to achieve a metallurgical bound at the joint as necessary joint strength. The amount of base metal dissolution and IMC growth are strong functions of the Sn content of a solder, reflow profile since the metal $\mathrm{Sn}$ is the most active metal to react with the surface finish layer during reflow process. It is interesting to note that a small addition of alloying elements such as $\mathrm{Cu}, \mathrm{Ni}$, $\mathrm{Fe}$, and Co can significantly change the characteristics of IMC growth. The BGA solder joints generally have the characteristics of a rapidly solidified microstructure since the solder volume is small and the solder joints are well connected to dissipate the latent heat released during the solidification process. The microstructure of solder joints is influenced by reflow parameters 
such as peak temperature, cooling rate, solder volume, package and substrate size and geometry structure etc. The microstructure of solder joints is affected by the nucleation and growth phenomena of constituent phases also. The research has found that the growth of large proeutectic phase can be reduced kinetically by a rapid cooling rate and microstructures of neareutectic ternary SAC alloys are significantly influenced by the cooling rate during a reflow process. However, the rapid cooling rate is mot always practical, especially with large thermal mass substrates. Some unwanted side effects such as thermal stress or strain in a substrate or package are induced under a rapid cooling rate for reflow process. The future research has focused on the alloy element contents.

\subsubsection{Silver contents}

The beneficial effects of a reduced $\mathrm{Ag}$ content in $\mathrm{Sn}-\mathrm{Ag}-\mathrm{Cu}$ alloy have been noticed and demonstrated well by many researches. Considering the high material cost and the potential impact to the environment during the extraction of its constituent elements, a low Ag content is replaced the high $\mathrm{Ag}$ content currently used for card assembly as $\mathrm{SAC}$ solders. Normally the $\mathrm{Ag}$ contents less than $3 \mathrm{wt} \%$ will minimizing the formation of large $\mathrm{Ag}_{3} \mathrm{Cu}$ plates. The other word, a large volume fraction of $\mathrm{Ag}_{3} \mathrm{Sn}$ plates will significantly change the mechanical properties and affect the long term reliability of the solder joints.

\subsubsection{Copper contents}

The content of copper presents a less sensitive than the influence of $\mathrm{Ag}$ content on $\mathrm{Ag}_{3} \mathrm{Cu}$ formation. However, the high $\mathrm{Cu}$ content can lead to the formation of large quantities of $\mathrm{Cu}_{6} \mathrm{Sn}$ rods that will increase the pasty range since a large pasty range may not be acceptable due to the fillet lifting to be dramatically raised. The content of $\mathrm{Cu}$ in the SAC alloy is less than 0.7-0.9 wt. \%.

\subsubsection{Add other alloys}

It is report that a small $\mathrm{Zn}$ to be added in SAC alloys will cause a drastic reduction in the formation of large $\mathrm{Ag}_{3} \mathrm{Sn}$ plate duo to the low cooling rate. It has a practical advantage over the standard SAC alloy because $\mathrm{Zn}$-modified SAC alloy is not much affected by the cooling rate 
during reflow. In addition, the $\mathrm{Zn}$-modified $\mathrm{SAC}$ alloys have different interfacial reaction characteristics with $\mathrm{Cu}$ and $\mathrm{Ni}$ metallization. The normal contents of $\mathrm{Zn}$ is $0.7 \mathrm{wt} . \%$. 


\section{Chapter 3 Theoretical background of flexural test methods}

\subsection{Flexural test methods review}

Flexural test methods are used to monitor behavior of materials and to determine their flexural properties for materials such as metals, unreinforced and reinforced plastics and rubbery materials, etc. There are many standard test methods, including ASTM (American Society for Testing and Materials) D-797 for elastomers, ASTM A-438 for cast iron, ASTM D-86 for glass, ASTM C-674 for fired whiteware, ASTM A-360 for steel products, ASTM E-190 for welds, ASTM D-1037 for fiberboard. These flexural test methods are generally applicable to both rigid and semi rigid materials. Standard specimens or molded products can be tested by these standards to determine flexural and mechanical properties of materials. These flexural tests are performed to determine the materials' bend or fracture strength, modulus of rupture, yield strength, modulus of elasticity in bending, flexural stress, flexural strain, and flexural stress-strain materials response, respectively.

\subsubsection{Three- or four-point bending tests}

Flexural test methods utilize either a three-point or a four-point loading system applied to a supported PCBA. Test boards are loaded at mid-span (three-point loading) or at two positions equidistant from the two supports (four-point loading). 3-point loading is a favorable configuration, but centered loading should be spread out to avoid local stress concentration. Test parameters to configure a test system include load, speed of loading, test method type, support span, sample geometry, and maximum deflection of the test sample, etc. Test sample thicknesses and types affect equipment requirements. In three-point bending, the simply supported board is supported on two outer points, and deformed by driving the third central point downwards. The maximum bending moment/stress is located at the mid-section of the sample. In four-point bending, the simply supported board is supported on two outer points, and deformed by driving two concentrated and equal loads. The maximum bending moment/stresses occurs in the center load-span. The simple drawing of three and four point bending is showed in Figure 3.1. 

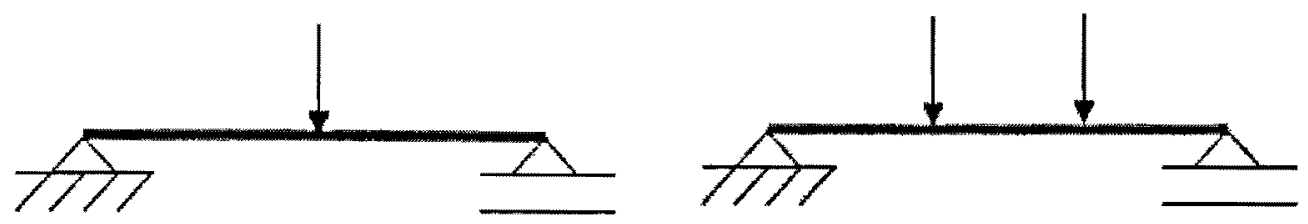

Figure 3.1: Three and four point bending

\subsubsection{Spherical bending tests}

A spherical bending test is one of flexural strength evaluation tests. A spherical bend mode provides the greatest load to deflection ratio on solder joints which is closer to what PCBs experience in manufacturing and assembly than 3 and 4 point bend modes. Spherical test method has better ability to emulate the bend modes that PCBA undergo during system assembly. For given level of strain on the PCBA, solder joints are more likely to fail using spherical bending than three or four point bending methods [10]. Figure 3.2 shows a layout of strain gauges in a spherical bending test.
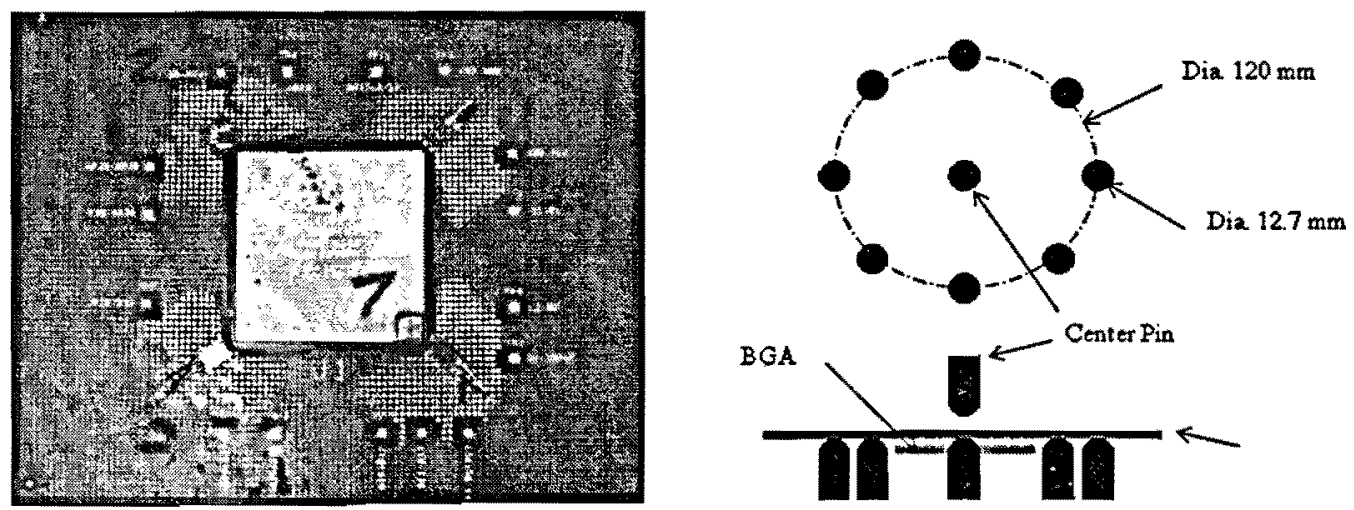

Figure 3.2: Layout of a spherical bending test

\subsection{Literature review for BGA solder joint flexural reliability}

Studies have been reported on performing experimental bending tests on BGA packages. Different tests focus on diversified aspects that may lead to failure of solder joints during second level manufacture and customer service environment. The studied researched many influencing 
factors such as surface finish processing methods, strain rates, thickness of board, die size, package configuration, load and displacement control, and optimized pad designs, etc. Some FEA (Finite Element Analysis) simulation processes were reported as well.

\subsubsection{Four-point bending tests}

A. B. Sam Yoon, Vadali Mahadew [1] discussed Flip-chip BGA as a presently the preferred technology for high-density organic flip chip package using ENIG finish. The test results presented that the 4-point bend tests conducted at strain rate above $5000 \mathrm{microstrain} / \mathrm{s}$ is in fact capable of creating brittle fracture failures as seen in high strain rate assembly and handling operations involving uncontrolled and excessive strains. In this study, the monotonic bending was conducted to relatively large peak displacements $(20-25 \mathrm{~mm})$. The tests were done in different components with different strain rate. The results have revealed the strain to failure and failure modes are strain rate dependent. At low strain rates (around $500 \mathrm{microstrain} / \mathrm{sec}$ ) the strain magnitude at failure is relatively high and the failure mode is PCB pad lifting; at high strain rates $(5000-13000$ microstrain/sec) the strain to failure is relatively low and the failure mode is a combination of brittle fracture at the component substrate ENIG interface and PCB pad lifting.

R. Darveaux, andA. Syed [2] have reported in "Reliability of Area Array Solder Joints In Bending" for investigating testing and analytical methods of the reliability of area array solder joints under bending. The article indicated PCB bending failure can occur in at least three different regimes. The first one is creep rupture caused by localized bending of a board that possibly due to a screw to secure a board to housing. The second board bending failure mode occurs due to key press action. The third one occurs when portable products are dropped. The strains were measured by group strain gauges in both 3-point and 4-point bend configuration. Four different failure modes were observed in the bend testing. The report discussed also some effect factors such as thickness of board, die size, package configuration, load and displacement control, and optimized pad designs.

A. Bansal, Y. Li, and V. Mahadev [3] developed a detailed finite element model to simulate the different 4 point bend test cases with different flip chip component sizes. The relationship 
between PCB strains and solder joints strain was established. The test results showed the PCB strain and peak strain at the solder joints will be almost identical to the case where a single component is mounted at the center of the board [3]. PCB strains at the onset of brittle solder joint failure should be the same for single or four component test configurations. In this study FEA and experimental work have been performed to predict the PCB strains with single and multiple components.

T. Koschmieder [4] has reported the strain curve abrupt change during the electronic resistance curve no change that indicated the onset failure. In the research both experience and computer modeling were used to determine rules of thumb about package placement on the board [4]. The researcher found the break strain is a function of support span width. The test results indicated that for FC-CBGA parts, the failure mode is catastrophic cracking of the ceramic substrate. The cracks preferentially occur outside the die attach area and high $\mathrm{Pb}$ solder joints failed at higher strain than $\mathrm{Pb}$-free solder joints [4]. The failure mode of FC-PBGA parts changed depending on the surface finish of the package side. Lead free solder joints in general have a higher strain at failure than eutectic $\mathrm{PbSn}$ one.

\subsubsection{Critical load detection}

The standard of IPC/JEDEC-9702 intends to characterize the fracture strength of a board level interconnects using the four point bending method to simulate the condition of flexural loading during manufacturing, packaging, and servicing. For flexural loading the phenomenon of strain rate change has been noticed and marked as onset or the critical point with strain hikes and drops or spike.

The onset point of strain rate indicates that the damage has occurred and will extend and development along the weak track resulting in failure of solder joints. While the characteristic points are identifiable from the strain curves, to determine the so-called critical or allowable loads for a specific type of packages needs to first define an acceptable level of interconnect damage. 


\subsubsection{Strain gauge placed on the substrate}

In order to assess the critical load, various testing methods have been developed. Geprge Hsieh and Alan Mcallister (Intel Corporation, 2005), Frank W Joyce (Intel Test Development Engineering, 2006), J. Bragg (Celestica Inc., 2007) respectively conducted onset load detection and strain relaxation phenomenon. Some interesting researches are done by Geprge Hsieh (Intel Corporation) for the flexure testing methodology. It is found that a strain gauge placed on the substrate corner can be a very useful experimental tool in flip chip ball grid array (FCBGA) component testing for the purpose of identifying the onset of cracking under lands on the PCB side [11]. The researchers of Intel Corporation have begun providing strain limits for its BGA components to help manufacturers identify processes which cause high strain. They used two strain gauge rosettes that are attached to the substrate corner and PCB in the same position but on opposite sides of the PCBA. The substrate strain corner monitoring has great value in flexure testing since it can detect the onset of pad cracking at the beginning of the interconnect damage progression. This is because the strain measurement on the substrate is more sensitive in responding to the interconnect damage induced stress transfer than the PCB strain. The electrical daisy chain only defines the failure at the final moment of the damage progression.

\subsubsection{Strain relaxation}

Another research by Celestica Inc. captured the strain relaxation phenomenon during flexural loading. The tests are done by attaching an extra strain gauge on the component. The test results indicate that interconnect fractures can cause component level strain relaxation and the strain response on $\mathrm{BGA}$ is an indication of the onset damage before electronic failure.

In the above modified test methods, a corner of the thermal lid above the substrate had to be cut off in order to place a strain gauge in the exposed substrate corner. This not only modified the original package structure but could also damage the substrate surface, leading to a redistributed stress/strain as compared with that in the original structure. The new method utilizing the optical Bragg grating strain sensor has been developed at Ryerson University to avoid these drawbacks in dealing with the mechanical testing of lidded BGA assembly. 


\section{Chapter 4 FBG grating strain sensor}

\subsection{Introduction}

Fiber Bragg Grating (FBG) is a type of distributed Bragg reflector that is constructed in a short segment of silica fiber. FBG can reflect predetermined narrow or broad range wavelengths of light and transmit the rest. FBG can be used as an inline optical filter to block certain wavelengths or as a wavelength specific reflector. FBGs are widely used in telecommunication. As sensors, FBG sense numerous parameters such as strain, temperature, and pressure. The fiber optics has undergone tremendous growth and advancement over the last 25 years. Ever since, optical fiber technology has been the subject of considerable research and development to the point to transmit vast amounts of data and information from one point to another. The reasons of optical fiber to become an attractive sensor element are their low loss, high bandwidth, immunity to electromagnetic interference, small size, light weight, safety, relatively low cost, low maintenance, etc. The wide applications are also due to their multiplex ability and durability for use at relatively high temperature and environmentally unfavourable conditions. Fiber Bragg grating sensors have attracted considerable attention for measurement application such as in mechanics, aerospace, chemistry and electronics. FBG technology is in particular used to monitor composite material curing and fatigue life evaluation, and to provide good measurement in large scale civil structures such as highway, buildings, bridges, as well as remote sensing for oil wells, power systems and pipelines.

\subsection{Literature review of FBG sensor application for strain measurement}

The FBG sensor is small, robust and durable suitable for operation in harsh environments. The FBG sensor has been used for a wide variety of sensing applications including monitoring of civil engineering structures such as highways, buildings, bridges, dams; remote sensing for example oil wells and gas, power cables, pipelines, space stations; smart structures such as airplane wings, ship hulls, composites structure, sports equipment; as well as traditional strain, pressure and temperature sensing. The main advantage of FBGs for sensing is that these devices perform a direct transformation of the sensed parameter to optical wavelength, independent of light levels, connector or fiber losses, or other FBGs at different wavelengths. 
A. Asundi, F. Spie, B. Zhao [5] reported a new optical strain sensor developed to rival the traditional electrical strain gauge in measuring in-plane strain in 1999. A diffraction grating bonded to the surface of the specimen follows the deformation of the underlying specimen. The report discussed the advantages of optical grating diffraction techniques such as in providing strain information directly and avoiding difficulty in fringe pattern interpretation that is associated with most optical techniques. The study mentioned the possible applications of sensor in precision measurements in the areas of microelectronics, advanced materials mechanics, micromechanics and nanomechanics.

S. Takeda, Y. Okabe, N. Takeda [6] has reported an application of FBG in the detection of the delamination of fiber laminates. The experimental tests were done by embedded small diameter FBG sensor in CFRP cross-ply laminates. The reflection spectra from the FBG sensor were measured at various delamination lengths through four-point bending test. As the delamination length is increased, the form of the spectrum changes sensitively. The calculated result reproduced the change in the measured spectrum very well. The results indicated the potential application for other laminate configuration.

K. Lau, L. Yuan, L. Zhou, J. Wu, C. Woo [7] has presented a theoretical model to evaluate the differential strains between the bare fiber and host material with different adhesive thickness and modulus of the protective coating of the embedded FBG sensor. The numerical analysis was done by using finite element method (FEM) and the experimental work was conducted in both glass fiber composites and FRP strengthened concrete beams with embedded FBG sensors. Investigation showed that the FBG sensor can be confidently used with sufficient length. In this case study it is found from the theoretical analysis that short bonding lengths influence the final strain measurement at the fiber optical grating region. The experimental results revealed the thick adhesive layer, low modulus of coating materials and short embedding length of sensor are not encouraged for embedded FBG strain sensing system because of the effect of thickness of adhesive layers.

J. S. Leng and A. Asundi [8] have studied the non-destructive evaluation (NDE) technologies of engineering structures with extrinsic Fabry-perot interferometric (EFPI) and fiber Bragg grating 
(FBG) sensors. The test results indicated that EFPI and FBG sensors can be used to inspect the structural damages such as delamination of composite laminates and cracks of aluminum plates. The flexural strain of damaged structures can be observed clearly since the strains are much higher than undamaged ones.

B.Yang, X. Tao, and J. Yu [9] have investigated some methods based on Fiber Bragg Grating (FBG) sensor for simultaneous measurement of strain and temperature. They are photogenerated in-fiber gratings, hybrid FBG/LPG (long-period grating), two FBGs, a single changed FBG and superstructure fiber grating. This report discussed the principle and accuracy of each type of measurement method as well as some future works. The analysis results showed SFBG have a potential of further development of multi-axis measurement with the possibility of simultaneous temperature measurement.

M. J. Bartow, S. G. Calvert, and P. V. Bayly [15] have reported their work of a new method for measuring tool motion with fiber Bragg grating strain sensors. The paper addressed several problematic aspects of vibration measurement in metal cutting processes and validated the use of fiber optic Bragg grating strain sensors for the measurement of micro machine tool motion.

P. G. LoPresti, D. Jali, C. Shrock [16] in his paper mentions that they demonstrated that differential measurement of strain using fiber Bragg grating provides significantly greater resolution than single-point measurement. It is demonstrated also that differential measurement can be potentially effective in detecting oil-water and oil-air boundaries for oil production and processing.

H. Hnyano and A. Mita [20] presented their test results in a FBG based strain sensor equipped with a mechanical temperature compensation system. The proposed sensor avoids broadening problems of the reflected optical spectrum due to fluctuation of strain distribution of the material under the FBG element. The report proposed a new FBG strain sensor mechanism that the proposed sensor can prevent unstable output caused by the direct bounding of the sensor element to a target object. 


\subsection{Theoretical background and operating principles}

A fiber Bragg grating is a wavelength dependent filter or reflector formed by introducing a periodic refractive index structure within the core of an optical fiber. Whenever a broad spedrum light bean impinges on the grating will have a portion of its energy transmitted through and another reflected off as depicted. The reflected light signal will be very narrow and will be centered at the Bragg wavelength which corresponds to twice the periodic unit spacing $\Lambda$. Any change in the modal index or grating pitch of the fiber caused by strain or temperature will result in Bragg wavelength shift. The fundamental principle of the theory of FBG is Fresnel reflection. Light may reflect and refract at the interface while traveling between media of different refractive indices. The grating will typically have a sinusoidal refractive index variation over a defined length. The reflected wavelength $\left(\lambda_{b}\right)$ called the Bragg wavelength, is defined by the relationship

$$
\lambda_{b}=2 n \Lambda
$$

Where

$n$ is the effective refractive index of the grating in the fiber core

$\Lambda$ is the grating period.

Any perturbation that can change effective refractive index $\mathrm{n}$ and periodicity $\Lambda$ will result in a shift in Bragg wavelength.

Based on a periodic refractive index change created in the fiber, the FBG selectively reflects one wavelength while transmitting others. The basic strain-sensing element is an optical Bragg grating that is fabricated by writing an index grating directly into so called single mode fibers that consist of a very small inner core of 4 to $9 \mu \mathrm{m}$ diameter and an outer part (cladding) of pure glass $\left(\mathrm{SiO}_{2}\right)$ with $125 \mu \mathrm{m}$ diameter. The core has a higher refraction index caused by high Germanium doping. The glass fiber is coated with acrylate, polyimide or organic modulated ceramic materials to protect it against water and hydrogen which may cause crack growing and reduce the mechanical stability.

The wavelength at which the reflectivity peaks is called the Bragg wavelength. The Bragg wavelength is a property of the grating that is determined by the grating pitch. The FBG wavelength filter consists of a series of perturbations in the index of refraction along the length 
of the optical fiber. This index grating reflects a narrow spectrum that is directly proportional to the period of the index modulation and the effective index of refraction. The spacing of the periodic variation of refractive index which is a function of strain will be elastically deformed with respect to the external strain on the fiber. If the sensor is subject to a stretch or compression to result in a grating pitch change, the Bragg wavelength will have a shift that is linearly proportional to the sensor's axial strain [7]. The shift can be detected with an optical spectrum analyzer, thus enabling a precise strain measurement if the original grating pitch and the wavelength of the light source are known. Figure 4.1 shows the basic transmission and reflection spectra of a fiber Bragg grating.
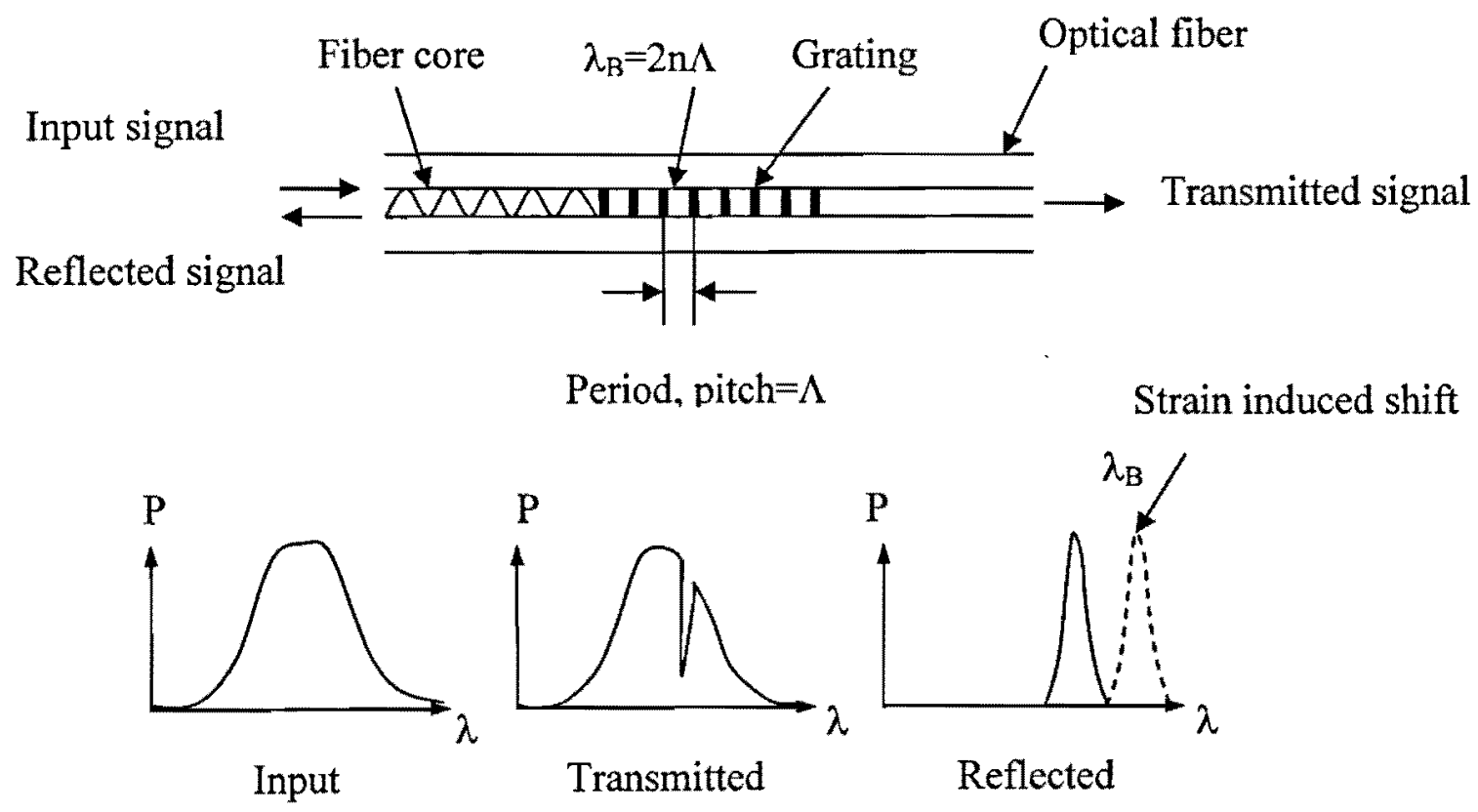

Figure4.1: Transmission and reflection spectra of a fiber Bragg grating

\subsection{Strain measurement by FBG}

The FBG technique offers strain measurement at a wide dynamic range and a high sensitivity (about 2 micro-strains). A typical FBG sensor consists of a short section (typically a few mm) of single mode fiber with a periodic modulation (typical 100s of $\mathrm{nm}$ ) of core refractive index [21]. The index modulation causes light in the forward propagating core mode to be coupled into the backward core mode. This causes the FBG to act as a highly wavelength selective rejection filter. When FBG sensors are bonding directly on the surface of the samples Strains caused by a tensile 
force extend the grating interval of the FBG element and the strains due to a compressive force reduce the interval of grating. Uniform strains caused by a tensile or a compressive force have linear relation to the wavelength shift until breakage of the optical fiber. Thus, the strains can be calculated from the wavelength shift.

The sensing mechanism of strain and temperature measurement is the change in $\mathrm{n}$, or the effective refractive index of the grating, in the fiber core and $\Lambda$, or the grating period, caused by the measured samples. The changes are applied directly or indirectly to the FBG sensors or the sensor modules and finally reflected by a change in $\lambda_{b}$ - the Bragg wavelength. For strain measurement, the shifts of the grating Bragg wavelength due to physically increasing or decreasing the grating spacing that changes in the refractive index as per the strain optic effect. For axial loads, the wavelength change is typically $1.2 \mathrm{pm}$ per microstrain or $12 \mathrm{~nm}$ for $1 \%$ strain. The wavelength shift can be also caused by the change of temperature since the FBG strain sensor is temperature dependent. Temperature change affects the Bragg response through thermal expansion and contraction of the grating periodicity due to the thermo-optical effect. For temperature measurement the temperature sensitivity of a grating is dependent primarily on the temperature sensitivitye of the refractive index of the fiber material and, to a lesser extent, on the thermal expansion of the material which changes the grating period spacing. Typically, the fractional wavelength change in the peak Bragg wavelength is of the order of $10 \mathrm{pm} /{ }^{\circ} \mathrm{C}$. 


\section{Chapter 5 Four-point bend test with BGA strain measured by FBG}

\subsection{Four-point bending tests}

Due to the high degree of integration, high component density and the resulting high production cost of the surface mount technology, the modern advanced SMC assembly has imposed more stringent reliability requirements on packaging design. IPC/JEDEC-9702 established a test method for documenting the solder joint reliability under flexure loading. IPC/JEDEC-9702 standard "Monotonic Bend Characterization of Board-Level Interconnects" provides a uniform set of guidelines on the test procedure and measure method of fracture resistance to board level assembly under flexural loading that may occur during conventional board assembly, shipping, handling, and field operation. This standard is used to evaluate the solder joint flexural strength under relatively high strain rate load with different component and various structures. The methodology mainly depends on monitoring the electrical resistance increase of daisy chain of assembly board undergoes flexural deformation. An abrupt and significant resistance change indicates that rapid fracture damage happened in the electronic chain and solder joints. Figure 5.1 shows a sketch of the universal tester.

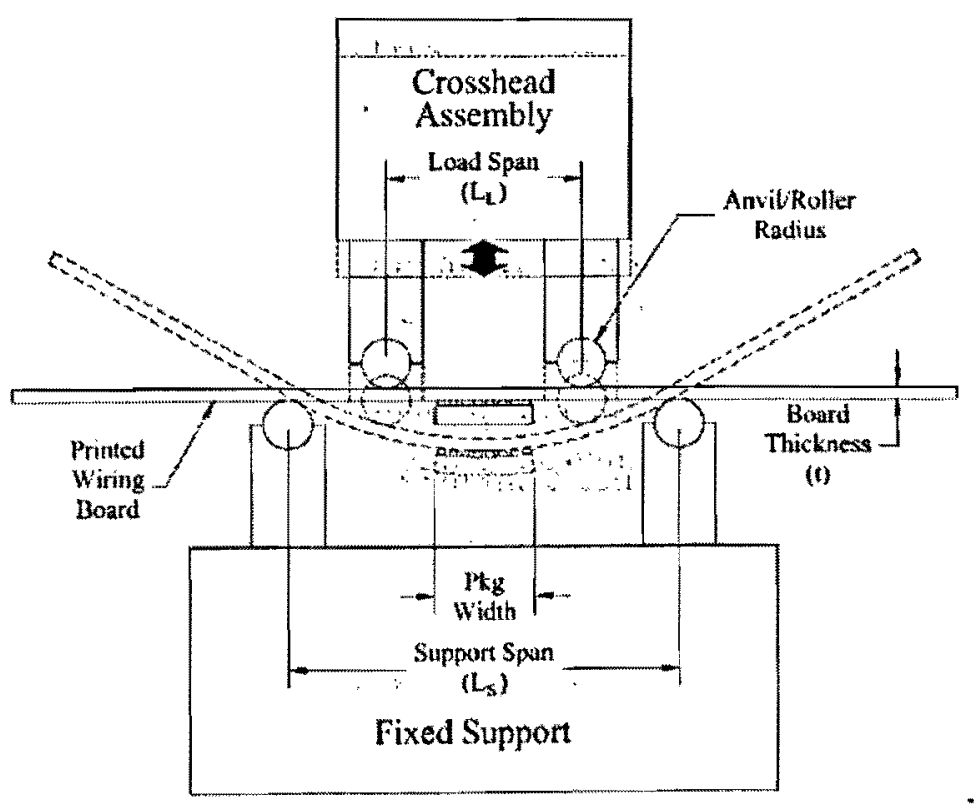

Figure 5.1: A sketch of the universal tester of 4 point bending test [23] 


\subsubsection{Test method specification}

The standard of IPC/JEDEC-9702 applied two simplified analytical relationship equations to establish the universal tester control settings for crosshead travel distance and crosshead speed based on global PCB strain and strain rate input variables, respectively. These equations are derived from classic beam theory and ignore end effects due to the packages and the Poisson's effect of a PCB in bending. The crosshead travel distance and speed are calculated by following equations:

$$
\begin{gathered}
\delta=\frac{\varepsilon\left(L_{S}-L_{L}\right)\left(L_{S}+2 L_{L}\right)}{6 t} \\
\dot{\delta}=\frac{\dot{\varepsilon}\left(L_{S}-L_{L}\right)\left(L_{S}+2 L_{L}\right)}{6 t}
\end{gathered}
$$

Where

$\delta=$ crosshead travel distance

$\dot{\delta}=$ crosshead speed

$\varepsilon=$ global PWB strain

$\mathrm{L}_{\mathrm{S}}=$ support $\operatorname{span}$

$\mathrm{L}_{\mathrm{L}}=$ load span (centered within support span)

$\mathrm{t}=$ PWB thickness

$\dot{\varepsilon}=$ global PWB strain rate

\subsubsection{Strain rate}

From the above equations, global PCB strain and global PCB strain rate are input due to different package configuration as well universal tester capability. The global PCB strain rate $5000 \mu \varepsilon / \mathrm{s}$ is recommended by IPC/JEDEC-9702 to determine the other test parameters such as the crosshead speed of test machine as well as load and support spans. In fact the data to be feedback from experimental tests indicated that higher strain rate is necessary because it was unable to induce solder joint failures [23]. In our initial trials the strain rate has reached to over $10000 \mu \varepsilon / \mathrm{s}$. The 
difference between load and support span may determine the strain rate when the universal tester machine is chosen. The small distance of support span and load span means that a high strain rate can be reached if there are no changes of other parameters at the same measured system.

\subsubsection{Maximum crosshead travel distance and speed}

The travel distance is set depending on the structure of component and PCBA and will vary upon types of test vehicles. The maximum crosshead travel distance varies with testing vehicles and is obtained by the electrical failure of all daisy-chain nets. The crosshead speed is set upon the test machine configuration and load capacity.

\subsubsection{Minimum crosshead speed}

The crosshead speed of a universal tester is approximately linearly proportional to the test board assembly strain and strain rate respectively [23]. The relationship between these variables can be determined empirically depending on the test machine capability and testing package configuration. Using nominal global PCB strain rate $5000 \mu \varepsilon / \mathrm{s}$ the value of the minimum crosshead speed is calculated.

\subsubsection{The constant bending moment}

4-point bend testing is a pure bend and destructive test. The 4-point bend testing method imposes a constant bending moment near the solder joints. Consequently, the method lends itself to unambiguous calculation of a standardized bending moment per unit width of PCB in the constant bending moment region.

$$
M^{\prime}=\frac{F \cdot a}{2 \cdot b_{p}}
$$

where

$\mathrm{a}=$ distance from load span to load support

$b_{p}=$ width of PCB

$\mathrm{F}=$ the force to be loaded 
From fundamental mechanics of materials, the measured bending moment per unit width of PCB can be converted to the equivalent surface strain that will determine damage of solder joints.

$$
\varepsilon=6 M^{\prime} \frac{\left(1-v_{p}\right)}{E_{p} \cdot h_{p}^{2}}
$$

where

$E_{p} /\left(1-v_{p}\right)=$ effective flexural modulus of FR4 based PCB

$h_{p}=$ thickness of PCB

$\varepsilon=$ the equivalent surface strain

The above equation provides a standard metric to compare solder joint strength against loading under assembly or installation conditions. Figure 5.2 shows a bended PCB under the force load for 4-point bend testing and bend moment diagram.

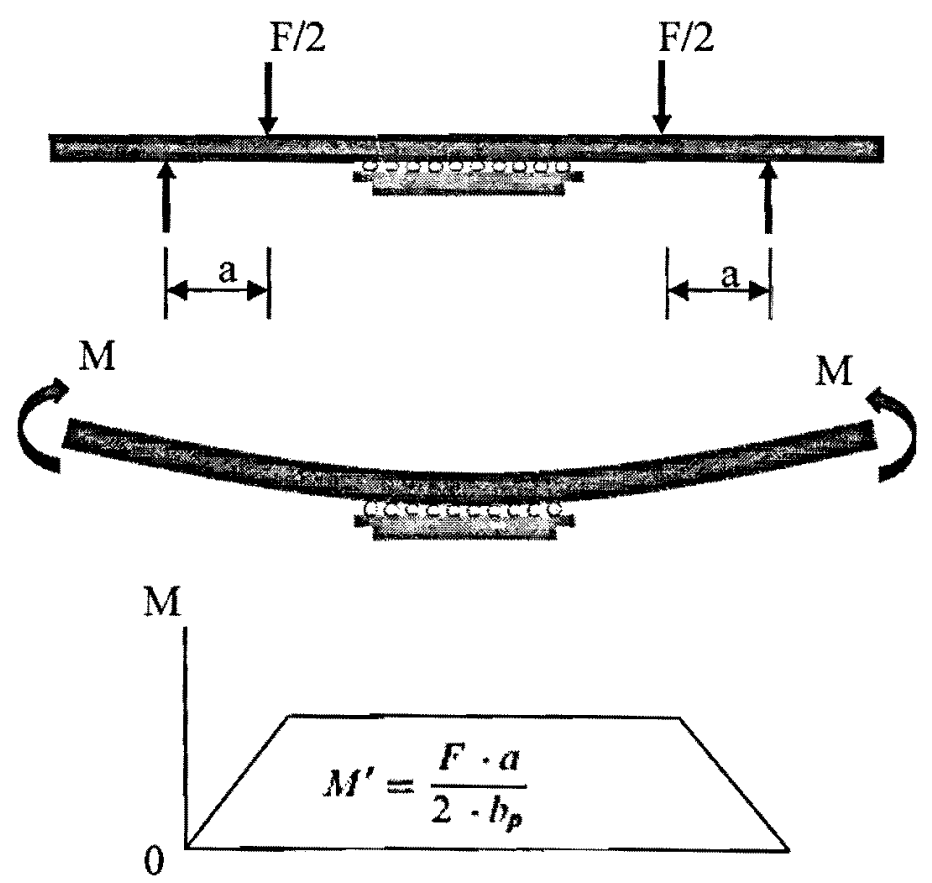

Figure 5.2: Bend moment diagram 


\subsubsection{Failure criteria}

According to IPC/JEDEC-9702 test standard, there are three strain gauges on a single component PCBA. Two gauges are mounted on opposite side of the PCB in a position between the component edge and the load frame anvil/roller, and the third one is applied to the PCB in the center of the component shadow on opposite side of the component. Three strain gauges recorded the strain variations during the bend testing. The electric voltage across the daisy chain is recorded and monitored for the damages of solder joints as the assembly package response to the bending. IPC/JEDEC 9702 standard recommends an electrical resistance increase of $20 \%$ of the daisy-chain net as the interconnect failure criterion.

\subsection{FBG sensor preparation}

\subsubsection{Fabrication of FBG Sensors}

The optical fibers for making the gratings were hydrogen loaded for two weeks at $1500 \mathrm{psi}$ pressure at room temperature prior to the fabricating process of the FBG sensors. The hydrogen loaded fibers can be kept in a freezer at $-20^{\circ} \mathrm{C}$ to slow-down the diffusion of the hydrogen molecules out of fiber. The gratings were fabricated using the phase mask method. All the gratings were written on hydrogen-loaded SMF-28 fiber. The collimated $\mathrm{KrF}$ excimer laser (Lumonics, Model PM 844) was used to emit a beam of $248 \mathrm{~nm}$ with energy from 150 to $350 \mathrm{~mJ}$ at a repetition rate of 30 pulses per second. The amplitude mask with a sine function is used to apodize the refractive index change in order to taper the strength of the grating at both ends. This apodization mask with a sine function and a complementary sine function declines gradually the refractive index and eliminate the unwanted side lobes in FBG's reflection spectrum. The naked fibers were then coated with polyamide after the gratings were written due to the strong adhesion of polyamide to the fiber. The FBG gratings were annealed at $150^{\circ} \mathrm{C}$ for 15 hours to ensure their long term stability. The FBGs used in the current experiments have a wavelength between 1530 and $1550 \mathrm{~nm}$ with approximately $3 \mathrm{~dB}$ bandwidth of $\sim 0.3 \mathrm{~nm}$ and a reflectivity of $80 \%-90 \%$.

The location of grating on the fiber was determined by a red mark as the basic reference point that was aligned with the edge of the phase mask during fabrication process. The position of laser beam was determined by irradiating a photosensitive paper that is aligned again the phase 
mask. The distance from the red mark to the center of the grating is $15 \pm 0.5 \mathrm{~mm}$. Once the preparation work was completed, the section of optical fiber was stripped off using a paint remover and was horizontally positioned behind the phase mask. The distance between the phase mask and the stripped fiber is important since it will determine requirement time to write FBGs. When the distance between the fiber and phase mask is greater than the spatial coherence of the UV light the absence of the interference pattern will make the grating not inscribable. During the writing process, 36 the spectrum of the FBG was monitored with the optical spectrum analyzer (Ando, model AQ-6310 B). In all experiments, the FBG sensors were characterized as follows: polyimide coated with an apodized index profile of $5 \mathrm{~mm}$ in length, $\sim 3 \mathrm{~dB}$ bandwidths of $\sim 0.320$ $\mathrm{nm}$, peak reflectivity greater than $80 \%$, and isolation of $\sim 27 \mathrm{~dB}$.

\subsubsection{Comparison tests}

\subsubsection{Strain gauge}

Strain gauge is a device used to measure the strain of an object. The most common type of strain gauge consists of an insulating flexible backing which supports a metallic foil pattern. The gauge is attached to the object by a suitable adhesive during strain measurement process. As the object is deformed the foil is deformed too and causes its electrical resistance to change. A Wheatstone bridge is designed to measure the resistance change and is related to the strain by the quantity known as the gauge factor.

The metallic strain gauge consists of a very fine wire and metallic foil arranged in a grid pattern. The grid pattern maximizes the amount of metallic wire or foil subject to strain in the parallel direction. The cross sectional area of the grid is minimized to reduce the effect of shear strain and poison strain. The grid is bonded to a thin backing called the carrier which is attached directly to the test specimen. The strain experienced by the test specimen is transferred directly to the strain gauge that responds with a linear change in electrical resistance. Strain gauges are available commercially with nominal resistance values from 30 to $3000 \Omega$, with 120.235 , and $1000 \Omega$ being the most common values. A quarter bridge strain gauge circuits are structured in figure 5.3. 


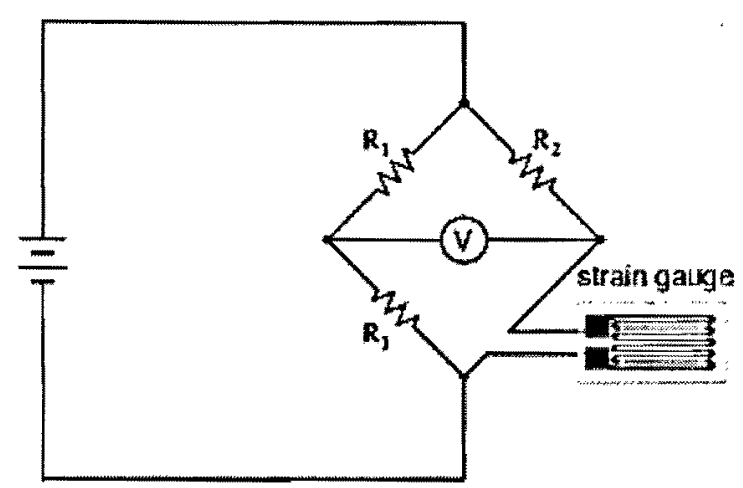

Figure 5.3: A quarter bridge strain gauge circuits

\subsubsection{Gauge factor}

A fundamental parameter of the strain gage is its sensitivity to strain, expressed quantitatively as the gage factor (GF). Gage factor is defined as the ratio of fractional change in electrical resistance to the fractional change in length (strain):

$$
G F=\frac{\Delta R / B}{\Delta L / L}=\frac{\Delta R / R}{\varepsilon}
$$

Where

$\varepsilon=\operatorname{strain}$

$\triangle \mathrm{RB}=$ change in strain gauge resistance

$\mathrm{RB}=$ unstrained resistance of strain gauge

$\alpha=$ temperature coefficient

The gage factor for metallic strain gages is typically around 2. According to IPC/JEDEC 9702 standard the uniaxial strain gauge is chosen to detect strain along a single axis. As a comparison and calibration tests for 4 point bending tests CEA-06-125UN-350 strain gauge with quarter bridge $350 \Omega \pm 0.3 \%$ resistance and gauge factor $2.1 \pm 0.5 \%$ is chosen in these tests. The strain limits are approximately $5 \%$ for gauge lengths in $3.2 \mathrm{~mm}$.

\subsubsection{Comparison of strain gauge and FBG}

Based on different principles, a FBG sensor bonded on a test sample functions very similar to an electric strain gauge. They both output a signal that is proportional to the sample's normal strain 
in the axial direction of the sensors, and both require evaluating a coefficient called the gauge factor, to be determined through a calibration test. A comparative verification experiment was conducted for this study, in which an FBG sensor and an electric strain gauge were attached to the opposite sides of a cantilever beam. As plotted in Figure 5.4, the obtained strains from the two types of sensors in responding to the cantilever's bending match very well, with an average difference of less than $0.5 \%$. The FBG is the type of hydrogen loaded SMF-28 and the grating was written on the fiber with a collimated $\mathrm{KrF}$ excimer laser (Lumonics, model PM 844) of 248 $\mathrm{nm}$ and $264 \mathrm{~mJ}$ per pulse at $30 \mathrm{~Hz}$ pulse rate.

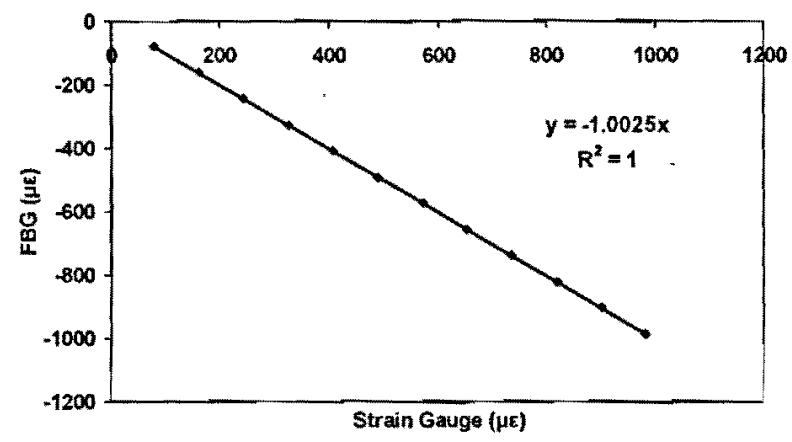

Figure 5.4: Correlation of FBG and strain gauge in a beam bending test

\subsubsection{Quality tests for FBG grating}

The measurement of the grating after the annealing is an important process as the values are known to change as a result of the polyimide coating and the annealing process. The wavelength of the FBGs at rest was recorded using OSA (Optical Spectrum Analyzer). As the FBG was surface mounted to the substrate, its initial wavelength was re-measured. This was performed because the cure of the epoxy used to attach the FBG onto the substrate will cause strain within the FBG which shifts the central wavelength of the FBG downwards. During the four-point bending tests, the initial wavelengths of the FBGs sensors were recorded from Si425. While the test is being performed, the changes in wavelengths were monitored with Si425. 


\subsection{Test vehicles description}

\subsubsection{Flip chip ball grid array package}

A single $55 \times 55 \mathrm{~mm}$ component with 2809 y/O flip chip ball grid array (FC-BGA) package was designed in accordance with the requirements of JEDEC/IPC9702. The component located on the center of the PCB. The IC chip was bounding with tin/lead $\mathrm{C} 4$ bumps at first level fabrication, and lead free solder balls made from SAC305 with SMD pads at second level manufactory. The diameter of the PCB SMD (solder mask defined) pad is $19.5 \mathrm{mil}(0.5 \mathrm{~mm})$. All internal layers are $1 / 2$ oz copper and outer layers are $1 / 2 \mathrm{oz}$. copper plated up to approximately $1 \mathrm{oz}$. copper. The modules were baked for 24 hours at $125^{\circ} \mathrm{C}$ before to be assembly in a reflow oven. After the assembly process, the boards were inspected by the transmission $x$-ray to detect any failure in the boards prior to running the bend test.

The test matrix comprised four variation module types (variations in the lid thickness). The different variations for component had different heat spreader designed and thicknesses. The PCBs constructed of 8 copper layers at 0.93 " $(2.36 \mathrm{~mm})$ thickness and 16 copper layers at 1.25 " $(3.175 \mathrm{~mm})$ thickness. The PCB was made of Polyclad 370HR laminates with organic solder preservative (OSP) surface finish. The PCBs' in-plane dimensions are $73 / 8$ " x $73 / 8$ " (187.3 x $187.3 \mathrm{~mm}$ ). The test vehicles include A, B, C, D four types with different lid and PCB thickness. The tests done quantity are 29 . The test vehicle specification is listed in table 5.1.

Table 5.1 Test vehicle snecification

\begin{tabular}{|c|c|c|c|c|c|}
\hline $\begin{array}{c}\text { Type of } \\
\text { samples }\end{array}$ & $\begin{array}{c}\text { Lid thickness } \\
(\mathrm{mm})\end{array}$ & $\begin{array}{c}\text { PCB thickness } \\
(\mathrm{mm})\end{array}$ & $\begin{array}{c}\text { Die size } \\
(\mathrm{mm})\end{array}$ & Capping & Quantity \\
\hline A & 2.0 & 2.36 & 18.8 & free & 5 \\
\hline B & 1.0 & 3.175 & 18.8 & free & 7 \\
\hline C & 0.5 & 2.36 & 18.8 & free & 9 \\
\hline D & 1.0 & 2.36 & 18.8 & force & 8 \\
\hline
\end{tabular}




\subsubsection{Strain gauge layout}

There are three strain gauges on a single component PCB board from the standard of IPC/JEDEC-9702. Two gauges are mounted on opposite side of PCB as component and one is mounted on same side of PCB as component center as well as between package edge and anvil/roller centerline. For the test configuration defined in IPC/JEDEC standard, finite element modeling indicates that the PCB principal strain angle is essentially coincident with the longitudinal board axis at all board locations. For monitoring bending testing uniaxial strain gauges are acceptable. A nominal strain gauge element size of $1.5 \times 1.5 \mathrm{~mm}(0.59 \times 0.59$ inch $)$ is recommended. The sensing direction of the uniaxial strain gauges must be aligned with the longitudinal board axis. In the formal testing, only Gauge $\mathrm{A}$ on the component side and located between the component edge and anvil centerline, and Gauge B in the opposite side at the center of the BGA shadow was used.

In the current 4 point bending tests the strain gauges used (Vishay Micro-Measurements, CA-06125-350) have $3.2 \mathrm{~mm}$ gauge length and $350 \mathrm{ohm}$ resistance. The gauges were bonded to the PCB surface with M-bond 200 adhesive. In the setup testing, three strain gauges were placed on the test sample. Gauge A is mounted on the same side of component and gauge B, C, on opposite side of component.

\subsubsection{Daisy-chain}

After board assembly there is a continuous electrical net conductive link connected in series with other conductive link. Each package has a single separately monitored daisy-chain net that will reduce the likelihood of external trace contact damage during testing. The test vehicles included a single daisy chain of all solder joints in the two outermost rows of the module. This daisy chain was used to monitor the electronic voltage vary during bending tests. Figure 5.5 shows the daisy chain diagram on the solder joints. 


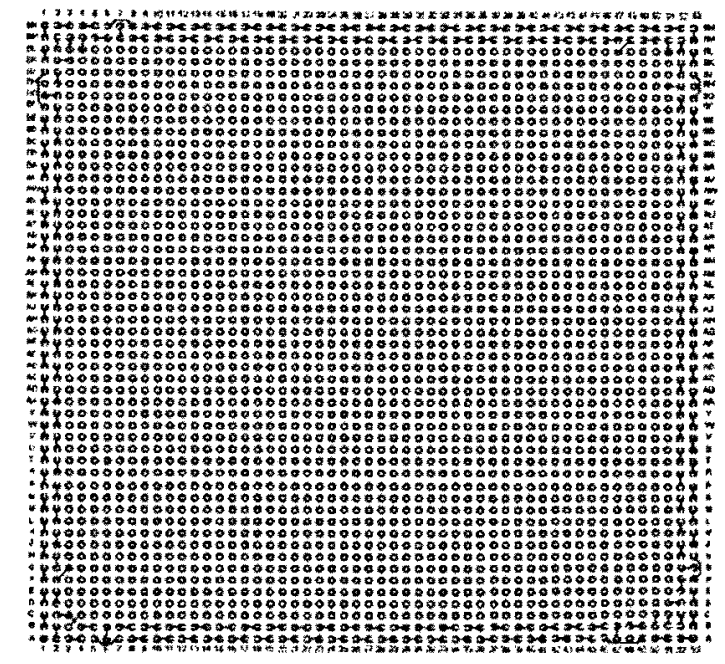

Figure 5.5: A daisy chain diagram

\subsubsection{Layout FBG on the substrate}

Finite element analysis indicates that the package solder interfacial strain at the package corner is most severe for the largest package body size as well as the largest array of test packages on a single test board. For BGA assembly the solder connections at the package corner typically fail sooner during monotonic bend testing than the connection on the middle of the package edge. The dimension of solder ball distribution was showed in Figure 5.6. The critical strain distribution for 4 point bend loading is showed in Figure 5.7. The critical strain distribution presented the outer columns of solder joints experience the largest elongation.

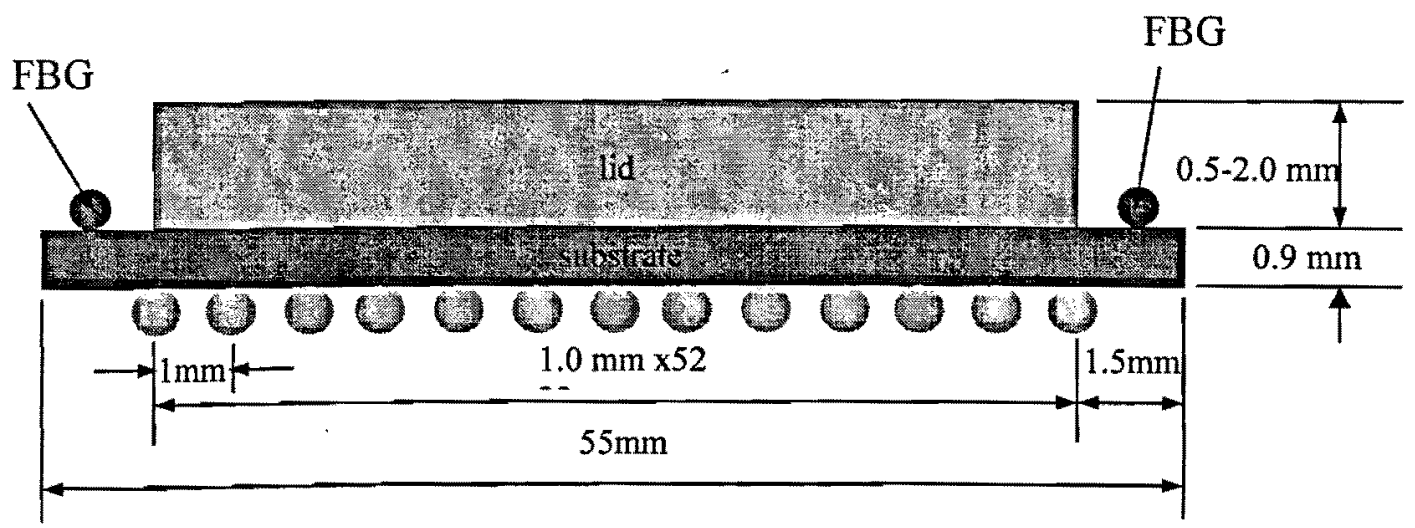

Figure 5.6: Dimension of solder balls 


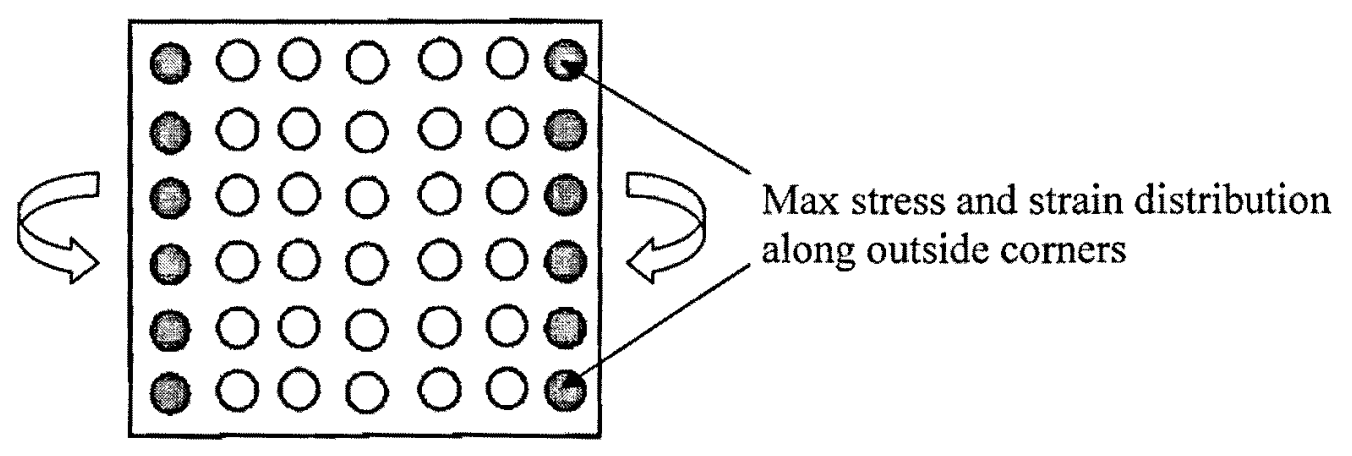

Figure 5.7: Critical strain distributions under flexible loading

The FBG sensors were laid in parallel with the substrate edges with $1.0-1.5 \mathrm{~mm}$ distance from the peripheral row of the solder balls. With the $5 \mathrm{~mm}$ grating length the FBG sensors were mounted each one of four corners in substrate surface to match $1 \mathrm{~mm}$ ball pitch. The one end of sensors was aligned with the corner ball and the other end was extended to coincide with the fourth solder ball in the row. The measured FBG strain varies depending on the global load as well as the connectivity condition of the nearby solder joints (the four solder joints in the sensor's immediate vicinity as well as the joints in the neighborhood in a less extent). After located FBG sensors on the correct position a thin layer of epoxy was applied to cover the FBG sensors and was followed by curing process at $80^{\circ} \mathrm{C}$ in 40 minutes. The installation of FBG sensors is showed in Figure 5.8. The bonding of the FBG sensors used epoxy-based glue. The curing took place at $80^{\circ} \mathrm{C}$ in 40 -minute duration.

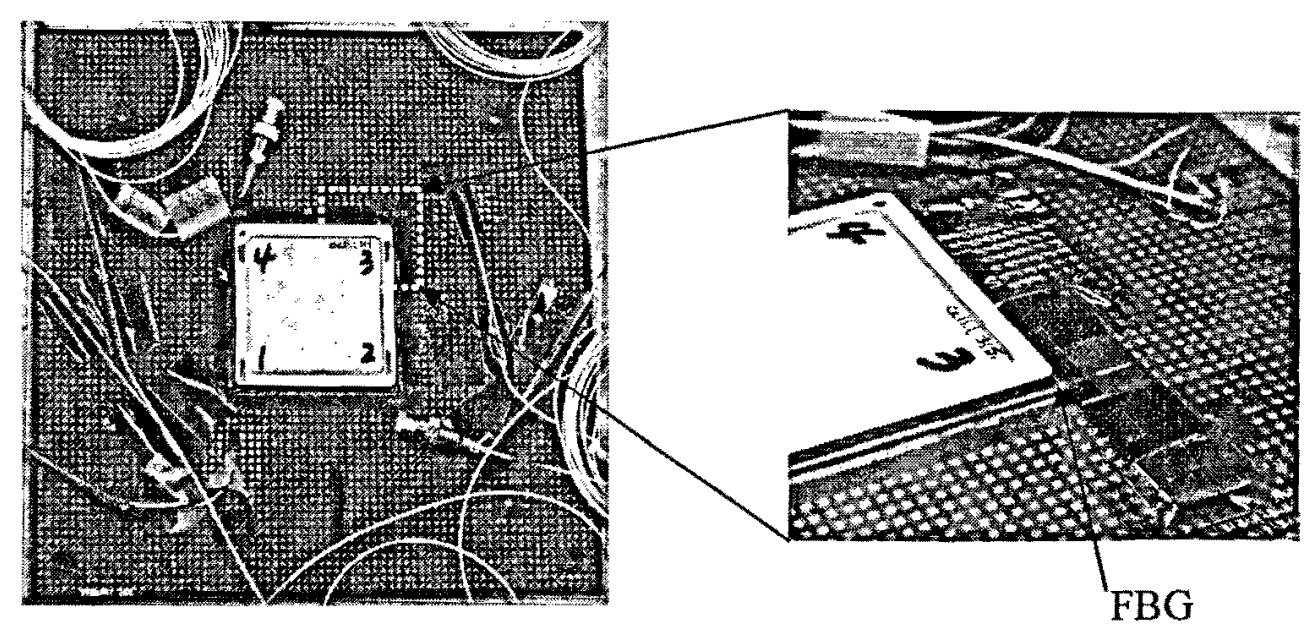

Figure 5.8: Installation of FBG on corners of BGA substrate 


\subsection{Description of 4-point bend tests}

\subsubsection{Signal synchronization}

The 4 point bending test system consists of three main pieces of hardware: a universal test machine undertaking load and support role, a data acquisition system with high frequency data collective ability, and an optical spectrum analyzer for FBG data gathering. The universal loading machine (United Technologies, model SSTMS) is a displacement controlled electromechanical tester with a load capacity of $5000 \mathrm{lbs}(22.3 \mathrm{~kg})$. The data acquisition system (Daytronic, "system 10" model 10KM851) constitute by a 16 bit A/D converter and a 36 channel signal conditioning system. This system can reach to a high frequency up to $10 \mathrm{KHz}$ to get more information for critical load detection. The FBG strain measurement instrument is a wavelength sweep laser system (Micron optics Inc., model Si425) of a maximum sweep rate of $250 \mathrm{~Hz}$. The test system of four point bending is showed in Figure 5.9. The signal synchronization between tensile machine and data acquisition system is obtained by connecting load cell to the data acquisition system to transfer the electronic signal to a load reading. The correlation between universal machine and FBG instrument is controlled by test time.

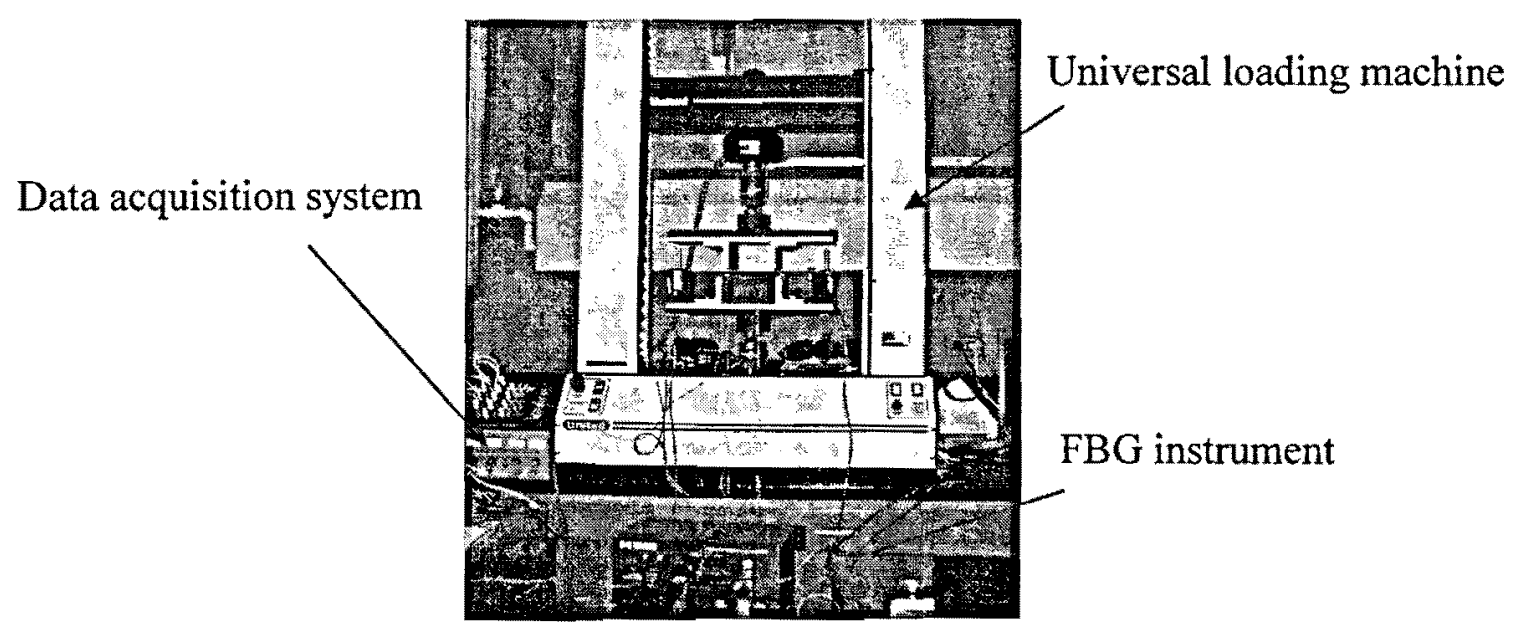

Figure 5.9: Four point bend test system

The data acquisition system includes a desktop computer with system software and a 16 bit A/D converter and a 36 channel signal conditioning system. This system can provide the interface for 
system control, parameter setting, data storage and real time graphical display. Using the channel signal conditioning system the signals from the load cell of universal test machine, the LVDT, the strain gauges and the daisy chain were monitored and controlled by the data acquisition system. The power source supplies a constant current of 0.2 ampere to the daisy chain of PCBA package that the electronic resistance of the circuit chain is proportional to the loop voltage. The universal test machine undertook the mechanical loading by a support and loading fixture. The support fixture is monitored for displacement balance by two LVDT (Linear Variable Differential Transformer) sensors located a diagonal layout. The load cell sensor was connected to the data acquisition system that can receive various voltage signals due to various forces and transfer to load reading. FBG instrument with two types of instruments with different frequency will keep synchronization with data acquisition system as well loading machine.

\subsubsection{Parameter set up}

The initial setting of the test parameters included the support span, the load span, the crosshead speed and the crosshead travel distance. The crosshead speed is an important parameter since it was interrelated with strain rate and failure models even though it is limited by the machine capacity. The finally set up of crosshead speed at $8.4 \mathrm{~mm} / \mathrm{s}$ because of the limitation of the capacity of universal test machine. The PCB global strain rate obtained under this speed was remarkably higher than the initial targeted $5000 \mu \varepsilon / \mathrm{s}$. The crosshead travel distance was set up to $2-6 \mathrm{~mm}$ as basic setting. Defining the parameters for initial setup required a series of adjustment trials to identify the weak points of the assembled PCB's and to find the proper test conditions, which lead to coherent failure trends. Table 5.2 gives out the test parameter set up.

\subsubsection{Balance adjust screws}

It is necessary to adjust the alignment in order to optimize the contact and load balance before started tests. The alignment test is completed by two symmetrically laid strain gauges about the mid-axis that is showed in Figure 5.10. The alignment test used a bare PCB with two symmetrically laid strain gauges about the mid-axis. Before the test started, the load (top) fixture was lowered until the anvils just touched the board. The tilt of the support fixture located on the bottom was then inspected visually to obtain an estimate of the tilt adjustment. The support fixture tilt adjustment was realized via four Jake screws and the load balance was verified as the 
strain gauges gave identical readings. Figure 5.11 shows a photo of the fixtures with the Jake screw mechanism. Four Jake screws are placed on the support fixture to adjust the high of support fixture in two directions to ensure two load rollers to touch the PCBA at the same time in order to reduce measured errors.

Table 5.2 Test setup parameters

\begin{tabular}{|l|l|}
\hline \multicolumn{2}{|l|}{ Specification of the test parameters } \\
\hline Sample types & $\mathrm{A}, \mathrm{B}, \mathrm{C}, \mathrm{D}$ \\
\hline Load span $(\mathrm{mm})$ & 115 \\
\hline Support span $(\mathrm{mm})$ & 147 \\
\hline Crosshead speed $(\mathrm{mm} / \mathrm{s})$ & 8.4 \\
\hline Crosshead travel distance $(\mathrm{mm})$ & $2-6$ \\
\hline Strain rate input $(\mu \varepsilon / \mathrm{s})$ & $10000-14000$ \\
\hline Frequency of data collection $(\mathrm{Hz})$ & 2000 \\
\hline Resistance of PCBA $(\Omega)$ & $9-12$ \\
\hline Current $(\mathrm{A})$ & 0.2 \\
\hline Specification of the FBG & \\
\hline Length of the FBG & $5 \mathrm{~mm}$ \\
\hline Wavelength & $1539.997(\mathrm{~nm})$ \\
\hline Bandwidth & $0.320(\mathrm{~nm})$ \\
\hline Isolation & $\sim 27 \mathrm{~dB}(+/-0.5 \mathrm{~nm})$ \\
\hline Reflectivity & $>80 \%$ \\
\hline Estimate splice loss & 0.008 \\
\hline Specification of the Strain Gauge & \\
\hline Length of the strain gauge & $3.2 \mathrm{~mm}$ \\
\hline Gauge factor & $2.1(+/-0.5)$ \\
\hline Transverse sensitivity & $+0.4(+/-0.2) \%$ \\
\hline
\end{tabular}

\subsubsection{Preload requirement}

To ensure a properly balanced contact at the start of the test, the assembly sample was preloaded. A recommended maximum pre-load is 100 micro-strains by JEDEC/IPC9702. The loads were added to the PCBA until a global PCB strain of $30 \sim 50 \mu \varepsilon$ was reached. With the position of the 
load fixture under the preload was used as a reference, the load fixture was then lifted by $20 \mathrm{~mm}$ above the reference position that can obtain uniform strain rate after eliminating the effect of crosshead speed. The data recording started when the load fixture began moving down to the end position and continued until the crosshead returned to its starting position.

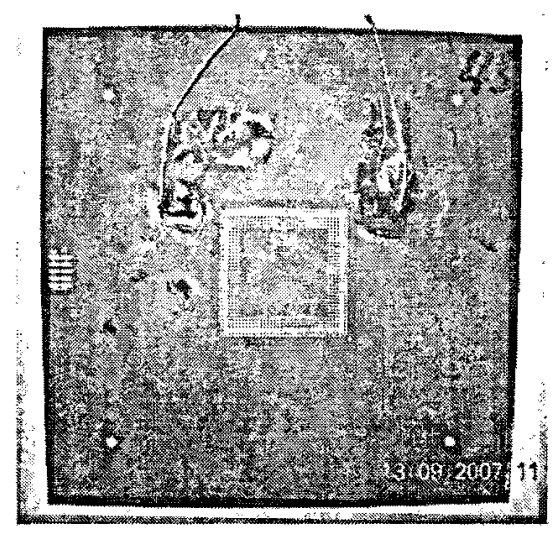

Figure 5.10: Balance tests by two strain gauges

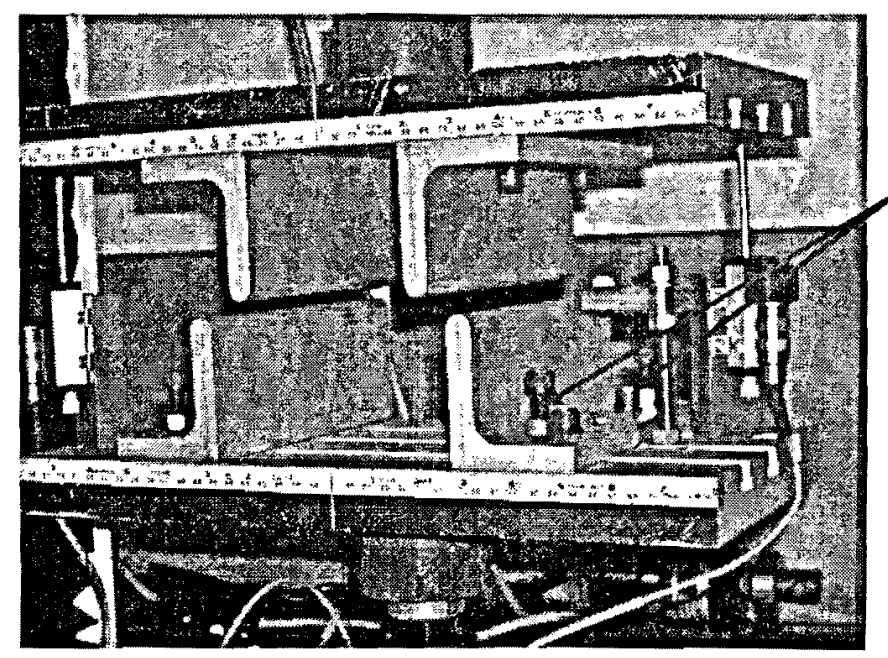

Four Jake screws on the support fixture

Figure 5.11 Jake screws for adjusting load balance

\subsubsection{Strain gauge and FBG layout}

There are 4 fiber Bagger sensors on the corners of the component that will monitor the normal strain along bending direction. One strain gauge is located between load and support fixture 
meeting the standard requirement and monitoring the global strain variation. The layout of strain gauge and FBGs is drafted in Figure 5.12.

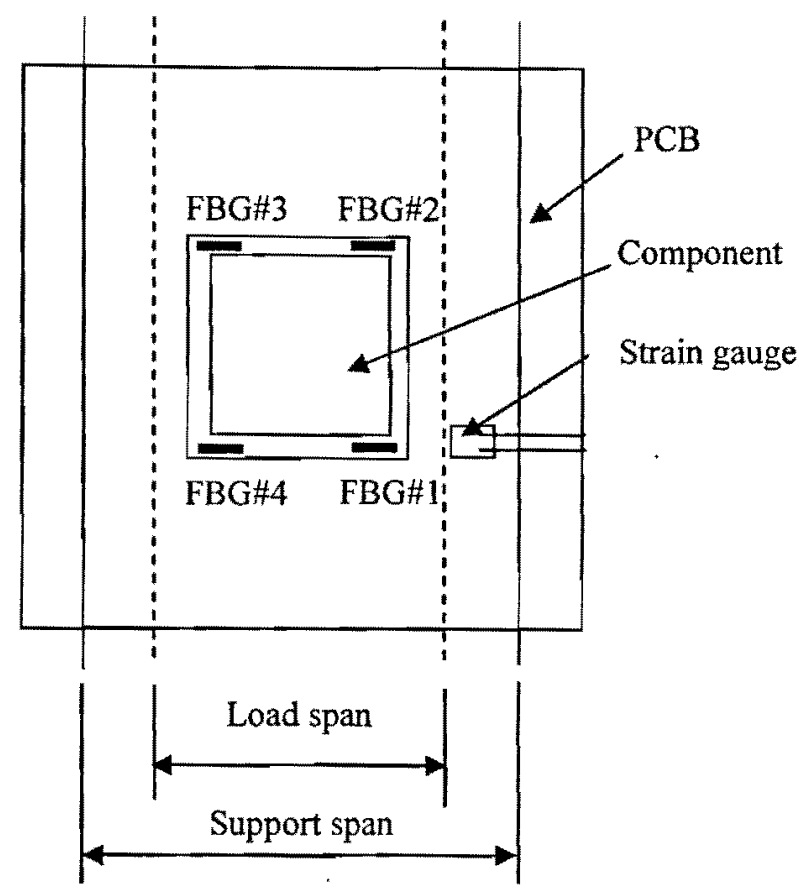

Figure 5.12: Strain gauge and FBG layout

\subsubsection{Test procedure}

The test system consists of three pieces of equipment as follows. The universal tensile machine with a four-point bend load and support fixtures is configured by a desktop computer that provides the software to control the universal mechanical tester. The data acquisition system (Daytronic, System $10^{\circ}$ model 10KM851) with the data acquisition rate of $10 \mathrm{KHz}$ is used to record data such as strain change of PCBA, voltage change of daisy chain of PCBA circuit, mechanical load, and displacement of the crosshead. The two optical sensing integrators used for recording the FBG strain were optical sensing integrator model si425 (frequency $250 \mathrm{~Hz}$ ), and another one is sm130 (frequency $2000 \mathrm{~Hz}$ ). During each test, the PCBA sample was connected to the two different data acquisition systems (mechanical and optical) at the same time. Two strain gauges, two LVDT, the load cell, and the resistor were connected to the mechanical interrogator while the FBG sensors are connected to the optical interrogator. Then two individual computers are employed to monitor tests and record test data. 
During four bending tests, the BGA solder joints are subjected to tension rather than compression since the solder joint failure is mostly attributed to the tensile stress rather than the compressive stresses. The two edges of the component were set to be in parallel to the load anvils. The anvils were adjusted to reach a load span of $115 \mathrm{~mm}$ while the support span is set as $147 \mathrm{~mm}$. These parameters were chosen based on the structure of PCBA and PCB thickness. The crosshead speed was set to $8.4 \mathrm{~mm} / \mathrm{sec}$ that is the maximum speed for this tensile machine. The observed PCB global strain rate was noticeably higher than the targeted value of $5000 \mu \varepsilon / \mathrm{s}$ at the above mentioned speed since high strain rate will give out reasonable failure models. The different test conditions parameters that were used are tabulated in table 5.3-5.6.

The test procedure is as follows: a pre-load corresponding to $50-100 \mu \varepsilon$ of PCB global strain is set up to ensure that the load anvils were in contact with the PCB surface; this is used as a reference point from where the load anvils will be lifted up by $20 \mathrm{~mm}$ from the board. Once the load anvil reached height, the test was executed by sending a $5 \mathrm{~V}$ trigger signal to the solder joint resistance monitoring the circuit to activate the recording function. During the experiment, the boards were deformed to a preset value of crosshead displacement; the setup was then dwelled for a few seconds before returning to its initial state. When the predetermined crosshead travel is reached, the monitoring systems will stop and the crosshead returns to the original position. While performing the experiment, the wavelength shifts of the FBG sensors since they are stressed, and the strain from the strain gauge, the load cell, displacement, and the resistance were monitored and recorded 
Table 5.3 Test conditions for A type component

\begin{tabular}{|c|c|c|c|c|}
\hline Test condition and samples & $\overline{A 1}$ & $\overline{\mathbf{A 2}}$ & $\overline{\mathbf{A 3}}$ & $\overline{\mathrm{A4}}$ \\
\hline Load span (mm) & \multicolumn{4}{|l|}{115} \\
\hline Support span (mm) & \multicolumn{4}{|l|}{147} \\
\hline Crosshead speed $(\mathrm{mm} / \mathrm{s})$ & \multicolumn{4}{|l|}{8.4} \\
\hline Crosshead travel distance $(\mathrm{mm})$ & 2.0 & 4.0 & 10 & 4.0 \\
\hline PWB strain under preload $(\mu \varepsilon)$ & \multicolumn{4}{|l|}{50} \\
\hline Daisy chain voltage (1 ohm resistor) (V) & 2.524 & 2.27 & 2.39 & 2.39 \\
\hline Resistance of daisy chain & 12.8 & 11.8 & 11.7 & 12.2 \\
\hline Daisy chain constant current (A) & \multicolumn{4}{|l|}{0.2} \\
\hline Frequency of data acquisition system $(\mathrm{Hz})$ & \multicolumn{4}{|l|}{2000} \\
\hline Frequency of si425 system (Hz) & 2000 & & 250 & 2000 \\
\hline
\end{tabular}

Table 5.4 Test conditions for B type component

\begin{tabular}{|c|c|c|c|c|c|}
\hline Test condition and samples & B1 & B2 & B3 & B4 & B5 \\
\hline Load span $(\mathrm{mm})$ & \multicolumn{5}{|l|}{115} \\
\hline Support span (mm) & \multicolumn{5}{|l|}{146} \\
\hline Crosshead speed $(\mathrm{mm} / \mathrm{s})$ & \multicolumn{5}{|l|}{8.4} \\
\hline Crosshead travel distance $(\mathrm{mm})$ & 10 & 12 & 10 & 8.0 & 4.5 \\
\hline PWB strain under preload $(\mu \varepsilon)$ & \multicolumn{5}{|l|}{50} \\
\hline Daisy chain voltage (1 ohm resistor) (V) & 2.16 & 2.31 & 2.29 & 2.17 & 2.18 \\
\hline Resistance of daisy chain & 10.7 & 11.4 & 11.5 & 10.8 & 11 \\
\hline Daisy chain constant current (A) & \multicolumn{5}{|l|}{0.2} \\
\hline Frequency of data acquisition system $(\mathrm{Hz})$ & \multicolumn{5}{|l|}{2000} \\
\hline Frequency of si425 and sm130 system (Hz) & \multicolumn{3}{|l|}{250} & \multicolumn{2}{|l|}{2000} \\
\hline
\end{tabular}


Table 5.5 Test conditions for $\mathrm{C}$ type component

\begin{tabular}{|c|c|c|c|c|c|c|c|}
\hline Test condition and samples & $\overline{C 1}$ & $\mathrm{C2}$ & $\mathbf{C 3}$ & $\overline{C 4}$ & $\mathbf{C 5}$ & $\mathbf{C 7}$ & C8 \\
\hline Load span (mm) & 110 & \multicolumn{6}{|l|}{115} \\
\hline Support span (mm) & \multicolumn{7}{|l|}{146} \\
\hline Crosshead speed (mm/s) & \multicolumn{7}{|l|}{8.4} \\
\hline Crosshead travel distance $(\mathrm{mm})$ & 6 & 8 & 10 & 4 & 4.5 & 8 & 4.5 \\
\hline PWB strain under preload $(\mu \varepsilon)$ & \multicolumn{7}{|l|}{50} \\
\hline $\begin{array}{l}\text { Daisy chain voltage (1 ohm resistor) } \\
\text { (V) }\end{array}$ & 2.34 & 2.24 & 2.24 & 2.34 & 2.26 & 2.13 & 2.38 \\
\hline Resistance of daisy chain & 11.7 & 11 & 12 & 11 & 11.7 & 11.2 & 11.8 \\
\hline Daisy chain constant current $(\mathrm{A})$ & \multicolumn{7}{|l|}{0.2} \\
\hline $\begin{array}{l}\text { Frequency of data acquisition system } \\
(\mathrm{Hz})\end{array}$ & \multicolumn{7}{|l|}{2000} \\
\hline $\begin{array}{l}\text { Frequency of si } 425 \text { and sm130 system } \\
(\mathrm{Hz})\end{array}$ & \multicolumn{3}{|l|}{250} & \multicolumn{4}{|l|}{2000} \\
\hline
\end{tabular}

Table 5.6 Test conditions for D type component

\begin{tabular}{|c|c|c|c|c|}
\hline Test condition and samples & D2 & D3 & D4 & D6 \\
\hline Load span (mm) & \multicolumn{2}{|l|}{100} & \multicolumn{2}{|l|}{115} \\
\hline Support span (mm) & \multicolumn{2}{|l|}{146} & \multicolumn{2}{|l|}{147} \\
\hline Crosshead speed $(\mathrm{mm} / \mathrm{s})$ & 6 & 8.4 & 8.4 & 8.4 \\
\hline Crosshead travel distance $(\mathrm{mm})$ & 4.5 & 4.5 & 4.0 & 4.5 \\
\hline PWB strain under preload $(\mu \varepsilon)$ & \multicolumn{4}{|l|}{50} \\
\hline Daisy chain voltage (1 ohm resistor) (V) & 2.28 & 2.22 & 2.67 & 2.34 \\
\hline Resistance of daisy chain & 11.6 & 11.6 & 13.1 & 11.5 \\
\hline Daisy chain constant current (A) & \multicolumn{4}{|l|}{0.2} \\
\hline Frequency of data acquisition system $(\mathrm{Hz})$ & \multicolumn{4}{|l|}{2000} \\
\hline Frequency of si425 and sm130 system (Hz) & \multicolumn{2}{|l|}{250} & \multicolumn{2}{|l|}{2000} \\
\hline
\end{tabular}




\section{Chapter 6 Failure inspection and analysis}

The electronic package is typically exposed to various types of loads such as the thermal loads caused by CTE mismatch between different materials, bending load induced from handling, key pressing and dropping, and impacts loads during assembly process and custom working environment. In a general case, mechanical and thermal load combine to lead to the failure of the solder joints. Failure mechanisms of the electronic package can be categorized to two groups. The first group is the overstress failure mechanism caused by excessive bending, dropping, immoderate temperature change and electrostatic discharge, etc. The second one is wear-out failure mechanism linked to thermal fatigue, creep, crack propagation, electro-migration, corrosion, large dendrite growth as well as solder interface intermetallic growth.

\subsection{Fracture modes under mechanical bend loading}

BGA assembly package interconnect fracture failure due to mechanical bending has several modes that are documented in the JEDEC/IPC 9702 standard. Figure 6.1 illustrates failure modes under bend loading. The modes of fracture failure include the package body cracking and cracking between the various lead, Intermetallic Compound (IMC), solder and printed writing board (PWB) metal pad interface.

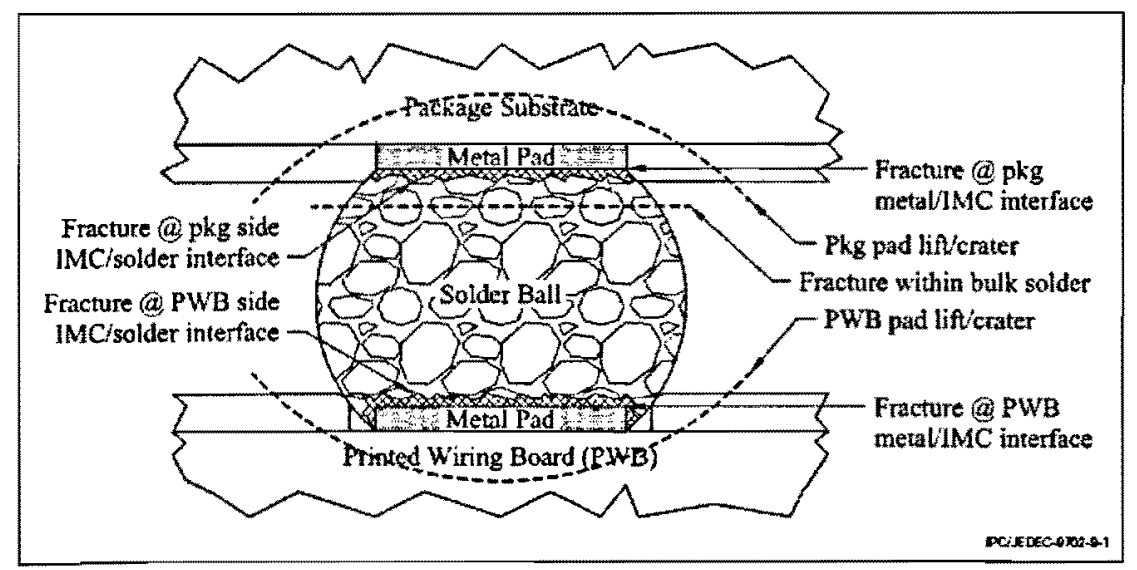

Figure 6.1 BGA interconnect fracture modes [23] 


\subsubsection{The second level interconnect failure mechanisms}

4-point bending tests commonly performed mechanical force loading on BGA packages can help determine the critical load of the ball attach process, but they are strain rate dependent typically. The strains on the solder joint are typically performed at a relatively low value if the package under a lower strain rates loading, where the solder joints are ductile. When the strain rate increases beyond a certain point, solder undergoes a ductile-to-brittle transition and change in fracture mode. The mechanical failure modes of 4-point bend testing were identified by the IPC/JEDEC 9702 standard. The failure modes includes lead cracking, package body cracking, and cracking between the various lead, IMC, solder and PCB metal pad interfaces. The four main failure modes that may be encountered during a four point bending test are: 1) the board pad delamination, 2) the board trace fracture failure, 3) the solder joint fracture failure around the pad, 4) solder fracture failure near the component interface. As a board pad de-laminated from the laminate core, it can move freely up and down. During this process, the test board continues to bend (PCB pad lift/crater) and the length of the fracture interface increases until a final rupture results in a failure. Such failure is only observed when the deflection is at its greatest. The solder joint failure around a board pad is characterized by cracks emerging from the outer edge of the pad along the trace. The crack then propagates towards the bulk solder. For board trace failure, the trace and cracks occur near the solder mask opening. A solder fracture around the component interface is defined by a fracture which occurs along the package's IMC/solder and metal/IMC interfaces [3]. These cracks are perceptible through visual inspection such as the dye-and-pry technique. It is possible to observe its failure on the test board pad interface, although this depends greatly on the board's materials.

\subsection{Dye and pry inspection}

Dye and pry technique is a destructive test method for the revealing of defects on the solder ball to pad interface that relies on a liquid to penetrate into existing micro cracks or under open solder balls. After letting the dye dry the component BGA is pried off from PCB and the solder balls are inspected for the presence of the dye that reveals any interfacial connection problem areas. 


\subsubsection{Dye and pry tests}

It is important to identify failure modes and failure distribution after bend testing in order to analyze the magnitude of the bending moment and damage levels for different test vehicles. The dye and pry test was conducted after bending tests in order to verify the solder joint damage including failure mode and location. The analysis offers a three-dimensional view of cracks in solder joints to a component. The tests boards are immersed in a low viscosity liquid dye in a vacuum chamber after finishing bend testing. The liquid penetrates any cracks, delaminates on PCB, component and solder joints, and marks those areas. After having applied the dye, the component was removed by bending the board numerous times. The fractured solder joints were then visually inspected and photographs were made to record the position that dye had penetrated into the joint. The dye and pry maps help illustrate that the interconnect fracture was initiated from the module corners and along the edges parallel with the anvils. The failure of solder joints could develop further inward when the board flexure is increasing. These observations lead to understanding of the substrate strain mechanics behavior in a better way.

The test results indicate that the pad-lifted solder joints are located at least four rows inward from the corners and pad-lifting failure dominated fracture of solder joints on the PCB side. Most fracture of solder joints took place in the IMC interconnect layer on the PCB side at sample type A that has a thick lid configuration. It is understood that a part of the bending load applied to the board is transferred to the module via the interconnecting solder joints, causing high stress especially in the corner joints. Figure 6.2 shows a specific pad crater and IMC layer crack at a cross section of the solder joint after the bending test. Pad-lift is one of the failure modes of bend testing that can occur in both sides of the component and PCB as failure mode5 and mode10 in the IPC/JEDEC 9702 standard. The experimental test results discovered $95 \%$ of solder joints failed as PCB side pad lifts. The crack initiates at the edge of copper pad, and growth continues around the direction perpendicular to the fiber bundles due to the geometry of the solder balls causing stress concentration in the pad comer. It is discovered by experimental bend testing that pad lifts which do not cause electrical failure may lead to reliability failures in the field. This is because electrical failure is due to dog bone trace breaks. So the failure criteria should be onset of pad lifts not electrical failure [30]. 


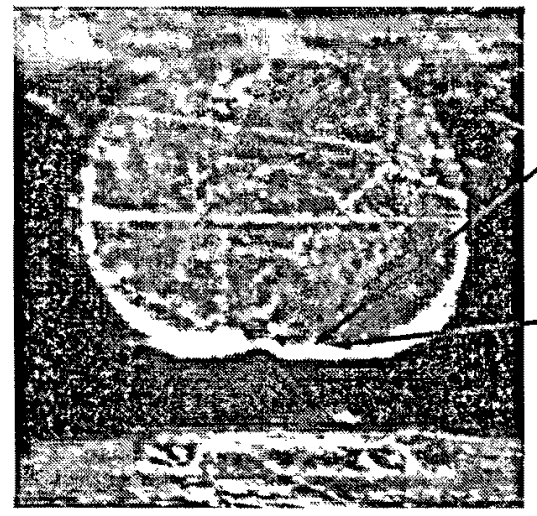

(a)
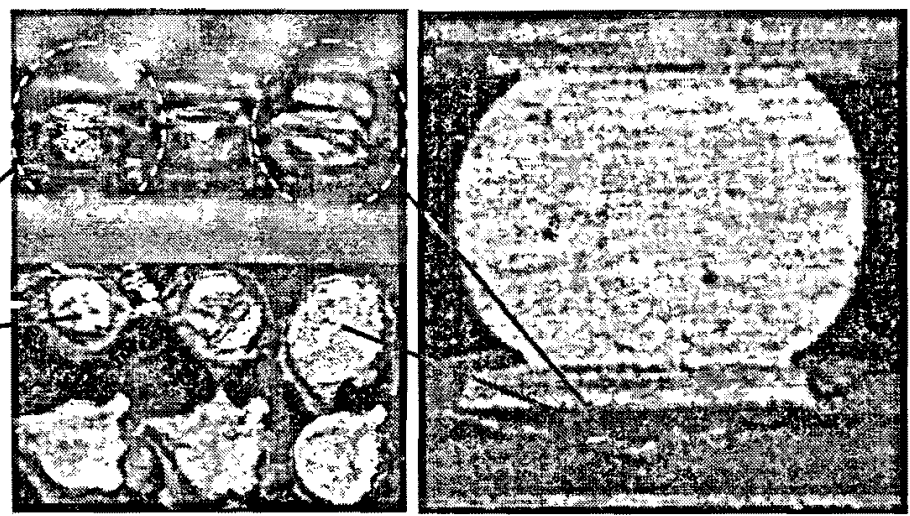

(b)

Figure 6.2: (a) IMC fracture on PCB side (b) pad crater on PCB side

\subsubsection{Failure maps}

Upon finishing the bend test, the sample was subjected to a dye and pry failure analysis to obtain a map of the damaged BGA solder joints. The failure analysis method is simple and very useful to identify the interconnect failure locations and the associated failure modes. In this case study, the fracture failure is concentrated on three kinds of failure mode, 1) fracture at package side as IMC or solder interface; 2) fracture at PCB side as pad lift or pad crater; 3) fracture at PCB side as IMC or solder interface. Figures 6.3-6.6 draft special failure maps of four test vehicles and normal strain versus time curves measured by FBG.
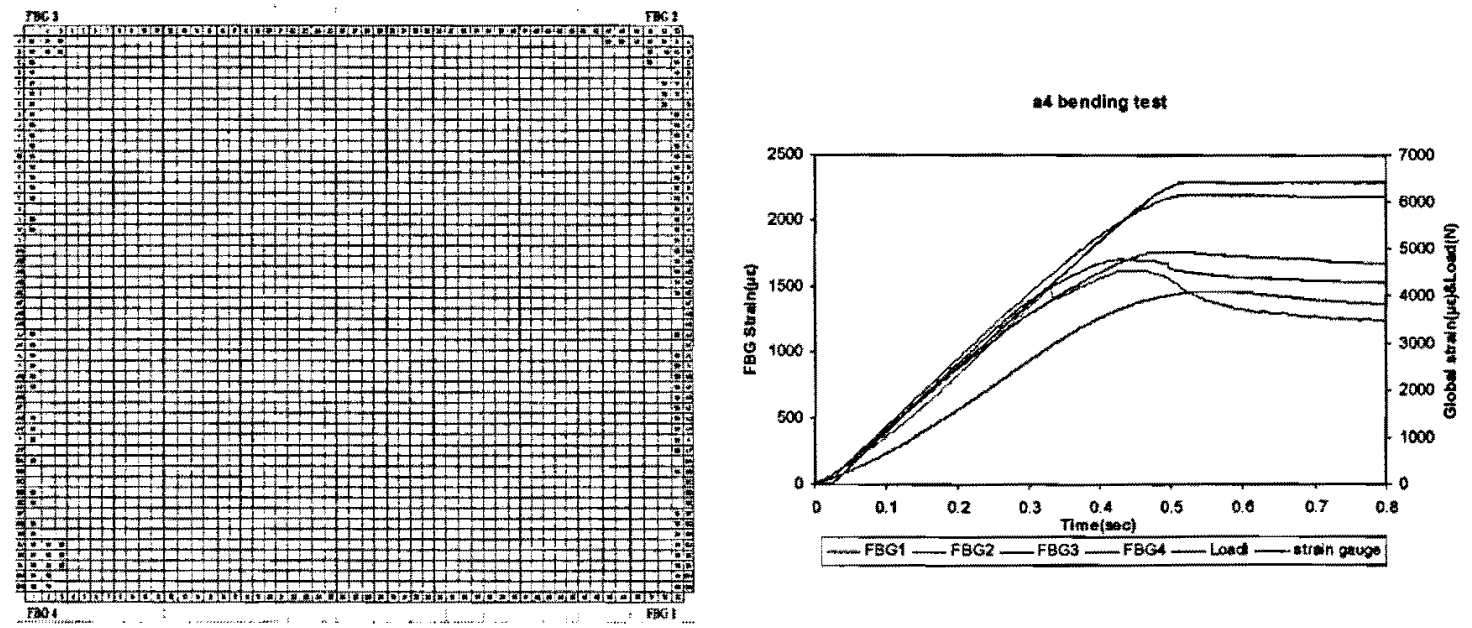

Figure 6.3: Sample A4 fracture failure map and strain curves 

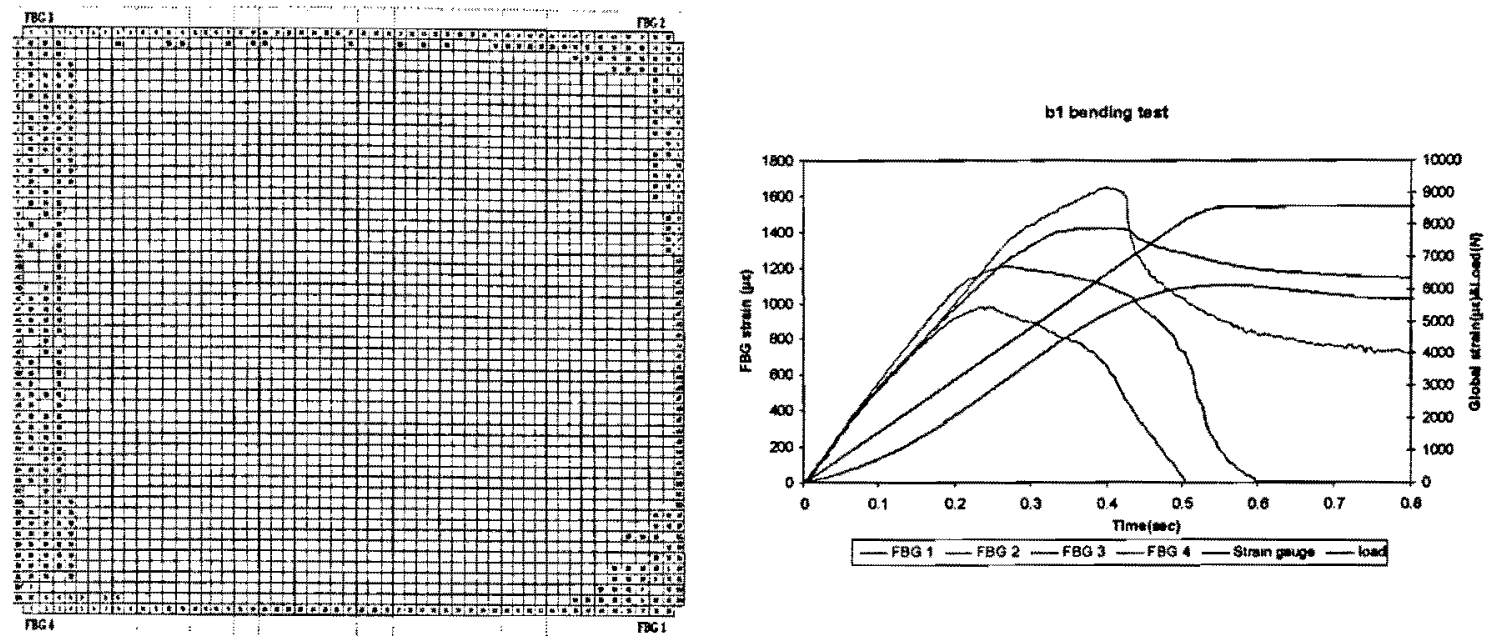

Figure 6.4: Sample B1 fracture failure map and strain curves
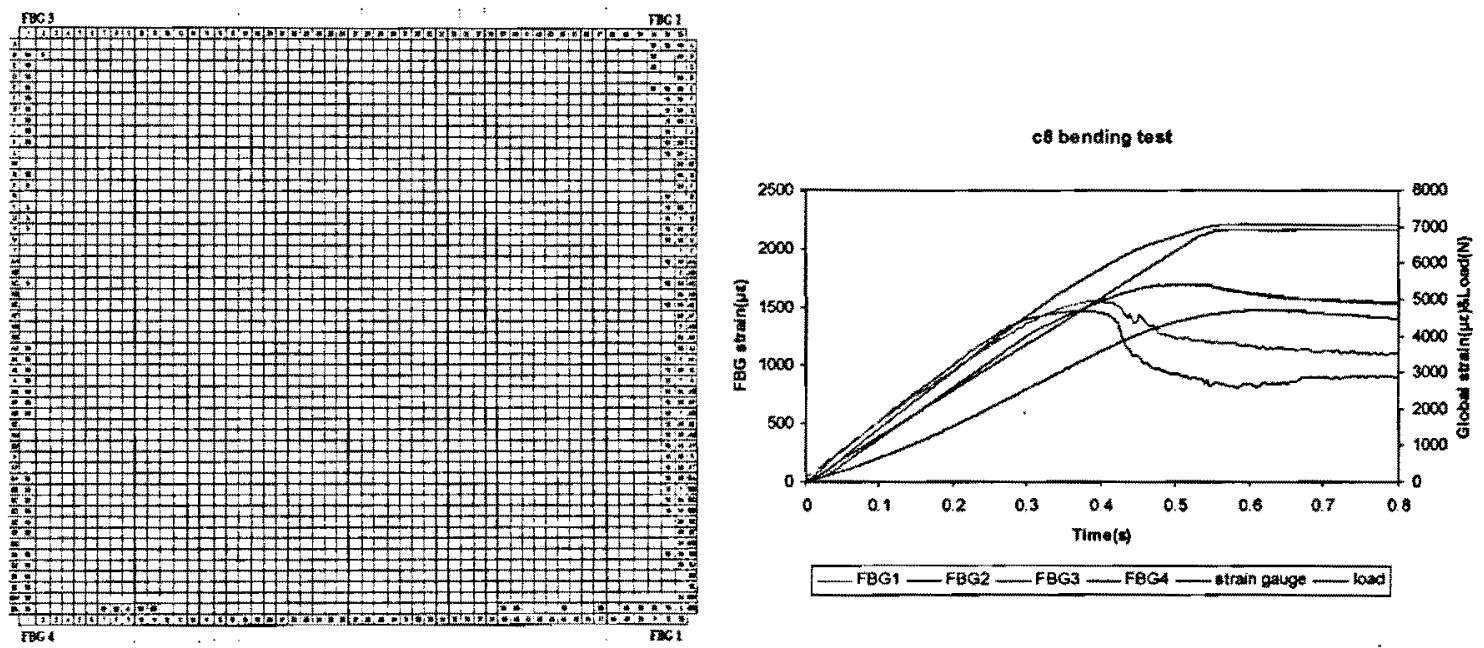

Figure 6.5: Sample C8 fracture failure map and strain curves
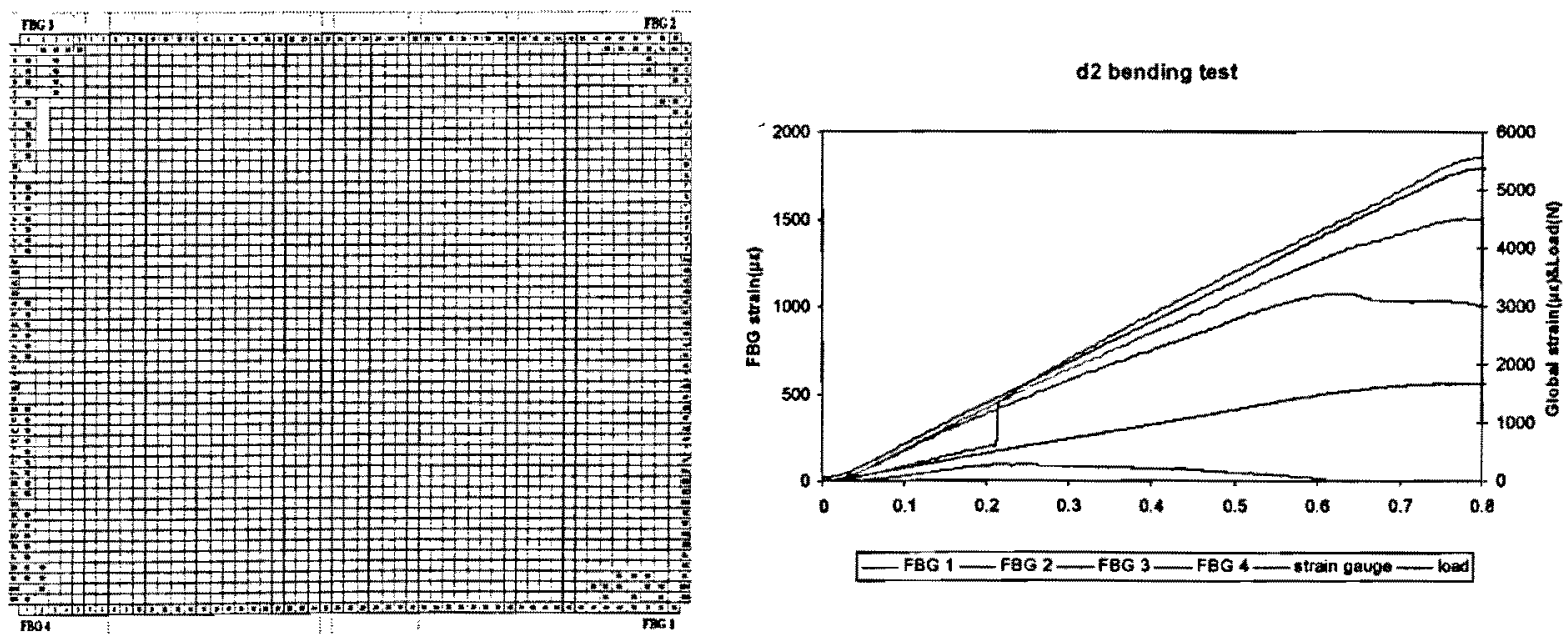

Figure 6.6: Sample D2 fracture failure map and strain curves 


\section{Chapter 7 Analysis and discussion}

The 4-point bend test is one of overloading and destructive tests that simulate these damages during board level assemblies susceptible to bending in manufacturing and installation. Unlike fatigue failures, BGA solder joint fractures typically occur during a monotonic stress event such as high strain rate flexural loading. The fracture of solder joints could be caused by different types of stress state that lead to different crack initial and propagation modes. The details by which mode fracture takes place depend on the geometry of solder joints, lid thickness, and PCB thickness. As known, the solder joints suffer complex 3D stress/strain state that consists of normal and shear stress/strain in three directions. Table 7.1 shows test result summary for type $\mathrm{C}$.

Table 7.1 Test results for type C

\begin{tabular}{|c|c|c|c|c|c|c|c|c|c|c|c|c|c|c|c|c|c|c|c|c|c|c|c|c|c|c|}
\hline Sample & \multicolumn{4}{|c|}{ c1 } & \multicolumn{4}{|c|}{$c 2$} & \multicolumn{4}{|c|}{ c4 } & \multicolumn{4}{|c|}{ c5 } & \multicolumn{6}{|c|}{ c7 } & \multicolumn{4}{|c|}{ c8 } \\
\hline $\begin{array}{c}\text { Crosshead speed } \\
(\mathrm{mm} / \mathrm{s})\end{array}$ & \multicolumn{4}{|c|}{8.4} & \multicolumn{4}{|c|}{8.4} & \multicolumn{4}{|c|}{8.4} & \multicolumn{4}{|c|}{8.4} & \multicolumn{6}{|c|}{8.4} & \multicolumn{4}{|c|}{8.4} \\
\hline \begin{tabular}{l|} 
Crosshead travel \\
distance (mm)
\end{tabular} & \multicolumn{4}{|c|}{5.3} & \multicolumn{4}{|c|}{5.4} & \multicolumn{4}{|c|}{4.0} & \multicolumn{4}{|c|}{4.5} & \multicolumn{6}{|c|}{5.0} & \multicolumn{4}{|c|}{4.5} \\
\hline $\begin{array}{l}\text { Resistance( }(\Omega) \\
\text { / change }\end{array}$ & \multicolumn{4}{|c|}{$2.344 / 0.294 \%$} & \multicolumn{4}{|c|}{$2.244 / 0.354 \%$} & \multicolumn{4}{|c|}{$2.34 / 0.169 \%$} & \multicolumn{4}{|c|}{$2.255 / 0.239 \%$} & \multicolumn{6}{|c|}{$2.13 / 0.277 \%$} & \multicolumn{4}{|c|}{$2.389 / 0.147 \%$} \\
\hline $\operatorname{Max} \operatorname{load}(N)$ & \multicolumn{4}{|c|}{4212} & \multicolumn{4}{|c|}{6934} & \multicolumn{4}{|c|}{4041} & \multicolumn{4}{|c|}{4779} & \multicolumn{6}{|c|}{6445} & \multicolumn{4}{|c|}{5201} \\
\hline FBG \# & 1 & 2 & 3 & 4 & 1 & 2 & 3 & 4 & 1 & 2 & 3 & 4 & 1 & 2 & 3 & 4 & 1 & $2 a$ & $3 a$ & 4 & $2 b$ & $3 b$ & 1 & 2 & 3 & 4 \\
\hline $\begin{array}{l}\text { Critical load } \\
\text { (N) }\end{array}$ & 5511 & 5010 & 5011 & 5511 & 4340 & 4340 & 4340 & 4340 & 333 & 3375 & 3375 & 3333 & 4206 & 4145 & 4303 & 4297 & 3949 & 3357 & 4431 & 3772 & 3711 & 3822 & 3247 & 3540 & 4309 & 4608 \\
\hline $\begin{array}{c}\text { Critical Strain } \\
(\mu \varepsilon)\end{array}$ & 3367 & 3731 & 3611 & 3392 & 2188 & 2491 & 2376 & 2049 & 1240 & 2353 & 1968 & 2160 & 1941 & 1841 & 2193 & 2280 & 1931 & 1803 & 2308 & 1873 & 1933 & 2435 & 1468 & 1554 & 1690 & 2195 \\
\hline $\begin{array}{c}\text { Global strain } \\
(\mu \varepsilon)\end{array}$ & 8915 & 8943 & 8943 & 8915 & 9038 & 9596 & 9596 & 9661 & 5813 & 5927 & 5927 & 5843 & 6661 & 6478 & 6906 & 6901 & 3766 & 3174 & 4248 & 3589 & 3528 & 83637 & 4630 & 4983 & 6178 & 6869 \\
\hline \begin{tabular}{|c|} 
Average critical \\
load of package \\
(N)
\end{tabular} & & 52 & & & & & 340 & & & 33 & & & & $42:$ & 38 & & & & 38 & & & & & 392 & 326 & \\
\hline $\begin{array}{l}\text { Overall average } \\
\text { critical load (N) }\end{array}$ & & & & & & & & & & & & & 41 & 160 & & & & & & & & & & & & \\
\hline
\end{tabular}

From above table 7.1, the daisy chain resistance increased only by a fraction of a percent during these tests and the change recovered upon unloading. The resistance recovery indicates that deformation of the daisy chain is elastic. It is believed that the very limited resistance change is caused by stretching of the wiring as the board is bent. There are no electric open in test cases that indicate the fracture failure occurred before electronic failure. The electric open happened only in one occasion, in which the travel distance is over $10.0 \mathrm{~mm}$. 
It is very helpful to explain the substrate strain behavior by confirming the failure modes, crack initiation and propagation by dye and pry tests. Dye pry tests revealed the pad-cratering type of delamination that dominated the interconnect failure. The pad cratering happened underneath the pad-laminate interface in the PCB side. Comparing the failure maps it has led to the understanding that the interconnect fracture initiated from the corners and the edges of the array and developed further inward as the board flexure increased.

\subsection{Brittle fracture}

An abrupt change of strain is particularly observed to reveal the behavior of strain on four type samples with different lids and PCB thickness. The spike of strain curve is defined as brittle fracture when crack happened on interconnect interface of solder ball and pad. The spike of strain curve was found in type A (component with $2 \mathrm{~mm}$ lid, $2.36 \mathrm{~mm} \mathrm{PCB}$ ) and type D (component with $1.0 \mathrm{~mm}$ lid, $2.36 \mathrm{~mm} \mathrm{PCB}$ ).

It is been discovered that strain rate raise or decline accompanies the phenomenon of curve spike. When a solder joint breaks in a brittle manner the respective substrate corner area consequently experiences a rapid load redistribution, which manifests as a strain rate increase or decrease. Such fast strain change is typical due to the brittle fracture of the solder joints that presented a very rapidly crack spread and increase in magnitude once they are initiated. The strain immediate increase in the substrate also indicates that the assembly has poor stress resistance and low tendency to elongate under stress.

Figure 7.1 and Figure 7.2 give out dye and pry maps at type A and type D with two spick curves with strain rate increase or decrease respectively. Both of these strains and strain rate changes occur before the global board deflection reaches the pre-defined maximum. The abrupt strain changes usually show as a temporary phenomenon since as the global load further increases, the local strains resume climbing after a transitory phase. It is observed that brittle crack occurred in the interface of intermetallic compound (IMC) on PCB side when the interconnection presents a weak point or with other defect such as avoids. 
If the brittle fracture occurs to a joint that is not one of those of the sensors immediate proximity, additional load will be transferred to the sensor area to cause a strain spike that indicates a sudden strain rate change. A strain rate increase is likely associated with the fracture of a solder joint far away the sensor in which the higher strain rate compensates the strain release and redistribution strain level. The strain rate decrease can be explained as the break of solder joints right beside the sensor due to strain release immediately.

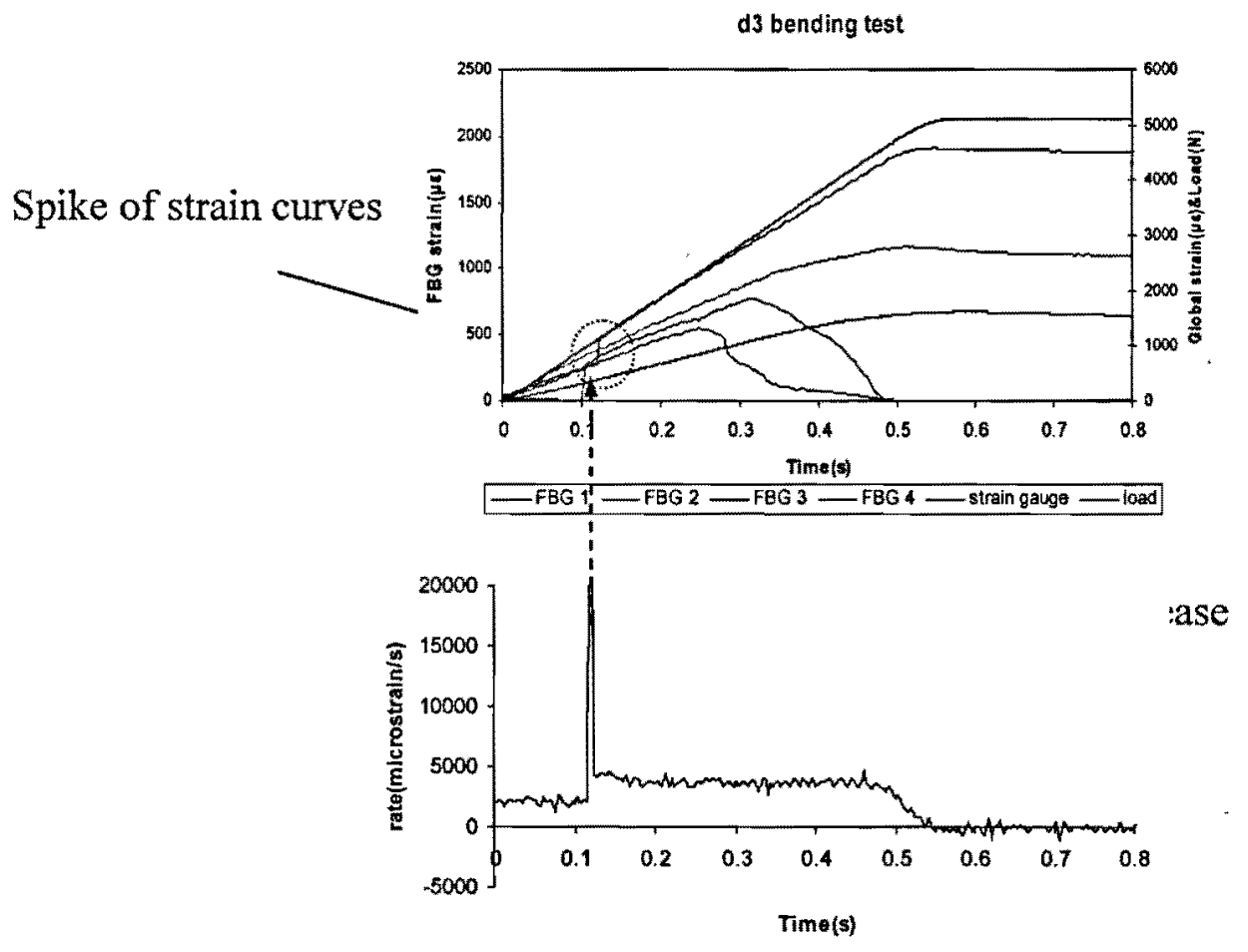

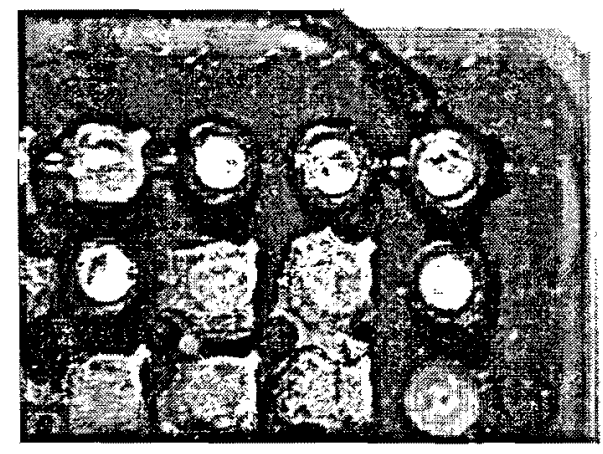

D3-FBG1-component side

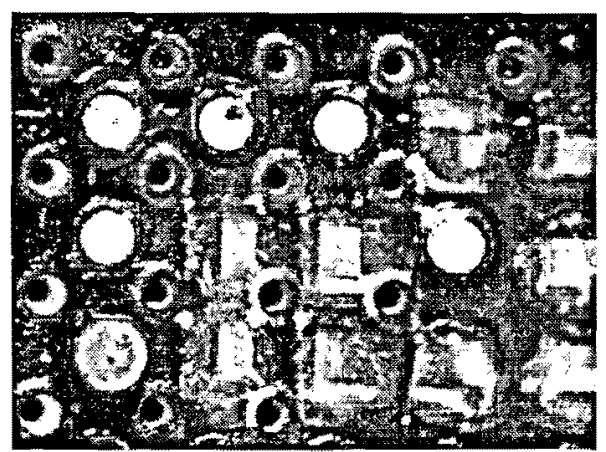

D3-FBG1-PCB side

Figure 7.1: Dye and pry maps and a spike of strain curve with strain rate increase 


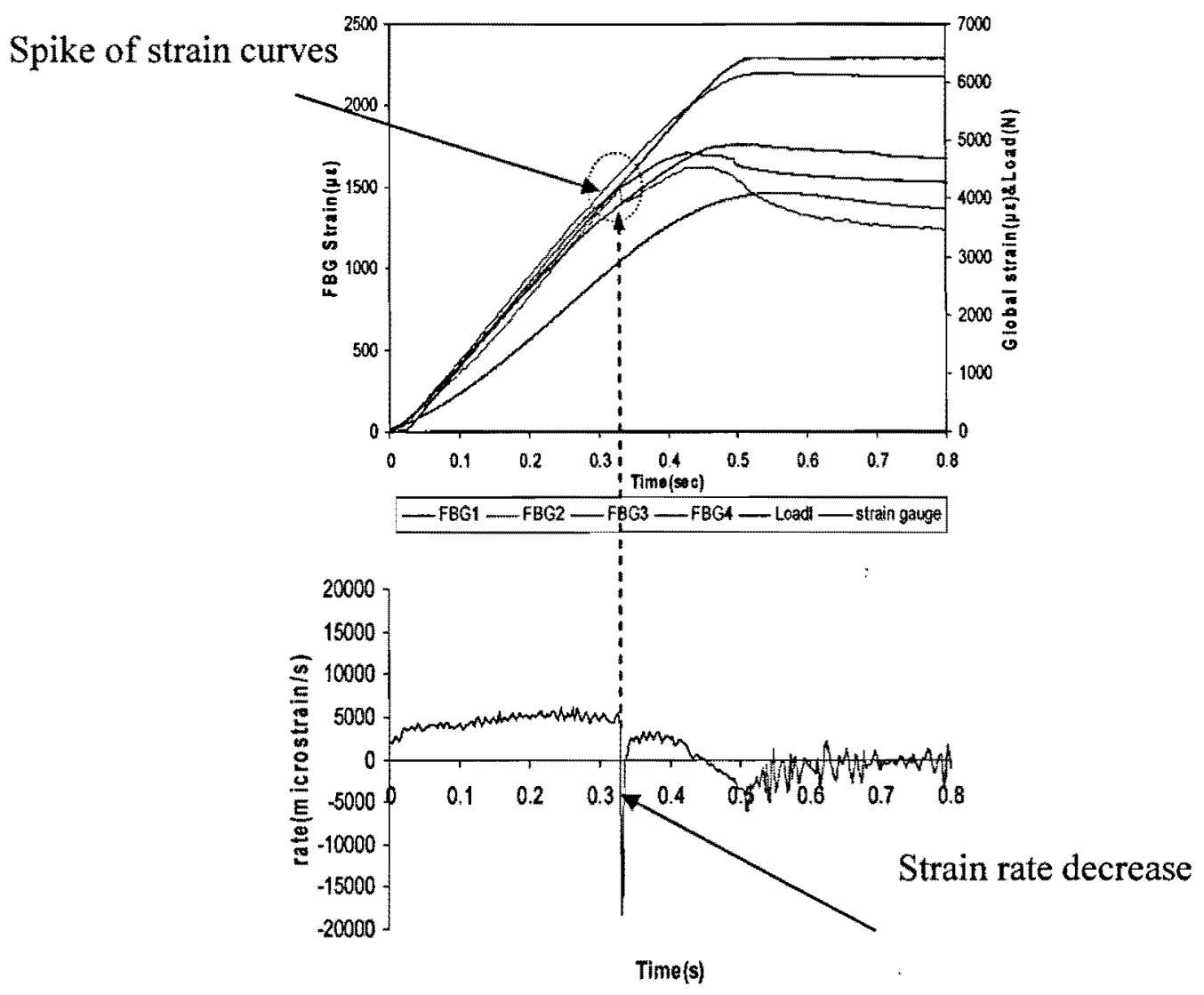

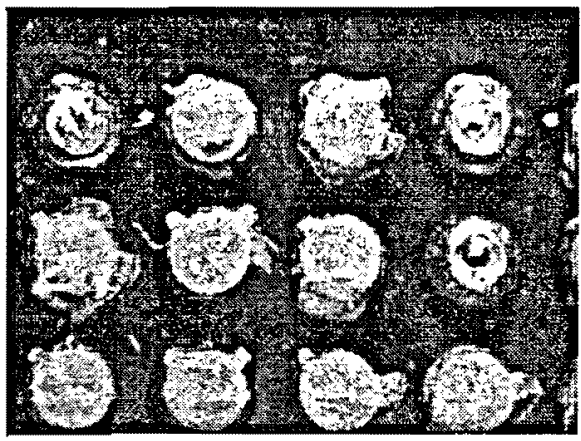

A4-FBG2-component

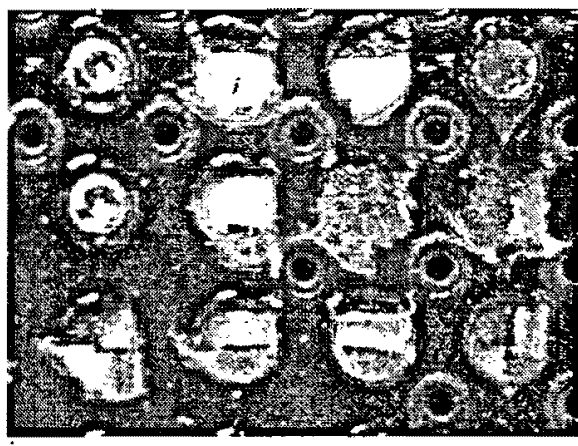

A4-FBG2-PCB side

Figure 7.2 Dye and pry maps and a spike of strain curve with strain rate decrease

\subsection{Ductile fracture}

Another crack pattern under bending load was found as ductile fracture on both sides of the PCB or the substrate as pad lift or pad crater. Ductile fracture was occurred in type B (with $0.5 \mathrm{~mm}$ lid, $3.175 \mathrm{~mm}$ PCB), type C (with0.5mm lid, $2.36 \mathrm{~mm}$ PCB). The ductile fracture is identified by FBG sensors in two ways for different sample types. One is the strain slope change in the stain 
curves that indicates the first failure has taken place already; another one is the strain drop down suddenly in the strain curves that foresee a large area solder array failure. Ductile break developed process in a gradual change due to that the crack moves slowly and accompany by a large amount of plastic deformation as loading increase results in failure of solder joints. PCB side ductile crack is a major fracture mode under flexible mechanical loading proved by dye and pry testing after loading tests. The strain rate at the same time to be noticed presents a gradually decrease change that indicates a ductile fracture to be on both sides of $\mathrm{PCB}$ or substrate. Figure 7.3 shows the dye and pry map at type C of the FBG2 corner, as well as the changed strain and strain rate curves that present a ductile fracture.

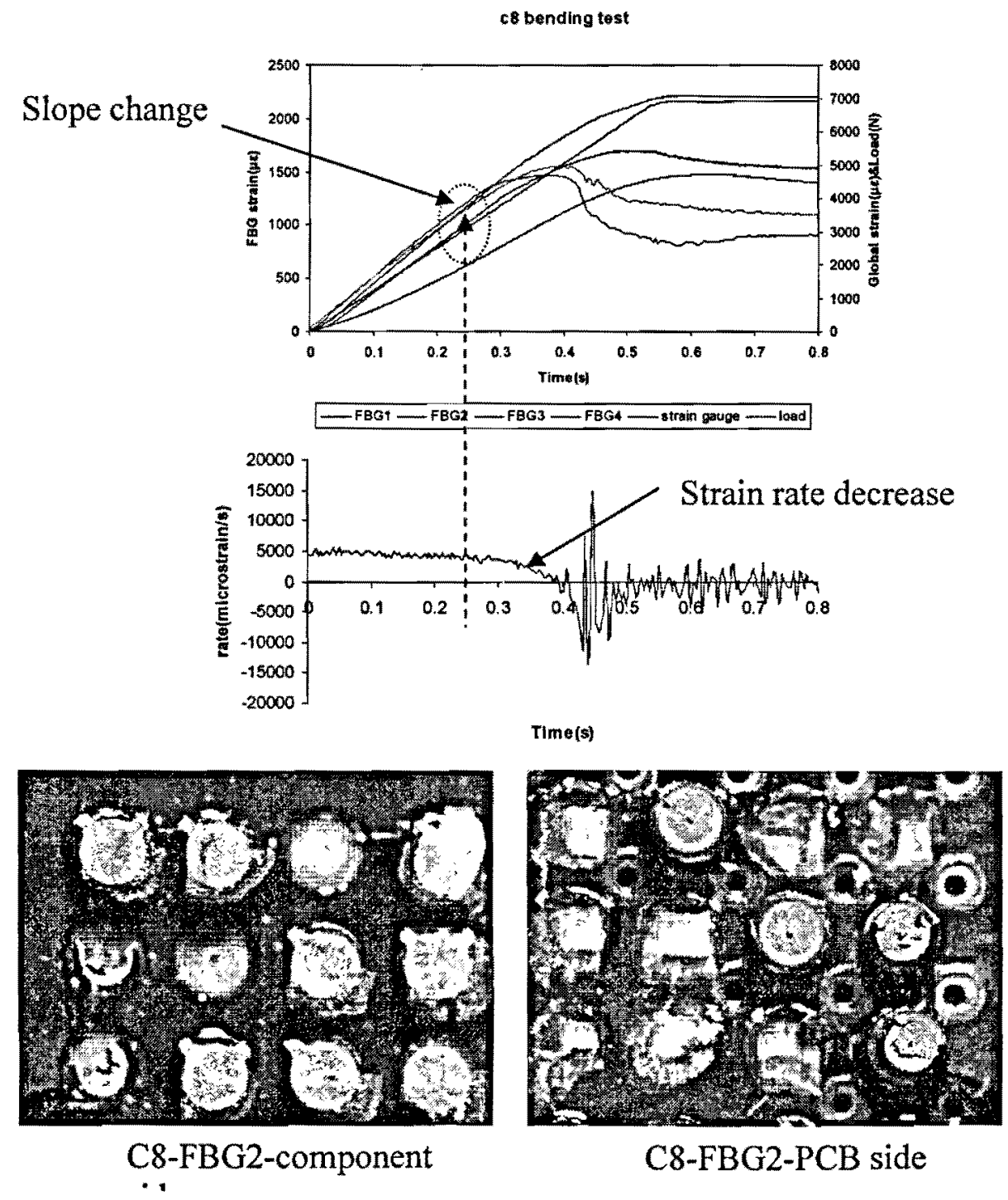

Figure 7.3 Dye and pry maps and a ductile crack with slop change of strain curves 


\subsection{Critical load detection}

A definition of the point of first crack is given as the point at which the slope of the curve departs from linearity by more than $5 \%$ during an interval of at least $0.01 \mathrm{~mm}$ by Morgan, Mindess and Chen (1995). It is also to be explained that the correct location of the first crack is at the point where the tension exceeds the tensile strength that presents an elastic-plastic behavior.

In four point bending tests, the phenomenon of strain rate change has been noticed and marked as onset or the critical point with strain hikes and drops or spike. The onset point indicates that the damage has occurred and will extend and development along the weak track resulting in failure of solder joints. Critical load indicates the strains at which cracks begin and not electrical connection broken that means the damage has occurred even though there is no electrical failure. Further, critical load of solder joints can be quantified by 4-point bend testing as a fracture limit of solder joint in second level manufactory.

It is known that the brittle or ductile fracture not only depends on the solder joint metallurgy, but also on the package's overall structure design for example lid and PCB thickness effect as well as the test parameters such as strain rate, etc. There are cases that the strain increases with the board deflection in a nonlinear relation yet with no obvious zig and zag. Such a smooth but nonlinear variation is a sign indicating a gradual process of the damage development, i.e., a ductile type of fracture of the joints.

In these cases, the critical point of the failure development from a strain curve is identified as the point of either a sharp slope change or the peak point if no such sharp slope change can be identified. While the characteristic points are identifiable from the strain curves, the critical or allowable loads are determined for a specific type of packages that needs to define an acceptable level of interconnect damage. In this project study, the critical load was defined as the global load (force/moment) corresponding to the first interconnected fracture detected based on the above-mentioned strain behavior and verified in the post-test failure analysis. With the sodefined criterion, four critical loads from four corners of each different sample were obtained by FBG measurement. Figure 7.4 plots the so-obtained allowable loads for each of the four types of assembly samples. From these result curves, it is found that sample type A has the smaller onset 
load due to its $2 \mathrm{~mm}$ thick lid. Compared to others, the type B with $3.175 \mathrm{~mm}$ thick PCB presents a large magnitude of critical load and type D shows an obvious small critical load resistance.

\section{Cratical load for different type PCBA}

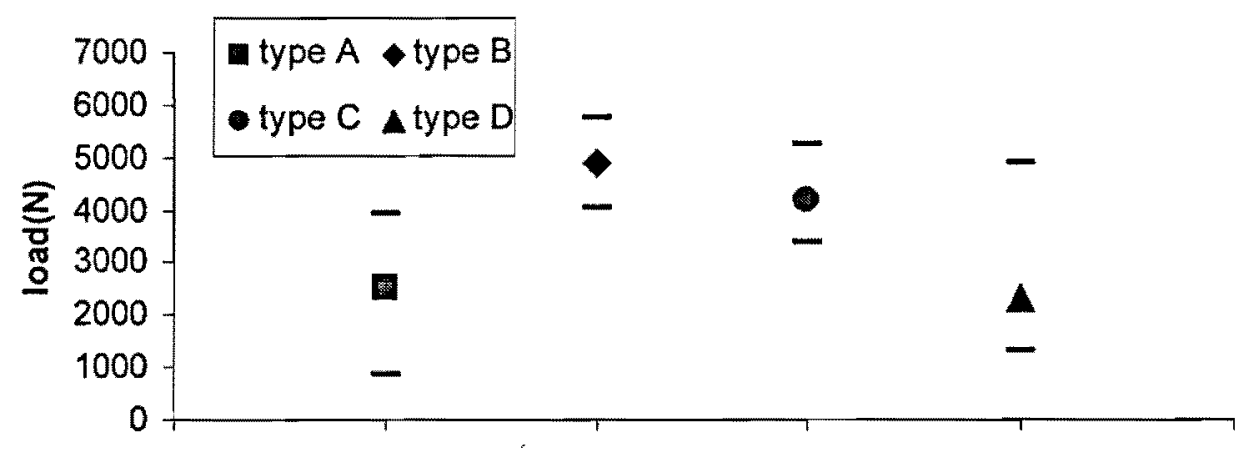

Figure 7.4: Critical load detection by FBG

\subsection{Strain relaxation}

The solder joint consists of solder ball, pads on both surfaces of PCB and substrate. The bottom of the solder ball is attached to the PCB during second level assembly processes. The strength of the attach point is determined by pad size, PCB material and construction of solder joints as well as mask defined or not, etc. The solder joint interconnect fractures can cause component-level strain relaxation.

The bend test failure analysis revealed that the pad-lift type of delamination dominated the interconnect failure for high speed 4-point bending tests. The Pad lift results in a component level substrate strain relaxation due to the strain redistribution that indicates the damages of solder joints occurs before electrical failure. Strain relaxation phenomenon is observed when the micro size FBG fibers that can be put on the position very closing to the edge of a substrate. The strain on the substrate decrease while the PCB global strain continues to increase with increasing applied deflection for a duration leading up to the damages of solder joints. The strain in the substrate corner will redistribute when a solder joint breaks in a brittle or ductile manners [28]. The experimental test strain curve presents a slope change or strain dropping down due to onset 
crack happened and strain transformation from one solder joint to others that predict the behavior of solder joint ductile and brittle fracture properties.

The strain relaxation phenomena indicate that there is a potential for latent mechanical fractures to grow and electrically fail in the field. The strain relaxation is found in 4 point bending tests due to the sensitive of FBG during the global strain and loads keeping increase. The maximum strain level before strain relaxation can be used to determine the critical load and detect the damage extent of solder joint under flexible loads. Figure 7.5 plots a measured strain versus time for type B1 sample and Figure 7.6 shows a failure map of B1 sample after doing a dye and pry test. The large magnitude of strain relaxation indicated that a large damage occurs such as in FBG3 and FBG4. The FBG strain results matched to the dye and pry failure map as the show in Figure 7.6. The whole left side of the substrate is debonded that lead to the complete strain relaxation for FBG3 and FBG4 while FBG1 and FBG2 show a partial strain relaxation.

\section{b1 bending test}

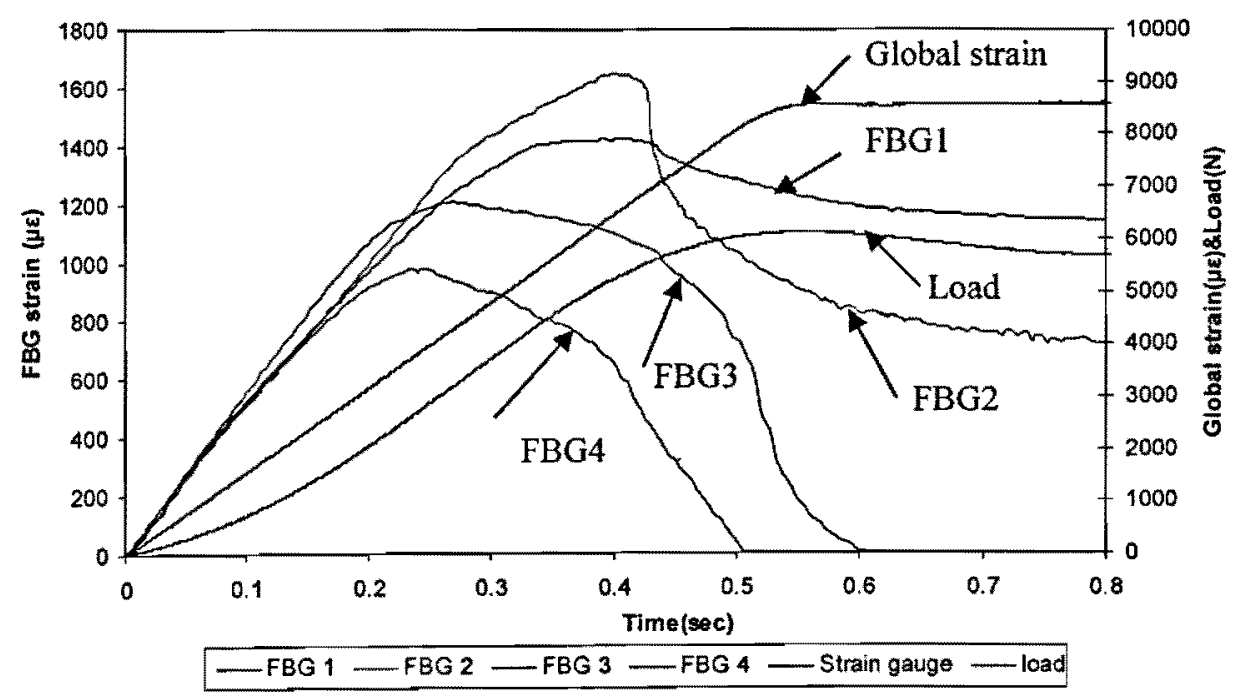

Figure 7.5: Strain curves versus time for sample B1 


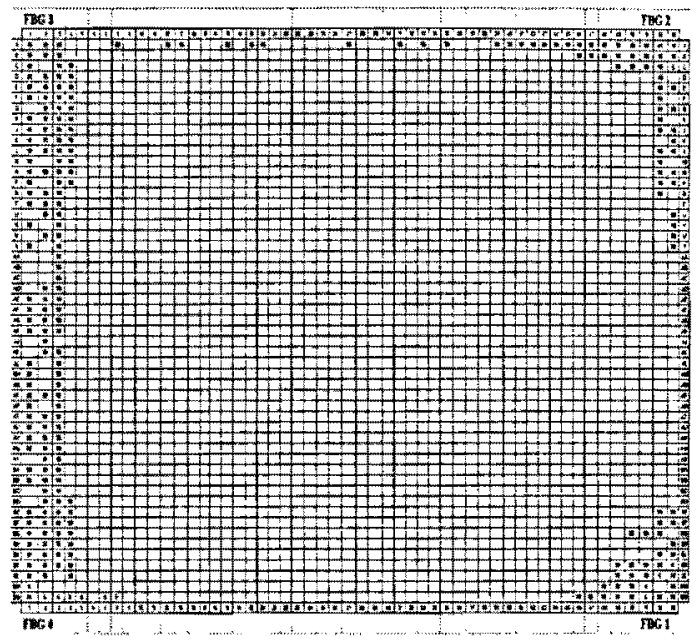

Figure 7.6: Dye and pray map for $\mathrm{B} 1$ sample

\subsection{Effect of some influencing factors}

\subsubsection{Lid thickness}

The critical load detection provided a better way to determine allowable strain scale for manufactories and terminal customers. Figure 7.7 plots the effect of lid thickness with different onset critical load levels. It is noted the onset load level declining during the lid thickness of components from $0.5 \mathrm{~mm}$ to $2 \mathrm{~mm}$. The result curve presents a regular trend that with the increase of the thickness of the lid the critical load level demonstrates a decline from 4000 to 2000. The results indicate that high stiffness of components appears low strain resistance.

\section{Lid thickness effect for 4 point bend tests}

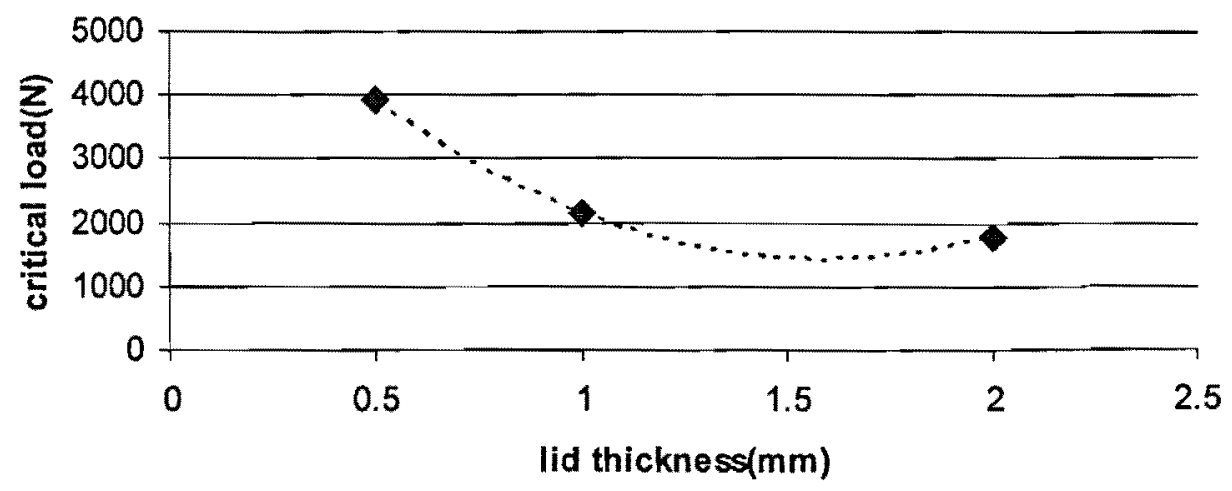

Figure 7.7: Effect of lid thickness 


\subsubsection{PCB thickness}

There are two kinds of PCB thickness in this experimental study. The thin PCB consists of 8 copper layers with $2.36 \mathrm{~mm}$ and thick PCB by 16 copper layers $3.175 \mathrm{~mm}$. Compared with other boards, the thick board has higher average critical load level in four corners on the substrate. 4point bend testing is a pure bend and destructive test. The constant bending moment is imposed to near the solder joints at a short time during 4-point bending test. The over load force with a high strain rate transfers force from one solder ball to another one-to-pad bond, resulting in the bond failure with strain rate dependent fracture. Consequently, the method lends itself to unambiguous calculation of a standardized bending moment per unit width of PCB in the constant bending moment region

$$
M^{\prime}=\frac{F \cdot a}{2 \cdot b_{p}}
$$

Where $a$ is the distance from load span to load support; $b_{p}$ is the width of PCB. From fundamental mechanics, the measured bending moment per unit width of PCB can be converted to the equivalent surface strain that will determine damage of solder joints [8].

$$
\varepsilon=6 \cdot M^{\prime} \frac{\left(1-v_{p}\right)}{E_{p} h_{p}^{2}}
$$

Where

$\mathrm{E}_{\mathrm{p}} /\left(1-v_{\mathrm{p}}\right)=$ effective flexural modulus of FR4 based PCB

$\mathrm{h}_{\mathrm{p}}=$ thickness of PCB

$b_{p}=$ width of $P C B$

Above equation provides a standard metric to compare solder joint strength against loading under assembly or installation conditions. Form the equation (7.2) the surface strain increase while reducing the PCB thickness that means the solder joint strength and critical load level increase. Figure 7.8 plots the effect of lid thickness at 4 type test boards with different PCB thickness. The thick PCB has a higher critical load scale comparing to thin one. 


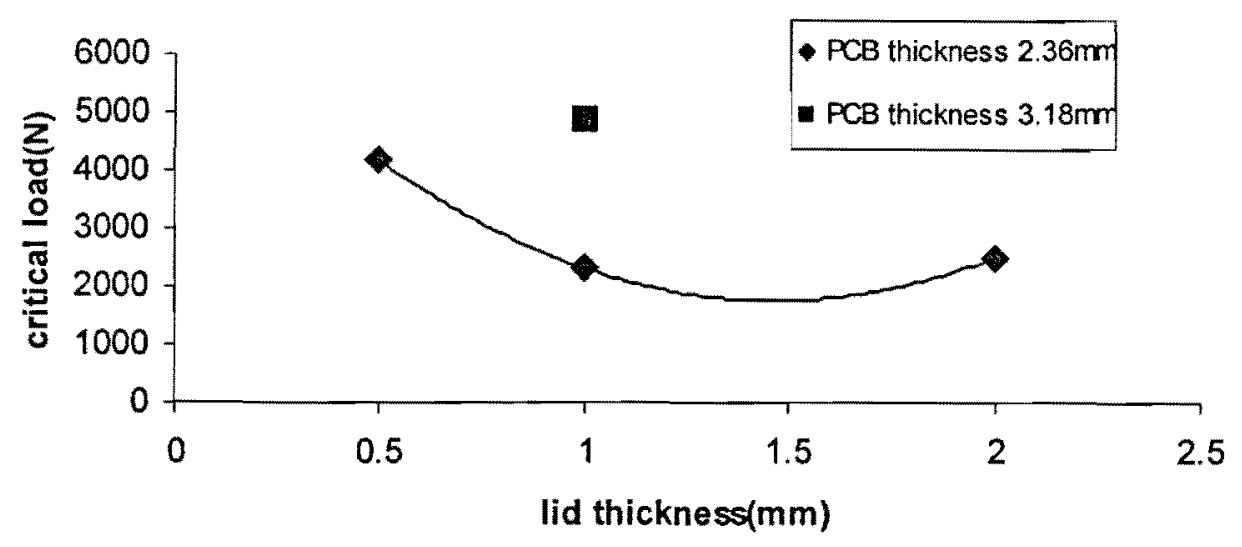

Figure 7.8: Effect of PCB and lid thickness for onset load 


\section{Chapter 8 Conclusions}

FBG as a new technology used in the electronic field has demonstrated an advantage aspect in small size of fiber and high sensitivity as well light weight. The experimental results have demonstrated that the FBG strain sensors laid at the substrate corners have sufficient sensitivity to detect the assembly interconnect failure initiation. In particular, the sensors captured the onset of the solder joint pad-lift. The characteristic strain behavior correlates well with the actual fracture surface morphology of the corner interconnects as confirmed upon failure analysis.

The FBG sensors have been very useful in this study because they circumvent important constraints associated with conventional sensors. The sensor's small size and light weight made possible a judicious positioning of these gauges on the substrates, to areas which otherwise are not accessible using conventional sensors. In addition, they have shown excellent sensitivity and reliable measurements. The potential of applying the technique to the packaging reliability study should go beyond the current application. The data scattering noticed in this work may be partially attributed to the random strength variation from one corner of the BGA to another. Nevertheless, there is still room for further improvement in the measurement accuracy by, for example, enhancing the loading alignment and more precisely positioning the sensors. The following additional points summarize the findings from the study:

- FBG onset load detecting can be the criterion used in determining the critical failure load and lead to the determination of allowable mechanical loads.

- The high dynamic response and sensitivity permit the FBG sensor to provide detailed strain information in relation to different modes of the interconnect crack.

- The FBG strain sensors laid at the substrate corner are sensitive to detect the assembly interconnect failure and in particular as well failure initiation.

- The characteristic strain behavior correlates well with the actual fracture in the corner interconnects.

- The test results show that the critical load is not dependent on the package deflection, nor on such limited strain rate change.

- The thicker lid appears to have an effect on interconnect bending strength. 
- The module with higher stiffness owing to the thicker lids tends to induce higher stress in the local areas of the package and easy producing a brittle fracture in the IMC interface.

- The assemblies with thicker lids have much lower interconnect strength when subject to bending deformation than the thinner lid ones that show the pad lifting failure of a ductile nature. 


\section{References}

[1] A. B. Sam Yoon, Vadali Mahadew, "Flexural strength of GBA solder joints with ENIG substrate finish using 4-point bend test" SMTA Pan Pacific Microelectonics Symposium, Kauai, HI, Jan 25-27, 2005

[2] R. Darveaux, A. Syed, "Reliability of Area Array Solder Joints In Bending" SMTAI, 2000

[3] A. Bansal, Y. Li, and V. Mahadev "Modeling and experimental correlation of BGA solder joints under PCB bending" ALTERA, 2000

[4] T. Koschmieder "Experiences with monotonic bend test of electronic packages" SMTA International, 2007

[5] A. Asundi, F. Spie, B. Zhao, "Optical strain sensor using position-sensitive detector and diffraction grating: error analysis" Optical Engineering, Vol. 39 No. 6, June 2000

[6] S. Takeda, Y. Okabe, N. Takeda "Delamination detection in DFRP laminates with embedded small diameter fiber Bragg gration sensors" S. Takeda et al. / Composites: Part A 33 (2002) $971-980$

[7] K. Lau, L. Yuan, L. Zhou, J. Wu, C. Woo "Strain monitoring in FRP laminates and concrete beams using FBG sensors", Composite Structures 51 (2001) 9-20

[8] J. S. Leng, A. Asundi "Non-destructive evaluation of smart materials by using extrinsic Fabry-Perot interferometric and fiber Bragg gration sensors", NDT\&E international 35 (2002) 273-276

[9] B. Yang, X. Tao and J. Yu "Fibre Grating sensor for simultaneous measurement of strain and temperature" Journal of Industrial Textiles 2004; 34; 97

[10] R. W. K. Honeycombe "The plastic deformation of metals", 1991

[11] G. Hsieh, A. Mcallister, "Flip chip Ball Grid Array Component Testing under Board Flexure", Electronic Components and Technology Conference, 2005

[12] D. Faear, H. Morgan and S. Burchett "The Mechanics of solder alloy interconnects", 1994

[13] G.E. Dieter "Mechanical Metallurgy", $3^{\text {rd }}$ edition

[14] S. B. Lee, I. Kim, T. S. Park, "Fatigue and fracture assessment for reliability in electronics packaging" Int J Fract (2008) 150:91-104

[15] M. J. Bartiw, S. G. Calvert, P. V. Bayly, "Fiber Bragg Grating sensors for dynamic machining applications", mjb3@cec.wustl.edu 
[16] P. G. LoPresti, D. Jali, C. Shrock, "Diggerential strain measurement using multiplexed fiber Bragg grating sensors" ISA Transaction 43 (2004) 195-204

[17] I.Minkoff, Wiley "Solidification and Cast Structure" 1986

[18] D.A.Porter, K. Easterling, Chapman \&Hall, "Phase Transformations in Metals" 1992

[19] M.C.Flemings, Mcgraw-Hill Inc "Solidification Processing" 1974

[20] H. Hayano and A. Mita, "FBG strain sensor with simple temperature compensation mechanism", Journal of Optoelectronics and Advanced Materials, 2005

[21] M. J. Connelly, S. Moloney and P. Butler, "Tunable Laser based Carbon Composite Strain Sensing Syatem using Wavelength Division Multiplexed Fiber BRAGG Grating Sensors" Smart Structures and Materials 2005, Smart Sensor Technology and Measurement Systems, edited by Eric Udd, Daniele Inaudi, Proceedings of SPIE Vol. 5758

[22] John H. Lau "Ball Grind Array Technilogy"1995

[23] IPC/JEDEC Association Connection Electronics Industry, "Monotonic Bend Characterization of Board-Level Interconnects" A standard developed by IPC and JEDEC 2004

[24] R. Katchmar, "Overload fracture of package solder joints" Microelectronics Reliability 40 (2000) $123-129$

[25] Lei 1. Mercado, G. Hsieh, and S. Girouard, "Electronic Packaging Solder Joint Reliability Assessment with a Mechanics-Based Strain Gage Methodology" IEEE Transactions on components and packaging technologies, VOL. 29, NO. 1. March 2006

[26] Yuqi Wang, K.H.Low, H.L.J.Pang, K.H.Hoon, F.X.Che, Y.S.Yong, "Modeling and simulation for a drop-impact analysis of multi-layered printed circuit boards" microelectronics reliability 46(2006)588-573

[27] http://www.p-m-services.co.uk/bt_epoxy data.htm

[28] M. Zhou, Hua Lu, "BGA component thermal warpage and implication for interconnect reliability" Proceeding of SMTAI, Orlando, October, 2007

[29] J. Lau, W. Dauksher, J. Smetana, R. Horsley, D. Shanguan, T. Castello, I. Menis, D. Love and B. Sullivan, "HDPUG's Design for Lead-Free Solder Joint Reliability of High-Density Packages", IPC SMEMA Council APEX, 2003

[30] J. Bragg, A. Lai, and S. Subramaniam, "Strain induced assembly and test failures" SMTAI, Toront, 2007

Af $f_{2}-12-2$ 